\author{
MIECZYSŁAW WRZOSEK \\ (Białystok)
}

\title{
POUFNE DOKUMENTY AUSTRO-WĘGIERSKIEGO MINISTERSTWA SPRAW ZAGRANICZNYCH DOTYCZĄCE SPRAWY POLSKIEJ W 1915 R.
}

\section{WSTĘP}

Do zestawu publikowanych dokumetów, oprócz pouf nych raportów barona Leopolda Andriana, który był dyplomatycznym przedstawicielem austro-węgierskiego Ministerstwa Spraw Zagranicznych w Królestwie Polskim, czyli na obszarach opanowanych w 1915 r. przez wojska niemieckie i austro-węgierskie, należą ponadto obszerne elaboraty oraz papiery ważnej korespondencji. Te wszystkie materiały dotyczą szeroko pojmowanej kwestii polskiej, spraw związanych z ogólną sytuacją na terenach okupowanych, a także dziejów Legionów Polskich. Istotne znaczenie mają między innymi dokumenty dotyczące wydalenia brygadiera Józefa Piłsudskiego z Warszawy w sierpniu 1915 r., aresztowania porucznika I Brygady Legiów Jana Gorzechowskiego w lipcu tegoż roku, a także szykan i utrudnień czynionych przez austro-węgierskie władze okupacyjne. Publikowane materiały zostały zaczerpnięte $\mathrm{z}$ zasobów wiedeńskiego Haus.-Hof - und Staatsarchiv, zespół akt Politiche Abteilung I (P.A. I), karton 900. 


\section{Dokument nr 1}

[1914 grudzień (?), Wiedeń]. - Raport autora nie wymienionego $z$ nazwiska skierowany do austro-węgierskiego ministra spraw zagranicznych, o akt ywości polskich działaczy politycznych.

Wiener Polnisches Nationalkomitee und die öffentliche

Meinung, hauptsächlich in Russisch Polen.

Streng vertraulich.

Ich habe hier oft Gelegenheit, auch im Verkehr mit dem Klerus, zu hören, wie scharf obiges Komitee kritisiert wird. Wie es heisst, sehen die meisten Polen und zwar die einflussreischsten aus allen Teilen und Ständen in der Tätigkeit dieses Komitees bloss Schreiberei, nationale Rücksichtslosigkeit und Verdächtigungsdrang. Ich wess, dass es Vieles, unleugbar auch Gutes getan hat und bin vom guten Willenund den besten Intentionen dessen Mitglieder überzeugt, bin aber gezwungen zu konstatieren, dass gewisse Fehler und hauptsächlich, auf Schritt und Tritt, Mangel an Diskretion, eine Gehässigkeit gegen das Komitee geweckt hat, dass es zu einem der wirksamsten Elemente der Verbreitung von Russophilie unter Polen gemacht haben soll - eine Gefahr, auf die ich aufmerksam machen zu sollen glaube und zwar desto mehr, dass es ein gefährliches Zukunftselement $\mathrm{zu}$ werden droht, das sich indirekt auch gegen unsere Regierung wendet.

Als Beispiel der Indiskretion die so ungeschickte, sogar gefährliche Verdächtigungs- manie bezüglich des Komitees in Lausanne. Baron [Roger] Battaglia konnte sich von deren Grundlosigkeit selbst in der Schweiz überzeugen, nichts destoweniger lebt sie immer wieder auf, letztens wegen nicht ganz billigender Worte, die in Lausanne über Wiener Komitee gefallen sind. Wenn Antipathie zu diesem letzten ein gegenüber Grund zur Verdächtigung der Russophilie wäre, dann wäre die erdrückende Mehrheit und zwar auch der besten Polen, russophil - also auch Galizien die gleichen, die die kaiserstreuesten immer bedingungslos für Budget und Rekruten stimmende Partei bildeten, daher Gołuchowski, der Statthalter und Landmarschall, die Gründer der Krakauer Partei, wie Graf Stanisław Tarnowski und Koźmian und so viele andere. Dabei hätte das Komitee in Lausanne bloss den Auf ruf, der beabsichtigt war, publizieren brauchen, um das Wiener Komitee - wenigstens als polnisches- aus der Welt zu 
Schaffen. Dies ist [s. z. - ?] gelungen zu verhindern und ist nun aus Rücksicht für Herrn [Leon] Biliński nicht mehr zu befürchten, von dem nan hofft, dass er mit der Zeit vorsichtig zur Sanation dieser beklagenswerten Zustände treten wird. Das Komitee von Lausenne ist von den bestehenden jedenfalls das Mächtigste, weil es aus Männern gebildet ist, die alle Polen kennen und ehren -es ist neutral, mit ausgesprochener Dankbarkeit zur Monarchie -man sollte es in Ruhe lassen. Verdächtigungen drängen ins gegnerische Lager und erschweren jede gute Einflussnahme, sie werfen ausserdem ein unelegantes Licht auf unsere Regierung, die es nicht verdient und auf die sich das Komitee in allem immer wieder beruft.

Meiner unmassgeblichen Ansicht nach würde ganz grosses geleistet werden, falls man geschickt das Wiener Komitee dazu bewegen könnte, sich aufzulösen und dann, mit Zuziehung auch der Mitglieder des Aufgelösten, ein grosses Komitee bilden würde, das für die Fehler des anderen nicht verantwortlivh gemacht werden könnte und welches, angelehnt an vornehme Tradition, Loyalität und Disziplin der früheren Polenklubs, Einfluss und Ehrfurcht in allen Teilen Polens geniessen würde. In diesem Einfluss würde auch unsere Regierung in eventuell schweren Stunden eine Stütze finden - anstatt der Gefahr, die das bestehende Komitee dadurch bildet - dass es immer ausserhalb Galiziens ganz ohne Einfluss, heute aber, mit Recht oder Unrecht, vor dem meisten Polen kompromittiert ist.

Ich muss konstatieren, dass jeden einzelne Mitglieddieses Komitees Vertrauen und Anerkennung verdient, das Komitee als solchen bildet aber eine wahre, ernste Gef ahr durch die Spaltung, die es unter Polen, derselben Gesinnung, erzeugt hat und durch den Genre den es hat, die Verantwortung für seine eventuelle Fehler und Taktlosigkeiten immer auch auf unsere Regierung auszudehnen.*

* Nic udało się ustalić ani autora, ani adresata tego ważnego dokumentu dotyczącego oceny Naczelnego Komitetu Narodowego i Komitetu w Lozannic.

Kopia, maszynopis.

Haus.- Hof und Staatsarchiv, Kricg, P.A.I., karton 900, folio369-370. 


\section{Dokument nr 2}

1915 kwiecień 1, Kraków.- Sprawozdanie barona Leopolda Andriana nr 18 o Legionach Polskich $i$ działalności emisariuszy polskiego Naczelnego Komitetu Narodowego w Królestwie Polskim.

Der Vertreter des K. u. K. Ministeriums des

Äussern bei dem K. u. K Armee - Etappen -

Oberkommando.

An Seine Exzellenz den Herrn Minister des k.u.k. Hauses und des Äussern Stephan Baron Burián von Rajecz.

Im Verfolge meines Berichtes vom 16 März leitendes Jahres Nr. 37 (Politische Bericht Nr. 11) sowie mit Bezugnahme auf den hohen Erlass vom 15 März leitendes Jahres Nr. 1616 beehre ich mich Eurer Exzellenz über meine diesmal im Berichte der 6. Armee gemachten Wahrnehmungen nachstehend zu berichten.

Der Unterschied in der Apreziation der Legionäre durch die militärischen Obrigkeiten von Petrikau und Noworadomsk von der durch die Generalität der 1.Armee ist ein sehr bedeutender. Bei meiner jetzigen Reise habe ich (auch im Kreise Dąbrowa, der zum Etappenbereiche der 1. Armee gehört) keine Klagen über die Legionäre vernommen, was viel bedeuten will, wenn man bedenkt, wie leicht Reibungen zwischen nebeneinander operierenden Truppenkörpern entstehen. So häufig Klagen über die schwierigen und unerquicklichen Beziehungen zu den deutschen Offizieren und der ihnen unterstellten Mannschaft laut wurden, so einmütig wurde diesmal konstatiert, dass weder die Werbetätigkeit der Legionäre, noch auch ihr Verhalten gegenüber den Offizieren der k.u.k. Armee Anlass zu Beschwerden geben. Diese erf reuliche Wandlung ist meines [E.] ${ }^{1}$ darauf zurückzuführen, dass einerseits die Legionäre infolge der strengen Ahnung der Vorfälle in Bolesław eingesehen haben, dass die überhaupt nur dann weiter existieren können, wenn sie in Harmonie mit der k.u.k. Armeeleitung und in Befolgung der erhaltenen Weisungen ihre Tätigkeit entfalten, anderseits, dass der in Piotrków residierende die Werbungen leitende neue Gruppenkommandant der polnischen Legion Oberst [Wiktor] Grzesicki als alter österreichischer Soldat über gute persönliche Beziehungen zu unseren Generälen vefügt und asserdem

' Sknót slowa oznaczającego w języku polskim mniemanic, albo przypuszczenic. 
die Mannszucht mit eiserner Strenge aufrechtzuhalten weiss. Auch der Erfolg der Werbetätigkeit ist in Gouvernement Piotrków ein besserer geworden. Ungefähr 700 Mann haben sich in den letzten Wochen in Noworadomsk und Piotrków $\mathrm{zu}$ den legionen gemeldet und gleichfalls kürzlichist eine Ersatzkompagnie vom 250 Mann an die Front gegangn. Auch den Kontakt mit der Bevölkerung pflegen die Legionäre, wie mir scheint, in ganz zufriedenstellender Weise, so dass sie in der Lage sind, als Bindeglied zwischen unserer begreifkicher Weise von der Bevölkerung durch eine Kluft getrennten Militärverwaltung zu funktionieren. Besonders ehoffe ich von ihrer Einwirkung eine Zurückdrängung der moskalophilen Elemente unter der polnischen Bevölkerung, welche sich mit ziemlichen Geschick trotz aller würdevollen Zurückhaltung unserer Armee gegenüber doch in den autonomen Institutionen zu behaupten gewusst und bei unseren Militärobrigkeiten den Eindruck erweckt haben, als seien sie die einzigen repräsentativen Elemente de Bevökerung.

In einer gemeinsamen Besprechung, die ich mit dem Armee-Etappenkommandanten General Heffele und dem Obersten Grzesicki, hatte, suchte ich nach Kräften die glücklich begonnene gegenseitige Kooperation auf die Gebiete der lokalen Personenpolitik zu fördern. Kürzlich haben die Legionäre in Petrikau ein grosses und gut besuchtes Fest zur Erinnerung an einen Jahrestag der 1863 - er Revolution organisiert, was immerhin bewies, dass die Bevölkerung anfägt ihre Zurückhaltung den Legionen gegenüuber aufzugeben. Durch die Anwesenheit des Feldmarschall Leutnannt Heffele und durch Singen der Volkshymne im Laufe der Veranstaltung wurde auch der österreichischf reundliche Charakter der Feier dokumentiert. Dass im Ubrigen die Legionäre nur polnische Politik machen, nicht österreichische, ist wohl für jeder Kenner der Verhältnisse selbstverständlich. Wenn sie uns aber einerseits eine gewisse militärische Hilfe sind, anderseits nützliche politische Informationen geben und Block der Nationaldemokraten und Konservativen in seiner Stellung unter der Bevölkerung lockern, erweisen sie uns, wie mir scheint, recht annehmbare Dienste. Mag auch der eine oder der andere der jungen Leute in seinen Kontakt mit den Landeseinwohnern darauf hinweisen, dass auch die Anlehnung an Östrrech-Ungarn nur etwas Vorübergehendes sei, bestimmt den Übergang zur vollen Unabhängigkeit vorzubereiten, das Úbel dürfte nich gross sein und derartige Enuntiationen junger Menschen werden auch von den Hörern nicht zu ernst genommen werden. Das Blatt, das die Legionen herausgeben und verbreiten, die "Wiadomości Polskie" unterliegen natürlich der Zensur und tragen jedenfalls mit ihren 20.000 Exemplaren, welche sich im Land verbtreiten, wesentlich zur Entwurzelung der russischen Orientierung im Lande beitragen. Alles in allem genommen möchte ich bezugnehmend auf den 
mir gütigst übersandten Erlass an den Grafen Thurn de dato 15 leitendes Monats $\mathrm{Nr} 1615$ meine Meinung dahin zusammenfassen, dass eine disziplinierte und verlässlich geführte polnische Legion uns auch bei der Landesbevölkerung nur von Nutzen sein kann. Gewiss wird sie uns im besten Falle nur die Sympathien der opferwilligen und nicht durch die viele materielle Interessen beschwerten Bevölkerungelemente zuwenden, also Teile des kleinen Adels, der städtischen Intelligenz, der Arbeiterschaft und vielleicht auch des Bauerstandes. Aber dies ist schon immerhin eine grosse Sache und ausserdem ist es selbstvertändlich, dass nichts ausser entscheindende Siege uns die Teile der Bevölkerung zuführen wird, welche sie es in Polen, sie es in Galizien, aus Opportunismus den Ausgang des Ringens zwischen uns und den Russen bestehenfalls passiv abwarten.

Wenn meines unmassgeblichen Erachtens eine Beibehaltung, ja auch eine bescheidende Ausgestaltung der Legionen für uns nur vorteilhaft sein kann, so könnte ich mich nicht mit gleicher Entschiedenheit für die Ausbildung des Systems von Delegierten des Nationalkomités für Russisch-Polen aussprechen. Ich habe den Eindruck, dass diese Delegierten, wie bescheiden auch sich die vorsichtigeren unter ihnen den Militärbehörden gegenüber stellen mögen, der Bevölkerung sich als die Organe der polnischen Nationalregierung gebe, welche berufen ist, nach Ablauf des Krieges die Stelle der k.u.k. Behörden einzunehmen. Schon die Art und Weise, wie sie sich im Lande einführen, als Delegierte der Finazsektion, der Ackerbausektion, der technischen Sektion, des Präsidiums et cetera des polnischen Nationalkomités deutet auf ihre Prätentionen und die Rolle, die sie spielen wollen, hin. Abgwsehen von einigen Verhaftungen auf den Deutschen Verwaltungsgebiete hat die zu deutlich manifestierte Tendenz einigen Herren, eine Regierung neben der Regierung zu spielen, in Petrikau zu sehr gespannten Beziehungeen mit den dortigen Kreisschef geführt. Dass ihre Tätigkeit auf sachlichen Gebiete (Wohlfahrtaktionen, Unterstützung des Ackerbaues) eine nennenswerte gewesen wäre, konnte ich weder an Ort uns Stelle, noch aus den Euer Exzellenz übersandten Mémoires entnehmen. Über einige konkrete Beschwerden und Vorschläge derselben werde ich mir erlauben, mich an anderer Stelle zu äussern und möchte hier nur erwähnen, dass die darin besprochene Fragen teils unabhängig von ihnen von den Militärbehörden der Lösung zugeführt werden, teils aus verschiedenen mit dem Kriege zusammenhängenden Ursachen überhaupt nicht lösbar sind. An eine fachliche Wirksamkeit dieser Delegierten kann ich nicht recht glauben und vermute, dass sie in Wesentlichen lediglich politisch tätig sind. Ich möchte nun meinen, dass sie einerseits mit der Bevölkerung, welche sie selbst bisher wenig kannten, in Berührung treten und dieselbe nach galizischen Muster organisieren respektieren sich der politischen Führung bemächtigen möchten, um, wenn nach 
Kriegsende uns polnisches Territorium des Russischen Reiches verbleibt, der Monarchie gegenüber geschlossen und mit einem sehr weitgehenden nationalen Programm, dass sie der congresspolnischen Bevölkerung einzurichtern versuchen werden, aufzutreten. Anderseits dürften sie versuchen, sich im Lande als Anwälte des Landes gegenüber den Militärbehörden aufzuspielen und die Resultate, deren Bemühungen zum Vokswohle als einen Erfolg ihres Einflusses in Österreich hinstellen. Mit einem Worte, mein Eindruck geht dahin, dass ohne eigene Leistungen auf militärischen und staatlichen Gebiete aber nicht ohne Geschick die bei fast völligen Versagen des Polentums vorbrachten Leistungen der österrichisch-ungarischen Armee in eine politische Besitznahme Polens durch Teil der bisherigen galizischen Machthaber ungewartet werden sollen.

Ich weiss es wohl, dass die Parteien, welche noch im Nationalkomité sitzen, diejenigen sind, deren Stellung Österreich gegenüber am einwandfreiesten ist. Seitdem ich von weiland S.E.dem Grafen Aerenthal mit der Berichterstattung über dis galizischen Verhältnisse betraut worden war, habe ich unblässig auf die Unzuverlässigkeit der Nationaldemokraten und auch teilweise der ostgalizischen Grossgrundbesitzer und auf deren moskalophile Tendenzen, hautsächlich in der Ruthenenpolitik,hingewiesen. Das Steigen des nationaldemokratischen Einflusses, welcher zu Sturze des Statthalters [Michał] Bobrzyński führte, hat gewiss auch, nicht weniger wie die Angst mancher ostgalizischer Herren, im Falle des Sieges der Russen mit ihren Besitz und vielleicht mit ihrer Freiheit für eine etweige Teilnahme an der Legionenwerbung zu büssen, zu der famosen mit humanitären Gründen dürftig bemäntelten Stellungsnahme gegen unsere Legionen geführt. Insoferne erscheint mir die Tätigkeit des polnischen Nationalkomités, solange dasselbe nicht alle polnischen Parteien umfast und vor allem nicht die vor Russland zitternden Nationaldemokraten und Podolier, weit weniger gefährlich, als wenn die Einigungsversuche gelingen und wir uns gegenüber den geschlossenen Block aller polnischen Parteien hätten, der austrophilen und der aus Opportunismus nach Russland schiedenden. Dieser Block kann naturgemäss erst dann zustandekommen, wenn entweder die austrphilen Parteien auf die Legionswerbung verzichtet haben oder aber die Nationaldemokraten und Podolier von dem Zweifel, ob sie doch unter Russischen Szepter kommen werden, bef reit sein werden. Verläufig haben wir es also mit dem uns bestgesinnten Parteien zu tun, welche mehr als irgend andere polnische auf unsere Rücksicht, ja Förderung zu rechnen haben. Aber es darf doch wohl nicht ausser Acht gelassen werden, dass alle Austrophilie polnischer Politiker eine bedingte und begrenzte ist. Das Postulat, ein vergrössterter polnischer Besitzstand Österreichs müsse unsern Polen dieselbe Stellung verschaffen, wie sie Ungarn im Rahmen der Monarchie 
besitzt, spuckt noch in den Köpfen. Schon aus diesem Grunde scheint mir eine intensive politische Arbeit der galizischen Politiker in den okkupierten Gebieten kaum opportun, falls noch kein Beschluss, über das Ausmass der Selbständigkeit, welches unsere Polen nach dem Kriege bekommen sollen, gefasst ist. Sonst könnte dann dank der Arbeit der galizischen Politiker das gesamte Polentum innerhalb unserer Grenzpfähle mit geschlossen formulierten weitgehenden Forderungen auftreten und im Falle der Nichterfüllung ernste innerpolitische Schwierigkeiten schaffen. Wie alle kulturell hochstehenden Nationen, die kein selbständigen Staatwesen bilden, hat ja die polnische im höchten Mass das Bestreben, sich der Staatsgewalt gegenüber als Einheit zu geben und dementsprechednd zum Schaden der Staatsinteressen ein Maximum von Sonderstellung herauszuschlagen. Recht charakteristisch hiefür sind die Wahrnehmungen, die ich in letzter Zeit hier im Umfange mit den vollkommen austrophilen Politikern der Demokratenpartei und der Westkonservativen gemacht habe, Um nich die Stellung des Polentums nach dem Kriege zu gefährden, sucht man trotzt aller Feindschaft gegen die Nationaldemikratische Partei deren Führer vom Verdachte des Hochverrates reinzuwachsen. Da man die Sprache des "Słowo Polskie", des schon vor dem Kriege recht antiösterreichisch orientierten Parteiorgans, seit dem Falle vom Lemberg kaum mehr rechtfertigen kann, so wird dessen Redakteur [Stanislaw] Grabski als räudiges Schaf der Partei hingestellt. Der ehrliche Oberst Grzesicki allein von allen meinen polnischen Gewährsmännern sagte mir gegenüber gerade heraus, s. E. Gehörrten die Herren von [Tadeusz] Cieński und Graf [Aleksander] Skarbek an den Galgen! Sonst versuchten ihre Landesleute, die Moskalofilie der von uns in Friedenszeiten so gehegten Nationaldemokratischen Partei teils fast entschuldigend $\mathrm{zu}$ erklären, teils zu minimisieren. Ich habe mir erlaubt diesen kleinen Zug als charakteristisch dafür auszuführen, dass auch die loyalsten polnischen Parteien, und zu diesen rechne ich sowohl die Krakauer Konservativen, wie die Partei des Dr. [Juliusz] Leo, sich doch in alleresrster Linie von Erwägungen leiten lassen, die dem polnischen Solidaritätsgefühl entspringen.

Ưber die Tätigkeit der Emissaäre des Nationalkomités werde ich bei weiteren Bereisungen neuerlich Erkundigunggen einziehen. Fŭr heute möchte ich mir nur ganz ergebenst zu beantragen erlauben, dass mit Rücksicht darauf, dass mehrere der leitenden Generäle im Okkupationsgebiete mir gegenüber den Wunsch aussprachen, es möge vorläufig von politischer Agitation in Russisch-Polen abgesehen werden, das Nationalkomité auf Entsendung weiterer Delegierter seiner verschiedenen Sektionen verzichte. Über das Weiterfunkionieren der bereits wirksamen Delegierten des Nationalkomités könnte viellecht vorläufig die Entscheidung aufgeschoben werden. 
Der k.u.k. Legationsrat Leopold Andrian.

Oryginał, maszynopis.

1 laus.-Hof und Staatsarchiv, Krieg P.A. 1, karton 900, folio 264-267.

Załącznik nr 1 do raportu.

K. u.k. Gruppenkommando für die Polnische Legion.

Piotrków 22 marca 1915

Oberst von Grzesiski

Hochwohlgeboren Herr Oberst von Hranilović

Chef der Nachrichtenabteilung AOK.

Gestern hat sich hier die Kościuszko-Feier im allgenein recht bef riedigend abgespielt. Das Ersatz Baon der Legion war mit 350 Mann ausgerückt formiert in drei Kompagnie und ein Reiterabteilung (12 Reiter), unter Kommando Hautpmann [Andrzej] Galicas. Vorerst fand um 10 [Stunde] eine Messe statt, welcher die Generäle und viele Offiziere der garnison beiwohnten. Nach der Messe besichtigte General [Hermann] von Kövess das ausgerückte Baon und sprach sich über dessen Haltung sehr anerkennend aus; hierauf erfolgte in der Hauptstrasse (ul. Kaliska) die defilierung in Zugskolonne vor General von Kövess, der das Auftreten der Lagionäre besonders lobte. Hiemit war die offizielle militärische Faeier beendet. Das Baon marschirte hierauf zum Friedhof, wo beim Grabe der in Jahre 1863 gefallenen Polen von dem Legionsgeistlichen und von Professor [Wacław] Tokarz (Vertreter Sikorskis) patriotische Ansprachen gehalten und Kränze niedergelegt wurden.

Nachmittag um 5 hora fand unter der Patronanz der Legion ein Konzert statt, dessen Program ich beilege. Die Generäle der Garnison und viele Offiziere wohnten bei und äusserten sich durchwegs befriedigt über die Darbietung der Mitwirkenden. Die österreichische Idee kam zum Ausdruck in Nr. 1 (Vorrede doktor Kots und Nr. 2 (Volkshymne).

Einige Vorstösse, wie zum Beispiel nicht genügende Ordnung, mangelhafte Vorsorge für dem Empfang der Gäste, wären durch die Neuheit der sache, mangelnde Erfahrung und den unerwarteten massenhaften Andrang des Publikums zu entschuldigen.

Das Erscheinen der Legionäre überhaupt rief einen nachhaltigen Eindruck hervor, der durch die Friedhof feier verstärkt wurde und beim Konzert hellen 
Begeisterung stieg. Es vollzieht sich unter Einwirkung des Militärische Sektion $\mathrm{OPKN}^{2}$ der Emissäre des OPKN (graf Michałowski, Abgesander [Jan] Hupka und andere) ein merklicher Umschwung in der Stimmung der hiesiegen Bevölkerung zugunsten der Legionen und der österreischische Staatsidee.

Heute früh kehrte das Ersatz Baon per Bahn nach Noworadomsk (Radomsko); dort wird heute noch die zum Abgehen bestimmte 1 Esatzkomagnie neu zusammengestellt aus Leuten, die schon 6 Wochen hindurch ausgebildet wurden. Morgen (Dienstag) wird die Kompagnie feldmässig ausgerüstet; nachdem gibt sie einige Schuss ab Mittwoch (24.III) erfolgt die Einwagonierung in Neue Radomsk. Die Kompagnie wird mit allem komplet versorfftsmäsig ausgerüstet sein; jeder Mann hat eine Decke und ein Zeltblatt, sowie technische Ausrüstung mit Munition, 160 Patronen pro gewehr, 1 unbespannte Fahrkiche geht mit; die Bespannung zur Fahrküche und 3 bespannte landesübliche Fuhrwerke als Train erhält die Kompagnie nach Eintreffen in Delatyn von 6 Armee Ersatz Kommando.

Am 19 III war ich in Neue Radomsk. Die Unterkunftsverhältnisse sind nicht günstig. Relativ gut ist bloss die erste Kompagnie untergebracht. Geeignete Häuser sind nicht mehr verfügbar. Ich beauftrage den Baonskommandanten in Kamieńsk (Sommerfrische $9 \mathrm{~km}$ von Radomsko) Umschau zu halten und $\mathrm{zu}$ berichten. Da ich den Ort gesehen habe und ihn für geeignet halte, denke ich mir die Unterkunft für Folge derart: Baonstab, Magazine, Ergänzugszentrale, Schule und 1 Kompagnie in Neue Radomsk. Rest in Kamieńsk. Konkreten Antrag werde ich erst stellen, bis ich genauere Daten habe. Schiessplatz in Neue Radomsk vom Baon ausgemittelt $2 \mathrm{~km}$ nördlichst, wird provisorisch adaptiert.

Die Anfrage des Ersatz Oberste Kommando um nicht sprachkundigen Verwaltungsbeamten werde ich erschöpfend beantworten; sammle eben die daten.

K/Nr. 5720 (Landsturmpflichtige Abgestellte der Militärische Sektion des OPNK-

Oberste polnische National Komittee) kann ich erst nach Rückkehr Sikorski's erledigen.

Podpis: Grzesicki, m.p. (miejsce postoju) Oberst.

Załacznik nr 2 do raportu.

${ }^{2}$ Oberste Polnische Nationsal Komitee; chodzi o Naczelny Komitet Narodowy. 
Ubersetzung des polnischen Programmes des musikalischen Abendes, Sonntag, 21 /III, 5 Uhr in Saale der Handwerk-Vereinigungs-Hilfe Piotrków, Schulallee.

1) Prolog von Doktor Stanisław Kot; bespricht Notwendigkeit Kampfes gegen Russland im Anschluss an Österreich.

2) Musikstücke der Bataillons-Musik (Polnische Musik und „Gott erhalte..."

3) Fragment aus „Dziady” von Mickiewicz (Leiden Polen unter Russland und Auf ruf zum Kampf); forgetragen von einem Krakauer Schauspieler.

4) Polen in Lied: Polonaise von Richard Wagner, Mazur von [Karol] Namysłowski; gespielt von Piotrkower Orchester (Geselschaft der Musikfreude).

5) Männergesang der Legionäre: „Uber die heimatliche Berge”, „Trompeterlied”, ")ägerlied.

6) Schlacht bei Racławice (Wie Kościuszko die Bauern zum Kampfe aufruft) vorgetragen vom Krakauer Schauspieler [Antoni] Siemaszko.

7) „Wernyhora”, Volkslegende, Auf ruf zum Kampfe gegen Russland dargestellt von Amateurschauspielern.

In den Pausen spielt die Baonkapelle. Begin $5 \mathrm{Uhr}$, Ende 81/2 Ukr am Abend.

\section{Dokument nr 3}

1915 kwiecień 18, Piotrków. - Poufny raport Departamentu Wojskowego NKN $i$ przestany austro-węgierskiej Naczelnej Komendzie Armii o sytuacji w Warszawie $i$ na obszrach okupowanych przez armię niemiecką.

Die politische Lage in Warschau.

In Warschau hat der anfangs starke Eindruck, welchen das die Vereinigung der polnischen Landesteile verkündende Manifest des Grossfürsten Nikolaus Nikolajewitsch gemacht hatte, gänzlich seine Wirkungskraft eingebüsst. Selbst so mancher von denjenigen Abgeordneten in der Duma, welche ursprünglich die russische Regierung unterstützten, haben sich jetzt unzweideutig gegen Russland ausgesprochen (Harusewicz ${ }^{3}$, Dymsza ${ }^{4}$ ).

\footnotetext{
${ }^{3}$ Chodzi o Jana Harusewicza.

4 Wzmianka dotyczy Dudomira Dymszy.
} 
Die Durchschnittsmeinung ist gar nicht imstande, sich von dem Misserfolg der russischen Waffen Rechenschaft zu geben, da letzterer vor der Öffentlichkeit sorgsam verschleichert wird; trotzdem greift eine für die Russen unfreundliche Stimmung um sich - einerseits infolge der Nachrichten über das Verhalten der Russen in Galizien, anderseits unter dem Einfluss der von Tag zu Tag an Intensität zunehmenden Tätigkeit der russisch feindlichen Unabhängigkeitskreise. Die bisherigen Anhänger Russlans haben sich diesem gegenüber misstrauisch verhalten und begannen um die Unterstützung der französischen und englischen Regierung zu werben.

Unter dem Drucke der wachsenden Unzufriedenheit ging die russische Regierung daran, eine Reihe von Verkehrungen zu treffen, um die Sympathien des Königreichs Polen zu gewinnen. Zuerst hat der Zar den Grafen Sigismund Wielopolski empfangen und hatte ihm gegenüber versprochen, grössere Zugeständnisse an Polen zu machen, als dies der Grossfürst Nikolaus in Ansicht gestellt hat. Úberdies unterstützte er lebhaft die Hilfsaktion für die durch den Krieg geschädigten Einwohner Russisch-Polens, indem er aus eigenen Schatulle eine Milion zweimalhundrttausend Rubel spendete. Die Summen, welche zugunsten dieser Hilfsaktion flossen, wuchsen rasch auf mehrere Milionen Rubel heran, insbesondere als die Nachrichten über dis schwere Lage der Flüchtlinge in Österreich zielbewusst gegenüber gestellt wurden.

Auf die materielle Hilfe folgte eine Reihe politischer Zugeständnisse. Zuerst wurde an die Stelle das den Polen unliebsamen Essen zum Generalgouverneur von Warschau [Paweł] Engałyczew berufen, welcher bis nun soviel Takt an den Tag legt, dass selbst die Oppositionellen ihm diesbezüglich Anerkennung zollen müssen.

Engałyczew unterhält Beziehungen zu den polnischen Politikern und trachtet, ihre Postulate durchzuführen. In erster Linie erwickelte er die Zuerkennung des Öffentlichkeitsrechtes an die polnischen Privatschulen, welch letzterer Frage man in öffentlichen Leben des Königreichs Polen stets grosse Bedeutung beizumessen pflegte. Im Monate April erhielt das Königreich ein städtisches Selbstverwltungsrecht in einer vorteilhafteren Fassung als dies seitens der Duma und das Reichsrates in Aussicht gestellt wurde. Mit 1 Mai hat die Regierung die Einführung der "Semstwo"s, das ist der Gouvernementautonomie, im Königreiche Polen angesagt. In den letzten Tagen wurde eine Reihe von Privatschulen verstaatlicht. Für den Monat Juli lässt Engałyczew die Einführung

\footnotetext{
${ }^{5}$ Chodzi o tak zwane „ziemstwo", czyli swoisty samorząd terenowy funkcjonujący w Rosji.
} 
der Selbstverwaltung für die Dorfgemeinden anzeigen. Ausserdem inspiriert die Regierung öffentliche Diskussionen über die zukünftuge Autonomie des Königreichs Polen, wobei sogar das Stellen von sehr weitgehenden Forderungen nach einer Selbstständigkeit gestattet ist. Ja näher die verbündeten Armeen an Warschau heranrücken, desto freigebiger wird Russland in seinen Zugeständnissen.

All diese Massnahmen, welche allerdings der Bruch mit dem bisherigen Abweisen aller polnischen Forderungen bedeuten, üben nicht einen so starken Eindruck aus, wie es den Wünschen Russlands entsprachen möchte. In Warschau werden sie mit einem Zuwarten aufgenommen, als Zugeständnisse, welche den Polen schon längst gebührt haben. Mehr als diese haben die geschickten Erklärungen der Tripelententemächte Russland an Kredit zugestiftet. Während seines Aufenthaltes in Warschau hat General [Paul-Marie]Pau die polnische Abordnung in den Personen des Grafen Sygmunt Wielopolski und des Dumaabgeordneten Dymsza versichert, dass Frankreich darüber wachen wird, damit Russland die gegebenen Versprechungen redlich hält. Nachdem er aber in Erfahrung gebracht hat, dass die Polen der russischen Regierung, insbesondere dem Minister des Innern, [Mikołaj]Makłakow, gegenüber mistrauisch gestinnt sind, dirigierte er ihre Hoffnungen an den Oberbef ehlshaber, indem er beteuerte, dass der letztere und seine Partei, nachdem sie einmal die Oberhand in Russland gewinnen werden, nach dem Friedensschluss eine breitangelegte Autonomie für die Polen als einen aus militärischen Rücksichkeiten wegen Nachbarschaft mit Deutschland und Österreich wichtigen Faktor durchführen werde, Gleichzeitig kehrte nach Warschau eine nach England entsendete Delegation Zurück, welche von den dortigen Regierungskreisen und von [Arthur James] Balfour die Versicherung entgegengenommen hat, dass England es als eine Ehrenpflicht betrachten werde, anlässlich der Fiedensverhandlungen die Realisierung der durch Russland versprochenen vollkommenen Autonomie des Königreichs Polen mit einem Reichstag in Warschau durchzuführen.

Obige Versprechungen jedoch, obwohl sie zur Desorientierung vieler beitragen, können heutzutage niemandem in Warschau zuf riedenstellen. Der Geist der Opposition gegen Russland entladet sich reichlich sogar trotz der strengen Zensur auf Spalten der legal erscheinenden Presse. Von den Tageszeitungen verbreiten mutig die Oposition in Warschau der konservative „Dziennik Polski” und der nationalbürgerliche "Goniec Poranny i Wieczorny”, zum Teil auch Organ der finaziellen Kreise "Nowa Gazeta”; in der Provinz zeichnet sich durch scharfen Aufreten „Ziemia Lubelska” (Lublin) und „Przegląd Wileński” (Wilna) aus. Ausschlisslich mit der Beleuchtung der öffentlichen Angelegenheiten vom 
russiscj-feindlichen Gesichtspunkt befassen sich die Wochenschriften „Tygodnik Polski”, „Prawda”, „Co Tydzień”, „Nowe Życie”, „Nurt”; als das bedeutendste Organ, welches die vortrefflichsten publizistischen Kräfte gegen Russland um sich schart, ist die durch ihre Gediegenheit geradezu imponierende „Myśl Polska”. Vielmehr einmütig als in Warschau selbst ist die Stimmung gegen Russland im Gouvernement Lublin.

Das in Warschau am 25 November 1914 ins Leben gerufene „Polnische Nationalkomitee"6, welches nach dem Muster des in Krakau entstandenen "Obersten Polnischen Nationalkomitees" die ganze polnische Bevölkerung des Königreichs Polen in seinem Lager versammeln wollte, jedoch unter dem Banner der Anlehnung an Russland, vermochte nicht im geringsten, sein Pläne zu realisieren. Es hat es nicht einmal zustandegebracht, diejenigen Parteien, welche nach Kriegsausbruch sich an die Seite Russlands gestellt haben, um sich zu scharen. Das Úbergewicht behält in dem Komitee die nationaldemokratische (allpolnische) Partei; neben dieser ein Teil der Konservativen sogenannten "Realisten" und einige Parteilose. Das Komitee, durchwühlt durch innere Zwistigkeiten, konnte bis nun keinen Vorsitzenden wählen, nachdem der einzige, welcher die Eignung für die Stellung besitzt, [Roman] Dmowski, bei den Realisten kein Vertrauen findet. Die Dmowskische Partei selbst erlitt im April eine empfindliche Schwächung, weil aus derselben eine Gruppe ausgetreten ist, welche im Organ „Nasze Ognisko" Zuflucht gefunden hat. Letzteres Organ wird durch denjenigen Teil der Aristokratie subventioniert, welcher ohne offiziell mit Russland gebrochen zu haben, im Stillen sich zum Rückzug vorbereitet.

Das „Polnische Nationalkomitee” kann wegen Mangel an Unterstützung durch die öffentliche Meinung sich zu keiner aktiven Betätigung emporschwingen. Sein einziges Unternhmen, di Organisierung, von Freililligen zugunsten Russlands, endete mit einem empfindlichen Fiasko und einer Kompromittierung, welches sogar in den Augen der russischen Regierungdie Bedeutungdes Komitees zugrunde richtete. Die Versamlungen der Grossgrundbesitzer aus einzelnen Gouvernments, welche im März und April abgehalten wurden, haben dem Komitee das Vertrauen nicht votiert; dies gilt insbesondere von den Versammlungen, welche einen demonstrativen Charakter hatten, und zwar diejenigen der Grossgrundbesitzer aus neun Gouvernemnts Litauens und Kleinrusslans ${ }^{8}$, der Gutsbesitzer in Radom (wo im ganzen 4 Personen es wagten, sich an die Seite Dmowskis zu stellen) und

\footnotetext{
${ }^{6}$ Codzi o Komitet Narodowy Polski.

' Wzmianka dotyczy Naczelnego Komitetu Narodowego (NKN).

- Chodzi o Bialoruś.
} 
in Lublin, wo die Gutsbesitzer den Abgeordneten [Jan] Stecki, Präsidenten das Agrarvereines, dazu verhalten, aus dem Komitee auszutreten.

Die Intelligenz und die bürgerlichn Elemente gruppieren sich in oppsitionellen Parteien und rüsten überall zur Anteilnahme für den Fall der Einführung des Wahlrechtes zu den Städtischen Selbsverwaltungskörpern, um durch das Resultat der Abstimmung die Dmowskische Partei aus dem öffentlichen Leben wegzuschaffen. Als die bedeutendste Erscheinung aber und als solche, die für den antirussischen Geist am meisten befriedigend ist, muss die Stellungsnahme der Bauern bezeichnet werden, durch welche selbst die Regierung überrascht und zu Vornahme von massehaften Verhaftungen in den Dörfern der Gouvernements Lublin und Warschau veranlasst wurde. Es hat sich herausgestellt, dass bei den Bauern ganze Magazine voll Waffen und verbotener Druckschriften beschlagnahmt worden sind. Die antirussische Aktion in Warschau und in der Provinz in ihre Hand zu nehmen, haben sich die Emissäre der Militärsektion des Obersten Polnischen Nationalkomitees und der Legionen zur Aufgabe gestellt. Teils ist dies gelungen, teils geht die Schwungkraft weiter, als dass man auf Grund des Legionenprogrammes ihrer Herr zu werden imstand wäre. Das Hauptergebnis ihrer Tätigkeit besteht jedoch darin, dass jenseits der Kamplinie die Bevölkerung in autentischer Weise über die Kämpfe und Bestrebungen der polnischen Legionen unterrichtet ist. Die Legionen üben eine grosse Anziehungskraft haupsächlich auf die Jugend aus. Die Familien der Legionäre, sehr zahlreich in jeder Stadt - in Warschau allein gibt es circa 4000 Familien, welche direkt oder mittelbar mit den Legionären verbunden sind - tragen selbstverständlich zur Verbreitung der Legionsidee bei.

"Wiadomości Polskie”, als eine über diese Angelegenheiten berichtende Zeitschrift, wird in Warschau immer mit Spannung erwartet, die Artikel werden in den geheimerscheinenden Zeitschriften sowie in Flublättern nachgedruckt und verbreitet; Die Artikel aus „Wiadomości Polskie”, welche die Kämpfe der Legionäre der I Brigade und die Kämpfe in den Karpathen beschreiben, wurden gesammelt als eine besondere Ausgabe in Druck gelegt ind in ganz Warschau verbreitet.

Die Gesamte Zusammensetzung der gegenwärtig im Königreich Polen wirkenden politischen Faktoren stellt sich folgendermassen dar.

1. Für Russland bekundet seine Parteinahme das „Polnische NationalKomitee", in welchem die Allpolen und ein Teil Konservativen vertreten sind. Was die sozialen Schattierungen dieses Komitees betrifft, so repräsentiert es einen Teil der Gutsbesitzer, ein Teil des des Klerus und einen Bruchteil der Intelligenz.

2. Eine schwankende Stellung nimmt die sogennte fortschrittliche partei ein, die die Kreise Bankiers und der Warschauer Advokaten umfasst. Diese Kreise 
sind an Zahl gering und da sie von jüdischen Elemente stark durchsetzt sind, sehr unpopulär.

3. Gegen Russland nimmt Stellung, ohne jedoch eine aktive Organisation zu Kampfzwecken ins Werk zu setzen, der sogennte Block der Mitte, das heist die Arbeiter gruppe, der ausschlisslich konservative Gutsbesitzer angehören (ihr Organ ist der „Dziennik Polski”) und die Sezessionsgruppe, welche aus dem Lager der Allpolen ausgeschieden ist, und der die Finanz -und Professorenkreise angehören: ihre Organe sind legale „Tygodnik Polski” und illegale „Głos Wolny”.

4. Das tätige antirussische Heerlager zerfällt in zwei Gruppierungen:

a) Die Unabhängigkeitskonföderation, die antirussische Elemente der rechtstehenden Kreise des Grossgrundbesitzes und der Geistlichkeit, sowie Bauern und Arbeiter vereinigt

b) Die Unabhängigkeitsunion umfast die Elemente der Linken, Radikale und Sozialisten.

Ausser den hier aufgezählten gibt es in Warschau und anderen Städten Polens keine anderen nennenswerten politischen Gruppirungen. Bei gewonneren Orientierung darüber, auf welche Kreise sich eine antirussische Politik stützen kann, kommen natürlich nur drei letzteren Gruppen in Betracht. Es bestehen zwar unter ihnen gewisse Unterschiede, doch sind sie darin solidarisch, dass sie eine Vereinigung mit dem Obersten Polnischen Nationalkomitee anstreben und die polnische Legionen gerne als Ausdruck ihrer nationalen Aspirationen ansehen möchten. Diese Gruppen bezeichnen sich selbst als „Unabhängigkeitsgruppen”, das heist als solche, die die politische Unabhängigkeit des Königreiches Polen anstreben ohne bezüglich des Verhältnisses des letzteren zu Osterreich einen ausgesprochenen Standpunkt einzunehmen. Während diese kreise früher ihre austrophile Gesinnung ganz deutlich bekundeten, so scheint jetzt unter dem Einflusse der politischen Ereignisse in diesen Kreisen eine gewisse Verstimmung gegen Osterreich Platz gegriffen zu haben. Indem von dieser Seite gegen Osterreich der Vorwurf erhoben wird, dass es kein Programm einer Zukunft Polens entwirft, wird zugleich auch die Erklärung hinzugefügt, dass offener Österreich mit einem Programme, das eine Anziehungskraft für die Polen hätte, nicht hervorzutreten vermöge. Die mutmasslichen Gründe dieses Verhaltens werden in der Abhängigkeit der österreichischen Politik von der gegen die Polen unfreundlichen Politik Deutschlands gesucht. Diese Kreise sind, obwohl sie anfangs ihren Anschluss an das Oberste Polnische Nationalkomitee angemeldet haben, jetzt in ihren Sympathien zurückhaltender und machen dem Obersten Polnischen Nationalkomitee den Vorwurf, dass es keine Garantie für die Selbständigkeit und Unteilbarkeit des Königreiches Polen gebe. Eine neue Teilung Polens würde alle 
diese Kreise gegen Österreich und Deutschland wenden. Die polnische Legionen haben ebenfalls in ihren Augen manches von ihrer Anziehungskraft eingebüsst, dass sie, ihrer Ansicht nach, in ihrer Absonderung eingeschränkt sind und dem Landsturm gleichgestellt werden. Nur für die Freiheit kann sein Blut freiwillig vergiessen; die Polen Galiziens könne gute Gründe haben, dem österrichischen Monarchen dankbar zu sein, jedoch die Untertanen des Königreiches Polen nehmen einen ganz anderen Rechtsstandpunkt ein; sie wollwe ihr Blut opfern, doch müssen sie deutlich das Ziel sehen, für das sie sich opfern. Den Heldenmut der polnischen Legionen lassen sie sich zur Ehre gereichen, als eine Erscheinung, die den Polen ein rühmliches Zeugnis gibt und daher verfolgen sie die Geschicke der Legionen mit inniger Teilnahme. Es ist ihnen bakannt, dass die Militärsektion die Werbetätigkeit für die Legionen im Königreiche Polen entfaltet, sie halten jedoch diesen Schritt für verf rüht, da das Oberste Polnische Nationalkomitee sein Programm bezüglich der Zukunft des Königreiches Polen noch nicht geäussert hat. Daher haben alle diese Gruppen zur Zeit der Osterfeiertage eine gemeinsame Zusammenkunft veransteltet, bei der beschlossen wurde, an das Oberste Polnische Nationalkomitee einen Delegierten zu schicken, der ihnen eine programmatische Äusserung des Obersten Polnischen Nationalkomitees und Nachricht über eine etweige Erklärung seitens Österreichs bringen soll, inzwischen aber eine zwar wohlwollende, jedoch abwartende Haltung einzunehmen.

Die erwähnte Abkhlung der Sympathien für Österreich wurde durch eine ganze Reihe von Momenten herbeigeführt, welche durch die russophile Agitation ausgenützt werden. Um die an Österreich geknüpften Hof fnungen abzuschwächen, wird allgemein über die Vorschlimmerung der Beziehungen zwischen den Polen und Österreich nacherzählt; in einemfort wird die ungastfreundliche Behandlung der galizischen Flüchtlinge insbesonders in Wien, sowie in den Baracken ausgemalt; es wird betont, dassdie Polen keinen Anteil an der Regierung haben; unausgesetzt wird das unpassende Wort des Grafen [Leopold]Berchtold wiederholt, welche angeblich in anwesenheit Exzellenz des gewesenen Ministers [Stanisław] Głąbiński gefallen ist, dass die österreichische Diplomatie noch keine Zeit hatte, darüber nachzudenken, was in der polnischen Frage anzufangen wäre; es werden bereits verschiedene Fehltritte und Missgriffe der neuen Verwaltung im Königreich Polen ausgehützt, insbesonders das Vorgehen der Deutschen, das Reizen der polnischen Nationalgefühle seitens der letzteren.von Zeit zu Zeit verschiedene Schikanen hervorgehoben, welchen die polnische Legionen ausgesetzt sind, wobei so mancher wirklich vorgekommene Fall, als zweckmässige zur Liquidierung der Legionen führende Tendenz dargestellt wird. Namentlich wird die Entsendung des 2. Und 3. Legionen-Regimsnts in die Karpathen als 
derenabsichtliches Fernhalten von dem heimatlichen Terrain, ihren Aspirationen zum Trotz, gebrandmarkt.

Derartige Agitation wird durch die Feinde Russlands bekämpft, wobei verschiedene Lügen dementiert zu werden pflegen; in vielen Fällen lässt jedoch der eigentliche Tatbestand das Dementi nicht zu, nachdem die Russophilen mindestens zum Teile sich auf wahre Informationen stützen. Daher eine Abschwächung der Hoff nungen mit bezug auf Österreich. Dies ist jedoch auf etweige Abschwächung der russenfeindlichen Bewegung ohne Einfluss, nur erfährt diese Bewegung eine etwas verschiedene Färbung. Es entstand eine politische Atmosphere durch und durch nervös. Die Einberufung der Stellungspflichtigen vom Jahre 1916 drohte schon einen Sturm zu entfachen. (Es ist allgemein bekannt, dass der Ausbruch der Revolution im Jahre 1863 ebenfalls mit der zwangsweisen Assentierung im Zusammenhange gastanden ist). Hunderte waren bemüht, zu den Legionen durchzudringen, einer wurde durch die Russen in Kielce gehängt. In Warschau und in anderen Städten kauft die Jugend Waffen an. Es bestehen schon grosse Vorräte der letzteren. $\mathrm{Zu}$ einer grossen Kraft sind die geheimen militärischen Organisationen emporgewachsen, militärische Kurse werden stets abgehalten; mit Rüchsicht auf die drohende Gefahr einer Provokation wurde im April die Aufnahme in die letzteren eingestellt. Trotz grossen Mangels an Geldmitteln verfügen die erwähnten Organisationen über ein grwisse Budget, nur die kleinen Geldsammlungen allein ergaben im März 11000 Rubel für die Rüstung zum Aufstand, wie dies aus einer Verlautbarung in der geheimen Zeitschrift dieser Vereinigung "Podchorąży” zu ersehen ist. In diesen Organ, welches einen sehr grossen Absatz hat, finden die Beschreibungen der Legionenkämpfe viel Raum, die Verlustlisten werden abenfalls publiziert. In der Aprilnumer des „Podchorąży” verlautbarte der Kommadant der Warschauer militärischen Organisation, dass die Anschläge auf die Bahnkörper, welche gleichzeitig auf allen Linien zwische Warschau und Russland in der Nacht vom 10 auf 11 April ausgeführt wurden, eine Probe der Betätigung genannter Organisationen gewesen ist. Die Organisationen werden moralisch sowohl durch die Konföderation als auch durch die Union unterstützt. Ihr Kontingent bilden die gewesene Jungschützen und betrachten als ihren Kommandanten den Brigadier Piłsudski, dessen einzelne Tagesbefehle an die I Brigade, polnischer Legionen, im „Podchorąży” an der leitenden Stelle nachgedruckt werden.

Die russische Behörden ahnen schon, dass irgend eine Feindseligkeit vorbereitet wird - daher fliessen einerseits in einem raschen Tempo in den letzteren Wochen verschiedene politische Konzessionen - anderseits Massenhaftungen, über welche (ebenso wie über die Anschläge auf die Bahngeleise) den Zeitungen zu 
berichten verboten wurde. Die zahlreichsten Verhaftungen wurden in der Nacht vom 16 auf 17 April vorgenommen; in Warschau allein gab es deren über 100, in Lubliner Gouvernement zirca 70. Eine Reihe von Personen wurde mit Waffen und Kundschaftsberichten festgenommen. Einzelne derselben haben Selstmord bagangen. Unter anderen wurde der bekannte Redakteur des Bauernblattes "Zaranie”, des Organs "Volkspartei”, Mikołaj" verhaftet. In einigen Lokalitäten in Warschu und Lublin sind grosse Depots vom revolutionären Druckschriften entdeckt worden. Den Verhafteten wurde ein Massenprozess wegen Verrates zugunsten feindlichen Kriegsmacht, sowie wegen Spionage eingestellt; die Verteidigung übernahmen die bakanntesten Warschuer Advokaten, bewährte Führer der Unabhängigkeitsbewegung; ausserdem haben sich zur Verteidigung sogar Advokaten aus Moskau aus eigenem Antriebe gemeldet. Der Prozess droht mit schweren persönlichen Verlusten und wird bedeutende Schäden inmitten der russenfeindlichen Organisationen, besonders unter den Bauern, nach siech ziehen. Die militärische Organisation wurde jedoch durch diese Verhaftungen nicht berührt. ${ }^{10}$

Odpis, maszynopis.

Haus.- Hof und Staatsarchiv, Krieg P.A. I. karton 900, folio 303 - 317.

9 Pomyłka - chodzi o Maksymilana Malinowskiego.

${ }^{10}$ Raport nie został opatrzony podpisem autora. Pod tekstem tego dokumentu znajduje się jednak odręczny dopisek.:Anmerkung. Dieser vertrauliche Bericht wurde vom Militärdepartament der polnischen legionen in Piotrków verfasst und am 18 April 1915 an das Armee Oberkommando gesendet. Tę uwgę podpisal przedstawiciel austro-węgierskiego Ministerstwa Spraw Zagranicznych przy AOK Franz Czaki. 


\section{Dokument nr 4}

1915 kwiecień 30, Wiedeń. - Pismo nieznanego wystawcy do austro-węgierskiego ministra spraw zagranicznych Stefana Buriana i trzy zalqaczniki.

Hochgeborner Graf?

In Erwiderung auf das geschätzte Schreiben vom 28 April dieses Jahres stelle ich die zwei Ausschnitte aus russischen Zeitungen und die Information des Obersten Polnischen Nationalkomitees mit besten Danke zurück"

Der zweite Teil des Ausschnittes aus der „Nowoje Wremja” ist geeignet, im Hinblick auf die italienische Aspirationen an der Ostküste der Adria besonderes Interesse zu erwecken.

Was die Information anlangt, so zweifle ich nich, dass dieselbe in Bezug auf die Haltung des allpolnischen Hauptblattes in Lemberg "Słowo Polskie" völlig zutreffend ist. Das Blatt kehrt unter den dermaligen Verhältnissen offenbar sein wahres Gesicht hervor und enthüllt längst gehegte, aber früher etwas versteckter bekundete Tendenzen.

In der Beurteilung der konservativen podolischen Stimmen vor allem des Lemberges Haupblattes "Gazeta Narodowa" müsste man meines Erachtens etwas vorsichtiger sein und vorerst prüfen, ob unter welchem politischen Hochdrucke der jetzigen Machthaber geschriben wird. Es erscheint mir geradezu undenkbar, dass Graf [Leon] Piniński und die bisherigen Leiter des Blattes nach ihrer freien Meinung so schreiben könnten.

Die freudige Konstatierung der antiösterreichischen Haltung, die das Blatt jetzt unstreitig zur Schau trägt, entspringt der feindseligen Stimmung im Nationalkomitee gegenüber den östlichen Konservativen. Es ist aber leider keineswegs ausgemacht, dass diese sittliche Empörung ganz und ausschlisslich nur in beleidigten österreichisch - patriotischen Empfindung wurzelt.

Empfangen Euer Hochgeboren die Versicherung meiner vorzüglichsten Hochachtung.

Podpis nieczytelny

"Spośród trzech wymienionych załączników do niniejszej publikacji została zakwalifikowana tylko informacja sporządzona przez NKN. Zostały natomiast pominięte odpisy artykułów ogłoszonych w gazetech rosyjskich. Artykuł ogloszony na lanach „Biriowyje Wiedomosti” (nr 214 kwietnia 1915) zawiera szkice Janko Garesku z podróży po Czechach, zaś artykuł wydrukowany prıez „Nowoje Wremia" był oparty na wywiadzie deputowanego włoskiego Supilo, a omawia terytorialne aspiracje włoskie ku wschodnim wybrzeżom Adriatyku. 
Załącznik zawierający odpis informacji sporządzonej przez NKN.

Die nationaldemokratische Presse Lemberg scheut keine Mühe und verschmächt kein Mittel die polnische Bevölkerung Ostgaliziens, die bis nun treu zu Österreich hielt, Russland in die Armee zu treiben. Diese Arbeit wird durch und durch perfider Weise und systematisch betrieben. Vor allem bestrebte man sich die polnischen Legionen bei der öffentlichen Meinung in Misskredit $\mathrm{zu}$ bringen, indem man sie als Werk einer von der Regierung betriebenen Agitation hinstellte. „Im Laufe des August und September vermochte man mit grossen Mühe in Krakau das zweite Regiment zu bilden. Die Rekrutierung von Freiwilligen $\mathrm{zu}$ demselben erfolgte in einigen Punkten Westgaliziens unter eif riger Mitwirkung aller Faktoren der Staatsverwaltung”. „Für das dritte Regiment besorgten die Rekrutierung die Bezirkshauptleute. Besonders eif rig stellte man den sogenannten ehemaligen östlichen Legionären nach ${ }^{12}$. Man sperte sie einfach ins Gefängnis ein und liess ihnen die Wahl zwischen den Gefängnis und dem Dienste in der Legion. Durch besonderen Eifer taten sich hervor die Bezirkshauptleute und ihre untergeordneten Organe von Limanowa, Neu Sandez, Żywiec und Biała". So schrieb das "Słowo Polskie" in einen längeren Artikel unter dem Titel: "Galizische Legionen" (zitiert aus dem "Kuryer Warszawski” vom 6 I $1915 \mathrm{Nr}$ 6, der obige Artikel in Auszügen veröffentlicht hat). Um den Kampswert der Legionsregimenter gänzlich herabzusetzen und sie dem Gespötte preiszugeben, schrieb „Słowo Polskie” im obigen Artikel über die Artillerie der Legion folgendermasse: „Man gab ihnen je eine Batterie von Kanonen aus dem Jahre 1875. Diese sehr laut schiessenden und viel Rauch entwickelden Greisinnen hatten gegenüber den modernen Schnellfeuer-Geschutzen die besondere Eigentümlichkeit, dass sie nach jedem Schuss sich überpurzelten. General Durski [Karol Trzaska-Durski] erklärte in Mszana [Dolna], dass sie „zum Einschüchtern und Signalgaben" bestimmt waren. Aber einstweilen waren sie das kriegerische Hilfsmittel, das diese unglücklichen Abteilungen in den späteren Schlachten basassen"13.

Dann schrieb "Słowo Polskie" des Langen und Breiten über die seitens der österreichischen Regierung den polnischen Politikern gegenüber geübten

12 Wzmianka dotyczy ochotników, którzy zgłosili się we Lwowie do szeregów Legionu Wschodniego, rozformowanego potem w Msznic Dolnej koło Nowego Targu.

${ }^{13}$ Stwierdzenia dotyczące artyleryjskiego wyposażenia pułków legionowych w Karpatach Wschodnich były zgodne z prawdą. Chodzilo w istocic o prarestarzałe działka górskie. Po upływie kilku tygodni wycof ane jednak $z$ użycia. 
Repressalien und stellte sie als eine gegen die Polen überhaupt gerichtete Intrigue dar. In der Nummer vom 8 Jänner berichtete es über die Verhaftung des Abgeordneten Zamorski. Nach Aufstellung der Verdienste, die er sich durch seine nationale Wirksamkeit erworben, schloss es den Artikel folgendermassen: „Nach Aleksander Skarbek - Jan Zamorski. Wir hegen die Gewissheit, dass die Litanai der Repressionen gegen die polnischen Politiker noch nicht beendet ist" Und wirklich, gleich in der nächsten Nummer wird über die, durch die österreichischen Behörden erfolgte Internierung der Abgeordneten Cieński und Stanisław Stroński berichtet. „Słowo Polskie” ist auch bemüht den Glauben an den Erfolg der österreichischen Waffen zu erschüttern, indem es Notizen, wie folgende über österreichische Gefangene bringt: „Wir sahen am Abend eine einige Tausend zählende Gruppe, die meistenteils aus österreichischer Infanterie bestand, Sie kamen von den Karpathen her. So weit man es bestimmen konnte, waren es Soldaten deutscher Nationalität. Es war ihnen anzusehen, dass sie erschöpft waren und frierten". Überhaupt fällt es auf, dass die österreichischen Soldaten, die jetzt in die Gefangenschaft geführt werden, ebenso bekleidet sind, wie zur Zeit, da sie im September durch Lemberg zogen, dass sie also für die strengen Fröste gänzlich unversorgt waren".

"Die Schilderungen aus den Karpathen sind schauererregend uns zeugen von einer unerhörten Geringschätzung des Menschenmaterials in der österreichischen Armee. Man erzählt, dass die Soldaten sechs Tage lang ohne Ablösung in den Schützengräben verbleiben und der Hunger bringt sie zu solcher Verzweiflung, dass sie beten, von einer Kugel getroffen zu werden oder um das Erbarmen der Gafangenschaft"

„Es wird erzehlt, das an einer Stelle in den Karpathen, eine angreif ende russische Abteilung eine Verschanzug vol toter Menschen antraf, die das Gewehr noch in den Händen hielten. Es waren ihrer einige Hundert”. („Słowo polskie” vom 13 Februar, zitirt vom Kuryer Warszawski" vom 24 Februar, $\mathrm{Nr}, 55$ ).

Die Führer der nationaldemokratischen Partei haben, über alle polnische Länder verstreut, ihre geheime Wühlarbeit nicht unterlassen und sind miteinander in unausgesetzter Verbindung. Stanisław Biega, der Stellvertreter des Grafen Skarbek, einer der Haupturheber der Auflösung der östlichen Legion, der angeblich bis jetzt in Österreich interniert war, ist schon in Lemberg aufgetauscht und hat eine einflussreiche Stellung in den dortigen Hilfskomitee („KuryerWarszawski”, vom 20 Februar, Nr. 51), Es wird uns auch mitgeteilt, dass auch einanderer allpolnischer Agitator aufgetauscht wäre, nämlich der Gehilfe des Biega, [Karol] Wierczak. Bald werden sich dort alle Führer der östlichen Legion zusammenfinden, nachdem wir hier ihre zersetzende Tätigkeit unmöglich 
gemacht haben, erfolgreicher von dort aus gegen Österreich in Warschau agitieren zu können. So zum Beispiel weilte das Meldungen der Warschauer Blätter zufolge, Ende Februar der Chef redakteur des "Słowo Polskie" Zygmunt Wasilewski.

Eine würdige Gefährtin des "Słowo Polskie" ist die "Gazeta Narodowa", das Organ der ostgalizischen Konservativen, der sogenannten Podolaken. In einer Korrespondenz aus Stanisławów sucht diese Organ die Zivilverwaltung der russischen Behörden im Gegensatz zu den früheren Zuständen in möglichst günstigen Lichte erscheinen zu lassen.

„Die Zivilbehörden bestreben sich vor allem die Fürsorge für die arme Bevölkerung zu organisieren, der gegenwärtig täglich 3000 Mittagessen und ebensoviel Portionen Tee unentgeltlich verabreicht werden, wobei sie ausserdem reichliche Geldunterstützungen erhält".

Stanisławów hat die Kriegsnot beinahe nicht gespürt - im Gegenteil, trotz des Krieges herrscht hier eine nie dagewesene Billigkeit".

"Auf Anregung des Herrn Generalgouverneurs von Galizien und des Guverneurs von Tarnopol, die am 24 Jänner leitendes Jahres in Stanisławów geweilt haben, werden von der Stadtverwalung Akcise-Abgeben von zum Verkauf nach Stanisławów eingeführten Feldf rüchten eingeführt werden, was zur Aufbesserung der Finanzen der Stadt beitragen wird".

„Es ist beinahe unmöglich auf diplomatischen Wege von der Wiener Regierung die Zusendung eines entsprechenden Geldvorrates für die Zeit nahezu 5 Monaten einfach ohne Existenzmittel zurückgelassenen Staatsbeamten zu erwirken. Blos den Beamten des hiesigen Gerichtes und des Steueramtes hat die russische Behörde die Auszahlung ihrer Gehälte für die Zeit von 15 Oktober 1914 an, versprochen. (Zitiert in der "Gazeta Warszawaska" Nr. 37 vom 6 Februar)".

Anlässlich der Kundmachung der österreichischen Armeeverwaltung, durch welche der von den Assentkommissionen während der Zeit vom 16 November bis 31 Dezember für tauglich befundene Landsturm zu den Waffen einberufen wurde, schreibt die "Gazeta Narodowa" wie folgt.

"Wie wir aus gut informierter Quelle erfahren, entbehrt diese nachricht aller Aktualität für den kleinen Rest von Westgalizien, der jetzt unter die österriscischen Herrschaft verblieben ist; die dortigen Behörden haben nämlich der galizischen Bevölkerunggegenüber besondere Mobilisierungsmassnahmen getroffen"

„So wurden bei der ersten Einberufung des Landsturms speziell in Galizien um einen Jahrgang mehr Leute eingereiht als anderswo. Die galizischen Rekruten wurden zur militärischen Ausbildung sof ort am selben Tage, also Mitte September herangezogen, während den in anderen Ländern der Monachie einberufenen ein allgemeiner Urlaub bis zum 15 November erteilt wurde. Die Folge davon war, dass 
während die zu derselben Zeit zum Militärdienst assentierten österreichischen Rekruten erst ihre Ausbildung erhielten - ihre galizischen Gefährten bereits ins Schlachtfeld zogen"

„Es ist noch zu erwähnen, dass die Assentierungskommissionen mit aller Rücksichtslosigkeit vorgingen und von den "Waffenufähigen" gegen $75 \%$ der Einberufenen ins Militär eingereiht haben. Die Assentierten wurden sofort zur Ausbildung nach dem österreichischen Schlesien geschickt".

"Die gegenwärtige Wiener Kundmachung zeugt von einer ähnlichen Methode der Behandlung, die die Regierung gegenüber den Staatsbürgern aus Galizien in Anwendung bringt. Die in den österreichischen Provinzen einberufenen Rekruten, die im Alter 24 - 28 Jahres standen, hatten sich erst in den ersten Tagen des Januar auszumelden, während die galizischen Rekruten der Altersklasse von 24 - 28 Jahren bereits seit dem 16 November 1914 unter den Waffen stehen.

(„Gazeta Narodowa” zietiert vom „Kuryer Warszawski” Nr 21 vom 25 Januar unter dem Titel : „Wie die Landsturmleute in Galizien einberufen werden”).

Es ist beachtenswert, dass derartige österreichfeindlichen Artikel in Warschau nachgedruckt werden, um die Bevölkerung des Königreichs Polen möglichst abgeneigt zu machen und dass die "Gazeta Narodowa" das Organ derselben Podolier ist von denen ein Teil die östliche Legion zu Auflösung brachte, ein anderer sich gegenwärtig in Wien alle Mühe gibt, das Oberste Nationalkomitee in seine Gewalt zu bekommen und die Agitation sowie die Werbetätigkeit der Legionen im Königreich Polen zu vereiteln.

Kopia pisma przewodniego i odpis załącznika, maszynopisy.

Haus.- Hof - und Staatsarchiv, Krieg, P.A. 1, karton 900, folio 341 - 348.

\section{Dokument nr 5}

1915 kwiecień 30. Wiedeń. - Pismo austro-węgierskiego ministra spraw zagranicznych do hrabiego nie wymieionego z nazwiska o aktywności Polaków w Szwajcarii.

Indem ich nur gestatte die von Ihnen gewünschte Notiz hiemit zu übersenden glaube ich daran einige ganz kurze Bemerkungen knüpfen zu sollen, die sich auf die dem Obersten Polnischen Nationalkomitee zur Last gelegte politische „Verleumdungsucht" beziehen. 
Eines muss ich von vornherein einräumen: die Tatsache dass irgend eine polnische Partei in Friedenszeiten für die Staatlichen Bedürfnisse der Monarchie gestimmt hatte, ist für mich noch kein Beweis, dass ihre Haltung während des Krieges als ine Korrekte bezeichnet werden müsste. Es haben doch die Nationaldemokraten, über deren Programm heute wohl nirgends Zweifel mehr bestehen, auch stets für die Staatsnotwendigkeiten gestimmt.

Abgesehen davon wird keiner einzigen polnischen Partei in Galizien der Vorwurf des Russophilismus seitens der im Obersten Polnischen Komitee vertretenen Parteien gemacht. Es ist einfach eine Lüge, dass der polnischen Geistlichkeit, dass hervorregenden Männern der podolischen Partei oder gar den Gründern der Krakauer Partei irgend woher Russophilismus vorgeworfen werde. Die Meinungsverschiedenhaeiten, die zwischen den genannten Elementen und dem Obersten Polnischen Nationalkomitee bestehen liegen gar nicht auf dem Gebiete der so genennten politischen Orientierung. Das zum Beispiel Graf [Agenor] Gołuchowski ein warmer Anhänger derselben Idee, die auch dem Obersten Polnischen Nationalkomitee voranleuchtet, nämlich der Angliederung Königreich Polens an die Österreichisch -Ungarische Monarchie, weiss bei uns jedes Kind. Selbstverständlich tritt das mit Beziehung auf die Gründer der Krakauer Partei die Herren grafen Tarnowski ${ }^{14}$ und Herrn von Koźmian ${ }^{15}$ auch zu.

Die Gründe, aus welchem Graf Gołuchowski das Komitee bekämpft sind Ihnen Hochgeehrter Herr Graf wohl bekannt. Sie stammen daher, dass Graf Gołuchowski aus seiner früheren Kariere wohl sehr viel äussere Autorität, leider aber sehr wenig Kenntniss der polnischer Frage nicht nur in Königreich Polen aber selbst in Galizien besitzt. Er teilt diesen Mangel, jedoch in sehr verschärften Masse mit seinen podolischen Gesinnungsgenossen, die in der Nationalfremden, Kultrurarmen, ostgalizischen Umgebung wie Halbgötter von der Westen Polens, insbesondere aber in Russisch Polen weit vorgeschrittenen Demokratiesierung der Geselschaft keine Ahnung haben. Mit einer verächtlichen Kavaliersgebärde wird von diesen Herren alles was nicht streng konservativ ist mit den Sozialdemokraten in ein Topf geworfen und es wäre manchmal ergötzlich, wenn es nicht so traurig wäre zu hören, wie zum Beispiel politische Parteien Königreich Polen die auf dem Unabhängigkaietsstandpunkte stehen, sonst aber von den Sozialdemokraten bis aufs Blut bekämpft werden, von den genannten.

${ }^{14}$ Chodzi zapewne o Adama Tarnowskiego.

is Wzmianka dotyczy zapewne Stanisława Koźmiana, czołowego działacza ugrupowania „stańczyków". 
Das Zentral Hilfskomitee für Polen in Lausanne steht unter dem Vorsitz von Heinrich Sienkiewicz, Erasmus Piltz und Professor [Szymon] Askenazy. Während Sienkiewicz von allen Anfange an die Tätigkeit des Komittes auf das rein humanitäre Gebiet beschränkt wissen wollte, wurden von den beiden anderen Herren Versuche unternommen den Wierkungskreis des Komitees auch auf das politische Gebiet hinüber zu spielen. Die bekannte Reise [Ignacy] Pederewskis ist auf das Konto des Herrn Piltz zu setzen, dessen politische Richtung wohl keiner näheren Beleuchtung badarf: Piltz stellte sich in seinen zahlreichen auch öffentlichen Aktionen, wie die Herausgabe einer „Dokumentensammlung zur polnischen Frage" ganz offen auf den Boden des Manifestes des Grossfürsten Nikolaus, Professor Askenazy kündigte in polnisch-amerikanischen Blättern die Ausbreitung der Tätigkeit des Komitees auch auf andere Gebiete der nationalen Arbeit an. Zum Glück bekämpften Piltz und Askenazy einander im Komitee bis auf Messer, denn der letztgenannte vertrat und vertritt die antirussische Richtung unter den Polen. Als daher das Komitee durch den Eintritt von hervorragenden Polen aus Warschau und aus der Schweiz wie [Jan] Kucharzewski, [Józef]Janowski und Gabriel Narutowicz verstärckt wurde, wurde es leicht allen diesen politischen Versuchen des Komitees ein Ende zu machen. Zur Charakterisierung der anfänglichen Tätigkeit des Komitees wäre hervorzuheben, dass zum Beispiel das ihm affilierte polnisch-amerikanische Hilfskomitee aus seinen Fonds eine Unterstützung für die Agenten des polnischen Nationalrates in Rom und in Paris gewährt hatte, über deren Tätigkeit noch weiter unter zu sprechen sein wird. Eine solche Tatsache dürfte sich jetzt nicht mehr wiederholen, seitdem einzelne der obengenannten neueingetretenen Komiteemitglieder mit ihrem Austritte aus dem Komitee für den Fall gedroht haben, als sich irgend welche politische Velleitäten nochmals zeigen sollten.

Aus alledem ist ersichtlich, dass die ursprünglich in den Kreisen des Obersten Polnischen Nationalkomitees gegen das Lausanner-Komitee gehegten Bedenken vollaufbegründet waren, dass sie aber durch die Vorkommnisse der letzterer Zeit glücklich zerstreut wurden. Es fällt derzeit niemanden der die Verhältnisse näher kennt ein, das Central Komitee in Lausanne als Stätte des Russophilismus zu bezeichnen.

Die im Schosse dieses Komitees, nicht ohne vertrauliche Einwirkungen seitens des Obersten Polnischen Nationalkomitee in Wien glücklich zurückgedrängten politischen Bestrebungen machen sich jetzt in einer anderen, im Werden begriffen Organisation Raum.

Es muss vorausgeschickt werden, dass der ehemalige Polnische Nationalrat in Lemberg (Präsident Tadeusz Ritter von Cieński) seit Ausbruch des Krieges seine 
Tätigkeit gar nicht unterbrochen hat, ja dass dieselbe sogar in der Zeit entfalltet wurde, als sämtliche polnische Parteien im Obersten Polnischen Nationalkomitte vertreten waren. Die Tätigkeit der Delegierten jenes Nationalrates im Auslande stand die ganze Zeit hindurch in grellen Widerspruche zu dem Programmme des Obersten Polnischen Nationalkomitees. Der Delegierte in London Józef Rettinger knüpfte sofort nach Ausbruch des Krieges enge Beziehungen zu der dorttigen russischen Botschaft an und propagierte weitgehende politische Aktionspläne, deren Finazierung, wie er offen bahaupte gesichert war. Lange Zeit vor der unglücklichen Auflösung der so genannten östlichen Legion, dennschon in der ersten Hälfte September erklärte Rettinger, dass diese Legion werde aufgelöst werden müssen. Der Delegierte des Nationalrates in Paris Kazimierz Woźnicki veröffentlichte in einem Interwiew im "Matin" vom 16 August 1914 Mitteilungen über angeblich russenfreundliche Stimmunng unter den Polen in Galizien; er schrieb das bekannte Telegramm nach Amerika, wegen Eintritt von Freiwilligen in die russisch-polnischen beziehungsweise französisch-ponischen Legionen; endlich gab er offiziell unter der Firma des Nationalrates eine Sammlung der französischen Pressestimmen über das Manifest des Grossfürsten heraus. Der Vertreter des Nationalrates in Rom Mattäus (Maciej) Loret veröffentlichte in der "Rivista di Roma" eine Enquette in der polnischen Frage vollständig in russischfreundlichen Sinn und übernahm die Vertretung des WarschauerNationalkomitees (Dmowski) für Italien. Auch in Wien besitzt der Nationalrat einen Agenten. Da Rettinger infolge einer unliebsamen Affäre persönlichen Charakters gezwungen war London zu verlassen, hat Graf Skarbek in der letzten Zeit und mit Berufung auf einen Autrag des Herrn von Cieński Verhandlungen mit einen anderen Polen in London angeknüpft, der die Vertretung des Nationalrates zu übernehmen hätte. Das Ergebnis der Verhandlungen ist derzeit noch nicht bakannt.

Im engsten Zusammenhange mit dieser auswärtigen Tätigkeit des Nationalrates steht nun eine Aktion, die sich erst in ihren Anfängen befindet; es soll in Lausanne ein Komitee gebildet werden, das die Centraliesierung der politischen Arbeit im Auslande, insbesondere aber der Presseaktion zur Aufgabe hat. Es soll ein polnisches Telegraphenbüro gegründet und polnische „diplomatische" Vertretungen in allen europäischen Städten gebildet werden. Die Gründung des Press und Trlagraphenbüros wurde vorläufig auf den Monat Juli verschoben; das Projekt einer auswärtigen Organisation wurde gestellt. Das Komitee ist streng geheim. An seiner Spitze steht Erasmus Piltz. Das Komitee ist in der letzten Zeit mit dem Fürsten Witold Czartoryski in Kontakt getreten. Der jetzt in der Schweiz weilende Graf Skarbek unterhält die Vrbindung zwischen 
dem neuen Komitee und dem polnischen Nationalrate beziehungsweise Herrn von Cieński.

Es wird schon vielleicht in der allernächsten Zeit möglich sein über die Deteils der inneren Organisation und der Tätigkeit des geheimen Komitees genauere Mitteilungen zu geben. Eines steht jetzt bereits fest, und zwar dass dieses von ausgesprochen russophiler Seite ins Leben geruf ene Komitee unter der Flagge der vollständigen Unabhängigkeits Polens segelt und bestrebt ist Beziehungen zu allen denjenigen Elementen zu finden, die die Unabhängigkeitslosung ohne Zusammnhang mit Österreich-Ungar auf ihre Fahnen geschrieben haben. Es wiederholt sich ganz genau dasselbe Schauspiel dass den politischen Hintergrund zur Auflösung der östlichen Legion gebildet hatte; auch damals bot die "Österreichische" Eidsformel der Legion den Vorwand zur Auflösung derselben. Den Herren von Cieński und Grafen Skarbek war die Legion nich polnisch genug. Sie wollten eine Organisation schaffen, die angeblich die reine Unabhängigkeit Polens zu verfechten hätte. Das sich hinter diesen Unabhängigkeitsbestrebungen die Idee einer Anlehnung an Russlan verbarg, ist wohl seither aus der Lektüre des "Słowo Polskie" klar geworden.

Es wäre verfehlt der künftigen Tätigkeit jenes geheimen Komitees eine übergrosse Bedeutung beizumessen. Da sich das Komitee an keine reale Macht anlehnt ist das ganze mehr eine Intrige als eine politische Aktion. Negativ darf aber die Sache auch nicht unterschätzt werden: unter der Flagge der Unabhängigkeit könnte wieder eine Verwirrung der geister in Polen gefördert werden, die sowohl der Tätigkeit der k.u.k. Behörden als auch der politischen Agitationen des Obersten Polnischen Nationalkomitees ernste Hindernisse bereiten könnte.

Kopia, maszynopis

Haus.- Hof und Staatsarchiv, Krieg, P.A.l., karton 900, folio363-366.

\section{Dokument nr 6}

1915 maj 28, Kraków. Tekst rozkazu dziennego, wydanego przez komendanta Legionów Polskich generała Karola Trzaska-Durskiego z zapowiedziq̨ możliwości zespolenia wszystkich formacji legionow ych. 
„Nowa Reforma" vom 25 [Mai] veröffentlicht einen Tagesbef ehl an die Polnische Legionen, welchen Feldmarschalleutnant ${ }^{16}$ Durski nach einer Ankunft in Pitrków erlassen hat. In dem Befehl wird ser Freude über die Tatsache, dass ein Teil der bisher in den Karpathen kämpfenden Legionenabteilungen den Boden des Königreichs Polen beschritten hat, Ausdruck gegeben. Dann wird die Hoffnung ausgedrückt, dass auch der Rest der leider noch auf einem anderen Territorium kämpfenden Abteilungen sich mit der heldenhaften Brigade Piłsudskis bald vereinigen wird. Dann heisst es in dem Befehl wörtlich:

„Euere traditionelle Tapferkeit gewährt die unerschütterliche Garantie, dass Ihr den würdigen Anfang der vaterländischen Armee bildet, welche mit Einwilligung des grossherzigen Monarchen auch weiterhin Freiheit unserem Vaterlande bringen wird und den Erbfeind Polens züchtigen wird".

Odpis, maszynopis.

I laus.- Hof und Staatsarchiv, Kriege, P.A.l., karton 900, folio 409.

\section{Dokument nr 7}

1915 czerwiec 3, Wiedeń.- Nemorial Naczelnego Komitetu Narodowego złożony w austro-węgierskim Ministerstwie Spraw Zagranicznych z propozycją rozbudowy Legionów Polskich do rozmiarów armii.

\section{Hohes K.u.K. Ministerium! !7}

Niemieckojęzyczna wersja dokumentu zawiera podpis: Präsident des Obersten Polnischen Nationalkomitees. [Polską wersję dokumentu zawiera publikacja wymieniona $w$ przypisach.

[Władysław Leopold] von Jaworski

Oryginal, maszynopis.

Haus.- Hof und Staatsarchiv, Krieg, P.A.l., karton 900, folio 413-416

${ }^{16}$ Wymieniony $w$ tekscie stopien wojskowy był odpowiednikiem generalskiego stopnia drugiej rangi, wymienianego w innych armiach jako generał porucznik, a Wojsku Polskim jako general dywizji. Ranga rzeczywistego marszałka armii austro-węgierskicj to Feldmarschall.

17 'Tytuł adresata niemieckojęzyčnej wersji memoriału. Polska wersja tego dokumentu w: Dokumnty Naczelnego Komitetu Narodowego 1914-1917, Kraków 1917, s. 143-146. 


\section{Dokument nr 8}

1915 czerwiec 12, Kraków.- Raport Leopolda Andriana dla austro-węgierskiego ministra spraw zagranicznych w sprawie pobytu emisariuszy NKN na obszarach opanowanych przez wojska austro-węgierskie w Królestwie Polskim.

An Seine Exzellenz den Herrn Minister des k.u.k. Hauses und des Äussern Stephan Baron Burián von Rajecz.

Im Anbuge beehre ich mich Euer Exzellenz ein mir vom EOK ${ }^{18}$ gesandtes Einsichtstück - eine Meldung des Kreikommandos in Dąbrowa über die Ausweisung von Emissären des Polnischen Nationalkomitees - sowie meine hierauf erfolgte Äusserung an das EOK zur hochgeneigten streng vertraulichen Kenntnisnahme zu übermitteln. Euer Exzellenz wollen den beiden beiliegenden Schriftstücken entnehmen, dass ich eineseits den Standpunkt vertreten habe, dass eine Entwikung unserer galizischen Emissäre auf die Bevölkerung Congresspolens, wie eine solche bei Entsendungen dieser Emissäre geplant war, nicht möglich ist, wenn diese ihre Reisen durch Land im Begleitung und unter Überwachung von Offizieren vornehmen müssen. Andrerseits glaubte ich den Antrag stellen zu sollen, dass der Ausdruck "Feindesland” aus den Proklamationen der Militärbehörden eliminiert werde.

Der k.u.k. Lagationsrat: L.Andrian

Orygina , maszynopis.

Haus.- Hof und Staatsar hiv, Krieg, P.A.I., karton 900, folio428

Załącznik do dokumentu nr 8.

K.u.k. Kreiskommando Dąbrowa 14 Mai 1915.

An das k.u.k. 1 Armee Etappenkommando

In Befolg des Befehles vom 10 dieses Monats op. Nr. 16968 melde ich folgendes.

Die im Bereiche vom 7 Mai 1915 Nr, 5212 erwähnten drei Herren des Polnischen Nationalkomitees kritisierten sof ort nach ihrer Vorstellung bei mir

\footnotetext{
${ }^{18}$ EOK - Elappen Oberkommando.
} 
den polnischen Text diverse Kundmachungen, darunter auch der vom 1 Arme Etappenkommando herabgelangten standrechtlichen Bestimmungen, welche sie deshalb beanständeten, weil im 2 Absatz derselben von Bewohnern des "feindlichen Landes" die Rede ist.

Am nächsten Tage machte sie mich erbötig, mir vom Nationalkomitee einen tadellosen Úbersetzer beizustellen, was ich mit dem Bemerken ablehnte, dass ich einen solchen bereits gefunden habe. Tatsächlich erklärte Dr Hupka die polnischen Übersetzungen in den Amtsblättern des Kreises Dąbrowa für vollkommen einwandf rei.

Hierauf bedeutete ich den Herrn, dass ich mit Rücksicht auf die in letzter Zeit ergangenen Befehle nicht in der Lage sei, sie in Dąbrowa zu belassen, bevor sie nicht über die erforderlichen Legitimationen verfügen und ihnen die entsprechenden Begleitpersonen von Seite des Etappen Obekommndo beigeben würden.

Daraufhin erklärten sie, dass ihnen ein solches Verlangen der Verwaltungsbehörden völlig unverständlich sei und dass sie darauf bestehen müssen ihre Mission ohne Überwachung und unabhängig von Offizieren durchzuführen, da erstere sonst zwecklos wäre.

Ich beharrte auf meinem Standpunkte und forderte sie auf, unbedingt am nächsten Morgen den Kreis Dąbrowa [Górnicza] und das okkupierte Gebiet zu verlassen; sie reisten, nachdem sie Aussichtslosigkeit weiterer Vorstellungen erkannt hatten, am nächsten Tage nach Wien.

Aus obiger Erklärung geht bereits zur Genüge hervor, dass die Tätigkeit dieser Herren sich unmöglich in den von der Militärverwaltung gewünschten Bahnen abspielen würde, da sie sonst eine Überwachungs seitens der Behörden nicht zu scheuen hätten.

Ich lege weiters einen kürzlich hier eingelangten Brief des hiesigen Pfarrers Augustynik vor, welcher bei den wiederholt erfolgten Aussprachen zwischen mir und ihm niemals auch nur im entferntesten eine Kritik an den verwaltungsbehördlichen Kundmachungen geübt hat; die in dem Schreiben kenntlich gemachte Stelle ist daher offenkundig der Agitation der mehrfach erwähnten Personen zu verdanken.

Dem Vorangeführten ist $\mathrm{zu}$ entnehmen, dass es höchst unzweckmässig wäre, Mitgliedern des Polnischen Nationalkomitees das Bereisen des Okkupationsgebietes $\mathrm{zu}$ gestatten, da hiebai lediglich einseitige nationale Propaganda die Triebeder ihrer Tätigkeit ist. 
Do tego pisma pułkownik Balcer dolaczył wypowiedź proboszcza Augustynika: "Ich dürfte Ew. Hochwohlgeboren noch bitten, Sie mögen in den Kundmachungen unseres Volk und Land als feindlich nicht erklären, weil wier Polen darauf nicht verdienen"

Załącznik nr 2. Kraków 10 Juni 1915

An das k.u.k. Etappenoberkommando

$\mathrm{Zu}$ den mir geneigtest zur Einsicht gesandten Berichtung des k.u.k. Kreiskommandos in Dąbrowa Nr. 5400 und des k.u.k. Militärgouvernements in Miechów Nr. 138 erlaube ich mir Folgendes zu bemerken. Wie den EOK aus meinen Berichte Nr.86 von 2 April leitendes Jahres bekannt, ist es mir nicht entgangen, dass die Delegierten des Polnischen Nationalkomitees stellenweise ohne Tendenz zeigen, sich als Behörde neben unseren Militäbehörden zu genieren, was keinesfalls geduldet werden kann. Andrerseits jedoch glaube ich bemerken zu sollen dass die bei der Entsendung verlässlicher galizischer Polen nach Kongresspolen von Anfang an von EOK und dem Ministerium des Äussern einvernehmlich bezwekt unauffällige Mitwirkung auf die Bevölkerung im antirussischen und austrophilen Sinne nicht möglich wäre, wenn die Emissäre unter der Aufsicht ihnen beigebenen Begleitpesonen das Land bereisen würden. Doch möchte mir also diesbezüglich ergebenst $\mathrm{zu}$ beantregen erlauben, dass etwa durch Opposition gegen die Behörden oder Unabhängigkeits propaganda sich bemerklich machenden Delegierten des Nationalkomitees der Aufenthalt im Okkupationsgebiet überhaupt untersagt, den übrigen gutösterreichischen Komitees Emissären aber Bewegungsf reiheit gestaltet werde, ohne welche eine Einflussnahme auf die Bevölkerung nicht gut möglich ist.

Was ferner den nicht nur von den Delegierten des Nationalkomitees, sondern von dem besonnenen und loyalen Pferrer Augustynik hervogehobenen Ausdruck "Feindesland" anbelangt, welcher sich übrigens nur in dem von der Bevölkerung gelesenen polnischen, nicht aber im deutschen authentischen Texte der Kundmachung findet, wo an seiner Stelle der Ausdruck "besetzte russische Gebietsteile" steht, so möchte ich mir ergebenst zu beantragen erlauben, dass die k.u.k. Behörden in Polen angewiesen werden, von Gebrauch desselben Abstand zu nehmen. Die vom EOK initirte und auch von k.u.k. Ministerium des Äussern durchaus geteilte Grundtendenz, Polen als von den k.u.k. Truppen befreites, in Zukunft den k.u.k. Staaten anzugliederndes, durch Gefühls -und 
Ineressengemeinschaft von Russland getrenntes und uns zugehöriges Land zu behandeln, lässt die Anwendung diesen besonders für die breiten Schichten der Bevölkerung missverständlichen Ausdruckes nicht ohne Schädigung der Sympathien Kongresspolens für uns zu. Da wir von der Bevölkerung Polens meines Erachtens mit Recht, eine über das Mass unumgänglicher auch im Feindesland $\mathrm{zu}$ beanspruchender Korrektheit hinausgehenden Grad von Loyalität und Freundschaft beanspruchen und auch grossenteils erhalten, von der unter einander zum Beispiel gerade eine Predigt des Pfarrers Augustynik am Frohnleichnamstag Zeugnis abgelegt haben soll, kann das erwähnte Gebiet wohl kaum in öffenntlichen Kundgebungen als Feindesland qualifiziert werden, mag auch diese Bezeichnung formalrechtlich scheinbar zutreffend sein. Wir befinden uns in diesem Territorium in annähernd ähnlicher Stellung der Bevölkrtung gegenüber wie die Franzosen in denen von ihnen akkupierten Teilen des Elsasses. Wengleich ich die überschwenglichen Freundschaftsbezeugungen der französischen Behörden gegenüber der Bevölkerung dieser okkupierten Gebiete keineswegs als Muster hingestellen möchte, so galaube ich doch dringendst befürworten $\mathrm{zu}$ sollen, dass die polnischen Teile des Russischen Reiches, zu denen wir in einer eigentümlichen zweiseitigen politischen Stellung stehen nicht mit einer Nomeclatur bezeichnet werden, welche gerade die zu uns hinstrebenden Bevölkerungselemente zu verletzen und zu entf remden geeignet ist, besonders in diesen Zeiten und in solchen Zusammenhange kann ein Wort viel Gutes und viel Bösen anstiften. Auch den beiliegenden Brief des Pfarrers Augustynik möchte ich als nichts anderes betrachten als eine in unbeholfener Sprache ausgedrückte Loyalitätskundgebung.

Was endlich die Unterschrift dieses Briefes anbetrifft, möchte ich auf die dem Namen des Pfarrers beigefügte Qualifikation "Generalvikar" uns auf meinen ergebensten Bericht $\mathrm{Nr} 229$ von 27 Mai laitendes Jahres letztes Alinea, hingeweisen, in welchem ich dem EOK auf Grund einer Mitteilung des Bischofs von Kielce die unberechtigte Verleihung des Generalvikarscharakters an Pfarrer Augustynik durch den den Bischif von Włocławek signalisiert habe. Ich möchte mir ergebenst $\mathrm{zu}$ beantragen erlauben, dass dem Pfarrer Augustynik - falls mitgeteilt werde, dass es dermalen umso weniger einem Generalvikar in der Diözese Kielce geben könne, als der von Seiner Heiligkeit dem Papste ernannte Diözesenbischof im freien Verkehr mit seiner Herde und auch mit der weltlichen Obrigkeit stehe und dass infolgedessen von den k.u.k. Behörden auch nicht als Generalvikar betrachtet werde. Des weiteren würde ich diesfalls, vorausgesetzt das Einvertändnis des EOK, das Ministerium des Äussern ersuchen, durch 
den Päpstlichen Nuntius Pfarrer Augustynik zur Einstellung seiner etweigen diesbezüglichen Tätigkeit zu veranlassen.

Der Vertreter des k.u.k. Ministeriums des Äussern beim EOK; [L.Andrian]

\section{Dokument nr 9}

1915, czerwiec 15, Wiedeń. - Pismo szefa Biura Prezydialnego Naczelnego Komitetu Narodowego (NKN) do austro-węgierskiego ministra spraw zagranicznych Stefana Buriana von Rajecz $z$ informacją, że NKN bierze odpowiedzialność za politycznq lojalność Adama Koca i Feliksa Turowicza.

Szef Biura Prezydialnego NKN

\section{Exzellenz !}

In Beantwortung der Auftragen vom 4. und 9 Juni nehme ich mir die Ehre Euer Exzellenz mitzutelen, dass das Oberste Polnische Nationalkomitee hiemit für die Herren Feliks Turowicz aus Warschau und Adam Koc aus Lemberg die Garantie der politischen Zuverlässigkeit übernimmt.

Indem ich mich beehre dies Euer Exzellenz zur Kenntnis zu bringen, ersuche ich Sie höflichst die Ausfolgung von Passierscheien an die genanten Herren durch die K.u.k. Gesandschaft in Kopenhagen gütigst veranlassen zu wollen, wobei bemerkt wird, dass die Angelegenheit des Herrn Adam Koc eine besonders dringende ist.

Genehmigen Eure Exzellenz den Ausdruck meiner verzüglichsten Hochachtung.

Ihr ganz ergebener W[ładysław] Michałowski ${ }^{19}$

Oryginal, maszynopis.

Haus.-Hof und Staatsarchiv, Krieg, 8 Polen, P.A. 1., karton 900, folio 457.

${ }^{19}$ Chodzi o Władysława Michałowskicgo, radcę Namiestnictwa we Lwowic, który od lutego 1915 r. był szefem Biura Prezydialnego NKN i ponadto pełnił funkcje łącznika między NKN a austro-węgierskim Ministrstwem Spraw Zgranicznych. 


\section{Załącznik}

Oberstes Polnisches Nationalkomitee (NKN)

$$
\text { Garantie - Erklärung }
$$

Das Oberste Polnische Nationalkomitee übernimmt die Garantie der politischen Zuverlässigkeit für Adam Koc aus Lemberg, derzeit in Kopenhagen, der um einen Reisepass nach Österreich ersucht.

Wien, am 15 Juni 1915

Podpisali: Preses NKN Leopold Jaworski

Szef Biura Presydialnego Władysław Michałowski.

Załącznik, odzyf rowany telegram.

\section{Dionis Graf Széchényi}

Kopenhagen, 16 Juni 1915

Mit Bezug auf meine Telegramme No 269 vom 2 dieses Monats und 271 vom 7 dieses Monats bitte ich Euer Exzellenz, mich wenn möglich umgehend telegraphisch zu ermächtigen, für die seit 14, beziehungsweise 9 Tagen hier wartenden Polen, von welchen einer aus Sibirien über Amerika gekommen ist, der andere (österreichischer Staatsbürger) dringende Mitteilungen an das polnische Nationalkomitee aus Russisch Polen zu überbringen hat, Reisebewilligung anzustellen.

Beide bitten, falls Zweifel bestünden, den österreichischen Grenzbehörden überstellt $\mathrm{zu}$ werden. Beider Identität wurde hieramts von dem mit Koc aus Warschau eingetroffenen und mit Pass der k.u.k. Gesandschaft in Stokholm von hier weitergereisten Aleksander Sulkiewicz, der dem polnischen Nationalkomuitee bekannt sein muss, bestätigt.

Odszyf rowany telegram, maszynopis.

I laus.-Hof und Staatsarchiv, Krieg, P.A.I., karton 900, folio 448. 


\section{Dokument nr 10}

1915 czerwiec 16, Wiedeñ.- Pismo Szefa Biura Prezydialnego NKN Wtadyslawa Michałowskiego do austro-węgierskiego ministra spraw zagranicznych Stefana Buriana z zapewnieniem, ze zostanq mu dostarczone szczególowe informacje o Wladyslawie Studnickim.

\section{Exzellenz!}

In umgehender Beantwortung des heutigen Schreibens Euer Exzellenz, beehrt sich das gefertigte Präsidium des Obersten Polnischen Nationalkomitees ergebenst mitzuteilen, dass es nach gepflegenen Erhebungen über die Person Herrn Władysław Studnicki Euer Exzellenz ausführlich und vertraulich in einigen Tagen berichten wird.

Mit dem Ausdrucke der verzüglichsten Hochachtung.

Władysław Michałowski.

Oryginał, maszynopis i załaczone pismo Władysława Studnickiego w maszynopisie.

Załącznik, 8 czerwca 1915, Pensjonat Marmier Av. Ruchennet.

\section{Euer Exzellenz !}

Schon seit Februar beabsichtigte ich es mich wieder nach Köngresspolen zu begeben und zwar nach diejenigen Prowinzen desselben, welche von deutsche und österreichische Truppen besetzt worden sind. Ich stamme aus Russisch - Polen und als politische Schriftsteller schon lange einen Namen erworben habe. Im Jahre 1907 habe ich in Warschau die Zweiwochen schrift „Volk un Staat" herausgegeben, wo ich alle Versuche eines polnisch-russischen Ausgleiches bekämpfte. Nach den die Herausgabe dieser Zeitschrift seitens der russischen Regierung verboten wurde, begab ich mich nach Peterburg, wo ich eine neue Zeitschrift unter Namen „Votum Separatum" ins Leben rief um den Neu-Slawismus zu bekämpfen. Wegen der Stellung meiner Zeitschrift zur zukunftigen Kriege wurde ich zum Emigration gezwungen. Ich kam in Jahre 1908 nach Galizien, während der bosnischen Krisis. Für mich, der die russischen Verhältnisse sehr gut kannte, war es wohl ersichtlich, dass der Krieg mit Russland unvermeindlich ist, dass die Beschleunigung des Krieges in der Interessen russischen Antagonisten liegen, weil jedes Jahr das Verhältniss der Kräfte zu Russlands gunsten verendert wird. 
Um diese Ideen zum Bewustsein der massgeben den Kreise der ÖsterreichUngarische Monarchie zu bringen, habe ich „Die Denkschrift für die ungarischen Staatsmännern in 1912, und "Die österreichisch-ungarische Frage” 1913 herausgeben.

Um die antirussische Stellung des polnischen Nation zu begründen, habe ich das Buch "Das polnische Problem” geschrieben, Hauptwerk der polnisch irredentischen Bewegung. Meine Hauptaufgabe war die psychische und physische Vorbereitung der polnichen Nation zum Krieg gegen Russland. Ich war ein eif riger Verteidiger des Bundes mit Deutschland.

Ferner arbeitete ich eif rig an der weiteren Entwicklung der polnischen militärischen Organisation, welche noch im Jahre 1912 der gegenwärtige Vorsitzende des Obersten Nationalen Komittes, Abgesandte Jaworski bekampft, und eine Resolution in den Polenklub gegen polnischen militärischen Verbindungen durchgeführt hat.

Während des Krieges weilte ich in Częstochowa, wo es mich gelang Hunderte von Freiwiligen unseren Legionen anzuwerben; in Częstochowa atand ich zu dem deutschen Militärbehörden mit guten Beziehungen.

Ich führte auch einige Zeit eine antirussische Propaganda in Bukarest. Der Vorsitzende des Obersten Nationalkomittes, Abgeordnete Jaworski versprach mir mehrmals, für mich von Euer Exzellenz den Erlaubnisschein zum Zutritt den Verbundeten Truppen besetzten Theilen Polens, zu erbitten. Aber ich meine, dass ich wegen meiner Tätigkeit berechtig bin einen diesbezüglichen Gesucht direkt zu Euren Exzellenz einzuschreiben.

\section{Achungsvoll Władysław Studnicki}

Haus. -Hof un Staatsarchiv, Krieg/8, Polen, karton 900 folio 452 i 462. 


\section{Dokument nr 11}

1915 czerwiec 18, Wiedeń. - Elaborat odzwierciedlajacy krytyczne stanowisko krakowskiego odłamu Stronnictwa Prawicy Narodowej w odniesieniu do polityki Austro-Węgier wobec Legionów Polskich i sprawy polskiej, podpisany przez galicyjskiego posła Ignacego Rosnera i przekazany austro-węgierskiemu ministrowi spraw zagranicznych Stefanowi Burianowi.

\section{Eure Exzellenz !}

Im Verlaufe der letzten Wochen wurde die Tätigkeit des Obersten Polnischen Nationalkomittees in Königreich Polen durch eine Reihe von Massnahmen des k.u.k. Armeeoberkommandos (AOK) wesentlich eingeschränkt. Verbürgten Gerüchten zufolge sollen weitere Massregeln in derselben Richtung nächstens getroffen werden. Das Gesamtresultat dieser Anordnungen wird einerseits in einer starken Lähmung der politischen Agitation des Obersten Polnischen Nationalkomitees in polen, anderseits in einschneidenden Änderungen in der Art.der Anwerbung für die k.u.k. Polnischen Legionen zum Ausdrucke gelangen.

Wie uns authentisch nittgeteilt wurde, sind die Besprochenen Massnahmen, ausschliesslich auf operative Gründe zurückzuführen, entziehen sich daher an und für sich jeder Laienkrietik. Eben darum aber werden in allen Kreisen der polnischen Bevökerung sowohl in Königreich Polen, als in Galizien politische Theorame konstruiert, die den "neuen Kurs" erklären sollen, die aber ihrerseits wieder auf die k.u.k. Verwaltung und zwar in den Zeitpunkte zurückwirken könnten, in dem, bei einem glücklichen Fortgange der militärischen Aktion die operativen Gründe allein von selbst entf allen würden.

Da nun die erwähnten, dem AOK beziehungsweise der k.u.k. Verwaltung fälschen zugemuteten politischen Begründungen des neuen Kurses ausnahmlos Irrungen darstellen, die für den Fortgang der politischen Eroberung des Königreich Polen verhängnisvoll werden könnten, so erachten wir es als unsere Pflicht, die Aufmerksamkeit Eurer Exzellenz, dem diese politische Aufgabe in erster Reihe zugefallen ist, auf den ganzen Komplex der hier in Betracht kommenden Fragen zu lenken.

Es wird von verschiedenen Seiten hervorgehoben, dass es der hauptsächliche Zweck Österreich-Ungarns sie, die gemässigten Elemente, die besitzenden Klassen in Polen, die sich bisher politisch reserviert verhalten, zu gewinnen. Die These ist ganz richtig gehalten, aber, was einer gewissen Pikanterie nicht entbehrt, speziell von den radikalen Elementen des Komitees, in erster Linie den sozialdemokratischen Delegierten in Polen sehr lebhaft verfochten. Die These ist 
schon deshalb richig, weil sich die radikalen Elemente im Lande von Vornherein gegen Russland gewendet hatten, sie also, solange diese negative Orientierung genügt, das heisst bis zur völligen Eroberung des landes, nicht gewonnen zu werden brauchen.

Die Frage ist nur, wie jene bisher "neutralen", teilweise der Monarchie gegenüber ganz ablehnenden gemässigten Elemente zu gewinnen seien. Und hier setzen gleich allerlei Trugsschlüsse ein. Es wird zunächst die Bhauptung aufgestellt, dass, eben da es radikale Elemente sind, die derzeit hauptsächlich die antirussische Agitation in Polen besorgen, durch eine Stellungsnahme gegen diese Agitation gewissermassen automatisch das Vertrauen ihrer politischer Gegner, der gemässigten zu gewinnen wäre. Dieser Schluss leidet an dem allgemeinen Fehler aller rein logischer Operationen in der Politik: er ermangelt jeglicher Psychologie.

Das einzige, was die vielfach gewitzigten besitzenden Klassen in Polen bestimmten kann, in das Lager Österreich-Ungarns einzuschwenken, ist die Úberzeugung, dass Österreich-Ungarn befähigt und gewillt sein, das Königreich zu erobern und zu behalten. Das Erstere hängt von dem weiteren Verlaufe des Krieges ab und wird hoffentlich täglich an Gewicht zunehmen. Bezüglich des Willen der Monarchie das Land zu anektieren herrscht aber bisher die grösste Uklarheit. Sie wäre durch ein kaiserliches Manifest zu Beginn des Krieges zu beseitigen gewesen, sie könnte heute noch durch solch einen feierlichen Akt gänzlich beseitigt werden. Abgesehen davon kommen aber nur solche Tatsachen in Betracht, die in der Juristensprache konkludente Handlungen genannt werden. Es muss zugegeben werden, dass solche konkludente Handlungen vielf ach schon durch die provisorische administrative Teilung des Landes beziehungsweise durch die Notwendigkeit gegenseitiger Rücksichtnahme unter den verbündeten Mächten erschwert werden. Allein Eines is sicher und ist gleichzeitig politisch das Konkludenteste von allem, dass ist eben die rückhaltlose Förderung jener politischen Arbeit, die in erster Reihe auf eine Losreissung Polen von Russland, in den zweiten aber naturnotwendig - wir kommen noch auf diesen Punkt zurück auf die Angliederung des Landes an die Monarchie hinzielt. Umgekehrt muss jede auf die Erschwerung dieser Arbeit gerichtete Massnahme der k.u.k. Organe als ein Zeichen gedeutet werden - und sie werden auch in dem Sinne allgemein gedeutet - dass die Monarchie eine Angliederung Polens nicht ernstlich anstrebe. Durch das Erwecken solcher Eindrücke und Stimmungen werden eben die besitzenden Klassen, die dann natülich wieder mit der Rückkehr der Russen oder im "besten” falle mit der allen Polen verhassten Teilung des Landes unter die Zentralmächte rechnen müssen, vollends abgestossen. 
Gegen diese ganze These sprechen übrigens jetzt schon sehr bezeichnende Tatsachen, un zwar die langsam aber sicher heranreif enden Früchte der bisherigen Arbeit des Obersten Polnischen Nationalkomitees, welches, wiejedes Kind in Polen weiss, die Idee der Angliederung des Landes an Österreich-Ungarn verkörpert. Gerade in den letzten Zeit hat sich zum Beispiel eine Organisation von Parteien, die sich bisher dieser Idee gegenüber ablehnend verhielten: der Nationaldemokaten, der Realisten und der Fortschrittler im deutschen Okkupationsgebiete an das Obesrste Polnische Nationalkomitee mit der Bitte um Einleitung ener politischen Aussprache zum Zwecke einer gegenseitigen Annäherung gewendet. Falls wir an diesen im Interesse der Monarchie zu führenden Verhandlungen nicht von den k.u.k. Organen gehindert werden, was ernstlich zu beführten ist, sollten dieselben bereits in den nächsten Tagen in Angriff genommen werden.

Die Erfahrung zeigt sohin, dass eine Orientierung der Politik in Polen gegen die so genannten Radikalen (auch das ist in diesem Lande ein sehr relativer Begriff, wie derjenige konservativ !) zu einer Gewinnung der "Gemässigten” durchaus nicht notwendig ist. Man kann dadurch höchstens nur die Radikalen selbst verlieren, gleichzeitig aber den Gemässigten alle Annäherungsverlleitäten austreiben.

Wir möchten aber auch auf den Grundfehler dieses ganzen Räsonaments hinweisen, der in der Anwendung der Volkspsychologie in Friedenszeiten auf die Epoche des Kampfes, die ihre eigene Kriegspsychologie besitzt, wurzelt. Selbstverständlich kann die Politik und die Verwaltung in normalen Zeiten sich nicht auf radikale Elemente stützen, ebensowenig wie es sich im Frieden mit Hilfe der Bajonette allein regieren lässt. Aber sowie das Bajonett im Kriege in den Vordergrund der politischen Argumente rückt, ebenso die politische Bedeutung der Massen. Für eine politische Eroberung des Landes sind dieselben gemässigten Elemente, die im Frieden die sicherste Stütze jeder Regierung bilden, ein vollständig ungeeignetes Instrument. In Zeiten, in denen das ganze öffentliche Leben, bis in die innersten Tiefen des Volkes aufgewühlt und in Bewegung gesetzt ist, werden die Massen zum eigentlichen Motor dieses Lebens. Sie reissen alles mit elemntarer Kraft mit sich fort. War beim Einzug in Warschau die Strasse für sich hat, hat auch die Gemässigten - aber nicht umgkehrt, oder vielmehr gerade umgekehrt: wer sich vor dem Einzuge in Warschau nur die (naturgemäss stillen) Sympathien der höheren Klassen gesichert hat, wird sie Strasse un in weiterer Folge auch jene Gemässigten gegen sich haben.

In diesem Zusammenhange muss auch ein wichtiger Umstand erwähnt werden. Eben so, wie es da Oberste Polnische Nationalkomitee war, dass bisher ganz allein und nach aussenhin auf eigene Faust die Losung: Polen mit 
Österreich-Ungarn (!) ausgegeben hat, so sind die im Verbande des k.u.k. Heeres kämpfenden, von dem Komitee ins Leben geruf enen Legionen bisher die einzige Gewähr, dass die Habsburger Monarchie diese Losung billigt. In dieser Beziehung ist die Wirkung der Existenz der Legionen allein, namentlich in Warschau eine viel stärkere, als gemeiniglich angenommen wird. Mangels jedweder Aufrollung der polnischen Frage durch Österreich-Ungarn ist es nur die Tätigkeit des Obersten Polnische Nationalkomitee die Tatsache der Legionenbildung, die die zahllosen Sezessionen und Spaltungen bei den Nationaldemokraten und Realisten hervorgerufen und zur allmähligen vollkommen Auflösung des so genannten rusophilen Lagers in Warschau geführt hat.. Es ist also auch ganz natürlich, dass die Behandlung der Legionenfrage in Ösrerreich-Ungarn, die Erfüllung oder Nichterfüllungder mit der Tätigkeit der Legionen verbundenen Wünsche, wie zum Beispiel ihre Vereinigung mit Königreich Polen, geradezu zum Hauptkriterium der Beurteolung der politischen Absichten der Monarchie geworden ist und dass die Art und Weise, wie die erwähnten Probleme gelöst werden, den soeben besprochenen politischen Zersetzungsprozess des so genannten russophilen Lagers in Polen ausserordentlich zu beschleunigenen, aber auch stark zu nehmen, ja (!) ganz zum Stillstand zu bringen vermag. In dieser Beziehung müssen Tatsachen, wie zum Beispiel die bei der zweiten Brigade der Polnischen Legionen planmässig durchgeführte Entpolonisierung des Kommandos und des Stabes, die Zuteilung von Offizieren nicht ein Wort polnisch verstehen und trotzdem fasst die nervorragendste Stellung in der Brigade einnehmen, jeden polnischöstrereichischen Patrioten mit schwerster Sorge erfüllen.

Nach disem der Legionenfrage gewidmeten Exkurse wenden wir uns wieder den allgemeinen Betrachungen zu.

Der angebliche neue Kurs wird nicht mit der Notwendikeit die Gemässigten zu gewinnen, sondern auch mit dem Hinweise auf positive Gefahren erklärt, die aus der bisherigen antirussischen Agitation in Polen entspringen. Eine Kategorie der dies bezüglichen Argumente kann kurz erledigt werden. Und sind dies die Bedenken, dass sich das Oberste Polnische Nationalkomitee als „Nationalregierung" etablieren möchte und könnte. Dieses Schlagwort wird leider auch von solchen Elementen unter den Polen verbreitet, die sonst das Ziell des Oberstes Polnisches Nationalkomitees: die Angliederung Polens an ÖsterreichUngarn warm und aufrichtig gutheissen. Das kommt aber daher, weil es meistens Leute sind, die in ihrer Jugend selbst "Nationalregierung" gespielt und die Folgen dieses gefährlichen Spieles schaudernd erlebt haben. Dass aber das Wesen der verflossenen polnischen Nationalregierungen darin bestand, sich die Exekutive anzumassen, Steuervorschreibungen vorzunehmen und, da sie auch dadurch zu 
keiner wirklichen Regierung wurden, schliesslich zum Terrorismus zu greifen - das entgeht den reuevollen konservativen Sündern des Jahres 1863 volkommen. Sonst ist aber das Wort "Nationalregierung” nichts, als eben ein leeres Wort und deshalb wurde der Begriff selbst von der jetzigen realistisch gewordenen Generation, vom Oberstes Polnisches Nationalkomitees in seiner Gänze und speziell auch von dessen radikalen Elementen klar und wiederholt abgelehnt.

Wichtiger als dieses Spiel mit Worten ist die Befürchtung, dass die Agitation des Oberstes Polnisches Nationalkomitees in Polen, wiewohl an der österreichischen Loyalität des Komitees selbst nicht gezweif elt werden kann, dort in radikalen Kreisen des Volkes eine Bewegung der Geister auslöst, die nicht auf einen Anschluss an Österreich-Ungarn sondern auf die volständige Unabhängigkeit Polens zielt. Dieser nicht immer ganz echten Befürchtung liegt eine starke Begriffsverwirrung zu Grunde.

Vor allem eine kleine Aufklärung. Es ist durchaus falsch anzunehmen, dass unter den antirussischen Parteien in Polen die Radikalen eher auf eine vollkommenen Unabhängigkeit hinarbeiten, die Gemässigten mehr für einen Anschluss an Österreich-Ungarn seien. Das gerade Gegenteil ist richtig. In Warschau zum Beispiel, wo ein Delegierter des Oberstes Polnisches Nationalkomitees vom Februar bis Mitte Mai leitendes Jahres weilte und eif rige Arbeit leistete, hat die eine Einverleibung in Österreich-Ungarn propagierte Tätigkeit des Oberstes Polnisches Nationalkomitees eben bei den Radikalen, wenn auch unter verschiedenen Vorbehalten, Sympathie und Billigung gefunden, während zum Beispiel die neueste adelig-konservative Sezession aus der Nationaldemokratischen Partei unter Führung des Herrn Antoni von Marylski, wiewohl stark antirussisch, sich vorläufig nur für ein ganz selbstständiges Polen erwärmen zu können erklärte. In der Praxis darf auf diesen Unterschied, falls die ganze Arbeit nicht aus operativen Gründen gestört und vernichtet wird, kein besonderes Gewicht gelegt werden. Für sehr zahlreiche Elemente in Polen, die am Anfange des Krieges mit den Russen gingen, ist das Betonen der vollkommenen Unabhängigkeit und Freiheit "nach drei Fronten hin" nichts anderes, als ein Übergangsstadium, nach dem sie ganz in das Österrechische Lager einschwenken werden. Es sind dies Rückzusgef echte und wäre ein schwer politisch-strategischer Fehler sie allzuernst zu nehmen.

Was aber die Selbstständigkeitslosung an und für sich anbelangt, so hat auch das in Galizien gebildete Oberste Polnische Nationalkomitee nie ein Hehl daraus gemacht, dass es den Aufbau eines staatlichen polnischen Organismus in Rahmen der Österreich-Ungarischen Monarchie anstrebe, dass es also eine mit der Einheit der Monarchie vereinbarliche sttatliche Selbstständlichkeit Polens 
als Programm aufstelle. Wenn also zwischen der vom Komitee gewissermassen offiziell proklamierten polnischen "Staatlichkeit" und dem in der Agitation seiner Organe in Polen vielleicht angewendeten Termin "Selbstständigkeit" oder „Unabhängigkeit” Unterschiede gemacht werden, so ist es gewiss in den meisten Fällen eine Haarspalterei.

Von der Bevölkerung des Königreich Polen selbst kann gewiss nicht gefordert werden, dass sie den Anschluss an Österreich-Ungarn als Postulat aufstelle, solange von Österreich-Ungarn die Frage der Annexion nicht einmal angedeutungsweise aufgerollt wurde. Bei einer solchen politischen Sachlage, muss man sich leider vorläufig garauf beschränken, alle für die Loslösung von Russland gestimmten und umzustimmenden Elemente zu sammeln und sie auf der ganz allgemein formulierten Grundlage einer staatlichen Selbstständigkeit zu organisieren. Es ist aber das höste politische Interesse Österreich-Ungarn, dass diese Arbeit von einem Organe geleitet werde, dessen eigentlichste Aufgabe ja darin besteht, die vielfach unklaren Unabhängigkeitsströmungen in Polen in der Richtung eines Anschlusse an die Monarchie so zu sagen zu kanalisieren. Bei dieser, angesichts des beharrlichen Schweigens der Monarchie in der polnischen Frage sehr schwirigen und heiklen Arbeit mag es manchmal Entgleisungen oder Taktlosigkeiten geben, aber dadurch wird diese Arbeit selbst von ihrer grossen und festen Linie so lange nicht abgedrängt, als man dem Obersten Polnischen Nationalkomitee nicht die Leitung der Agitation unmöglich macht. Dann allerdings würde sich diese ganze Tätigkeit in tausend Richtungen zersplitten, deren Resultante etwas ganz unberechenbares wäre. Dan erst könnte die Bewegung der Geister, die kein "apolitisches" Verwaltungsprogramm der Welt zu bannen im Stande ist, für die Monarchie wirklich gefährlich werden.

Und da gelangen wir eben zu der piece de resistance des angeblichen neuen Kurses. $\mathrm{Da}$, wie wir schon gehört haben, die politische Agitation für die polnische Unabhängigkeit "bedenklich" ist (wo Begriffe fehlen, stellen in Österreich zur rechten Zeit sich die Bedenken ein) so sei es das klügste, aus der Behandlung des Königreiches Polen jede Politik auszumerzen, das Land einfach zu verwalten, nichts mehr!

Es steckt in diesem Postulate eine geradezu erschreckende Weltfremdheit. Ein ganzen Volk mit grosser historischer Überlieferung fühlt, dass es sich um seine nationale Zukunft handelt - die Leiden des Krieges und die Gedanken an diese Zukunft stürzen es täglich aus dem einem Extreme der Verzweiflung in das andere wildester Hoffnungen - man kann sagen es existiert nur mehr politisch, wenn es sich auch nach Aussen verschlossene zeigt - und dieses Volk will man apolitisch behandeln! Und warum ? Ein solches „Programm” wäre noch von 
Seiten Deutschlands, wie einige misslungenen Versuche aus dem Anfangsstadium des Krieges zeigen, ausserstande ist eine politische Idee nach Polen zu exportieren. Aber Österreich-Ungarn, die Monarchie, zu deren Wesen die Freiheit der sie bewohnenden Völker gehört! Sie sollte nicht in der Lage sein, Politik in Polen $\mathrm{zu}$ treiben oder vorläufig für sich treiben zu lassen; sie sollte gezwungen sein ein politisches Abstinenzlerprogramm aufzustellen und dem Phantom eines während des Weltkrieges plötzlich apolitisch gewordenen Polens nachzujagen!

Denn die Herstellung eines politisch luftleeren Raumes in Polen ist ganz und gar unmöglich. Wenn dort die Arbeit in der für die Monarchie günstigen Richtung lahmgelegt wird, so wird mit der Notwendigkeit eines Naturgesetzes sofort die Arbeit in der engegengesetzten Richtung eingesetzen, eine geheime unteirdische Arbeit im russischen Sinne, die von keiner k.u.k. Behörde kontroliert und überwacht werden kann. Diese Arbeit hat ja keinen Augenblick lang geruht und sie mus Schritt für Schritt zurückgedrängt werden. Durch apolitische Wahnideen wird man ihrer nicht Herr werden.

Selbstverständlich muss die k.u.k. Verwaltung gerecht für alle sein, ohne Unterschied der politischen Partei im Lande, aber apolitisch kann während des Krieges nicht einmal die Verwaltung sein, auch sie in den Köpfen der Bevölkerung atatt sie zu klären und zu vertiefen.

Es ist nur fast eine Nebenwirkung dieser idyllischen Auffassung der Dinge im Kriege, dass auch die These aufgestellt wurde das Oberste Polnische Nationalkomitee, das ja der politischen Idee der Eroberung Polens für ÖsterreichUngarn seinen Ursprung verdankt das die polnischen Legionen als militärisches Werkzueg dieser Idee geschaffen hat, solle sich der Sorge für dieses Werkzeug widmen, seine politische Idee aber hübsche unter den Scheffel stecken, mit anderen Worten auch „apolitisch" werden ! Eine ganze Welt stürzt ein, eine neue soll entstehen - wir aber hören von politischen Kompetenzstreitigkeiten, von Zweifeln, ob. es nicht doch vielleicht die so genannte "politische Kommission" des Polenklubs sei (das einzige während dieses Krieges wirklich apolitische Geschöpf, das überhaupt nicht funktioniert), die für die politische Orientierung des polnischen Volkes (in Königreich Polen!) zu sorgen hätte !

Durch die Tatsache der Existenz der polnischen Legionen allein ist das Oberste Polnische Nationalkomitee ein politisches Gebilde durch und durch. Wenn seine Politik dem vorläufig pro foro laterno gehegten politische Zwecke des Krieges nicht entspricht, hört es von selbst auf zu existieren. Wenn seinen Vertreter und Organen in Polen sich etwa politische Fehler zu Schulden kommen lassen, möge es offen gesagt werden und es wird das Komitee Mittel und Wege finden, dass sich Solches nicht wiederhole. Wenn einzelne polnische Parteien, 
die villeicht die politische Überfuhr versäumt haben, abseits vom Komitee bleiben, welches vom Beginne des Krieges an, unbeirrt von allem Wandel des Kriegsglückes, in den Traurigsten Augenblicken der verflossenen Monate fest und treu zu seunem österreichichen Programme stand, wenn jene Parteien, nach der bekannten Regel, die beste Parade sie der Hieb, noch den Mut finden gegen das Komitee als eine "sozialistische”, „revolutionäre" Nationalregierung mit Anklagen aufzutreten - so sollte allem diesen "schwakenden Gestalten" bedeutet werden, dass es ihre polnische und ihre österreichische Pflicht sei, das Obersten Polnischen Nationalkomitee als Träger der polnisch-österreichischen Idee zu stärken und nicht durch Wühlereien zu schwächen! Aber aus jeden unbequemen oder unerfreundlichen Tatsache den Schluss ziehen, dass es am besten wäre, das Obersten Polnischen Nationalkomitee, dessen Tätigkeit, das Königreich Polen, ja das polnische Volk überhaupt politisch zusterilisieren, heist, Österreich-Ungarn den polnischen Trumpf für das schwere Spiel des Friedensschlusses aus der Hand zu reissen!

Gestatten Eure Exzellenz, dass ich im eigenen sowie im Namen sämtlicher Mitglieder der Krakauer konservativen Partei im Obersten Polnischen Nationalkomitee mit Wunsche schliesse, es möge Euer Exzellenz, dank den glücklichen Fortschritten der glorreichen österreichisch-ungarischen Waffen baldigst gegönt sein, der derzeit durch operativen Rücksichten geschaffenen „politischen" Episode in Polen ein Ende zu machen!

Genehmigen Eure Exzellenz den Ausdruck meiner ausgezeichneten Hochachtung.

Euer Exzellenz ergebener: Abgesandte I. Rosner

Oryginał, maszynopis.

Haus -. Hof und Staatsarchiv, Krieg, P.A. I., karon 900, folio 558 - 563 


\section{Dokument nr 12}

1915 lipiec 7, Wiedeñ.- List hrabiego Stefana Ugrona, austro-węgierskiego przedstawiciela $w$ Warszawie okupowanej przez wojska niemieckie, do przedstawiciela austro-węgierskiego Ministerstwa Spraw Zagranicznych przy austro-węgierskiej Naczelnej Komendzie Armii radcy Fryderyka von Wiesnera $z$ ważkimi wynurzeniami i ocena postawy Polaków wobec spraw zwiq̨zanych z niepodleglościq Polski i ze szczególnym uwzględnieniem działalności NKN.

Vielen Dank für Ihr sehr interessantes Schreiben vom 28 Juni, das ich erst heute zu beantworten in der Lage bin.

Ich möchte die Ihnen aufgeworfenen Fragen der Reihe nach kurz durchgehen.

Ihre Bemerkung, dass Sie in der polnischen Frage ganz ausgeschaltet sind, entspricht keineswegs meinen Standpunkte.

Ich habe, seidem ich die Leitung des Referates übernomen habe, alle jene Eingaben, Memoranden et cetera, die für Sie von Interesse sein könnten, nach Tatsachen übersendet und werde es auch künftighin tun.

Ich kenne allerdings nicht die Details der Vorgeschichte der Ernennung Andrians, aber ich kann Sie versichern, dass sowohl Ihre persönlichen, an mich gerichteten Mitteilungen wie auch die Berichte des Grafen Thurn im Gegenstande mir stets sehr willkommen sein würden. Es kann uns nur höchst angenehm sein, wenn wir von verschidenen Seiten informiert werden. Ich bin gewiss, dass dies nicht nur mein eigener privater Standpunkt ist, sondern fass er auch von allen leitenden Stellen des Ministeriums geteilt wird.

Was nun den informativen Teil Ihres Schreibens anbelangt, so konstatiere ich mit Vergnügen, dass ich in vielen (allerdings nich in allen) Beziehungen mich Ihren Ausführungen anschlissen kann

Die Tätigkeit des Oberstes Polnisches Nationalkomitees gibt auch mir zu mancherlei Bedenken Anlass. Eine nicht offen eingestandenen Tendenzen erfülen mich, trotz des allzu aufdringlich betonen österreichischen Patriotismus, mit Misstrauen. Auch diesem Grunde ging vom ersten Augenblicke an mein Bestreben dahin, dem Polnischen National Komitee bei der von Seiner Majestät gebilligten Legionsbildund freie Hand zu lassen, bei seinen politischen Treibereien aber genau auf die Finger zu schauen. Wir dürfen nicht gestatten, dass es zu einer Art. Nebenregierung werde, das später die Quelle grosser Unannehmlichkeiten für uns werden könnte. Die auch in Ihren Briefe erwähnte radikal-sozialistische Richtung flösst auch mir für die Zukunft gar keine Vertrauen ein. 
Aber anderseits muss zugeben werden, dass in diesem Kriege das Polnische National Komitee für uns tätig war und uns auch politisch viel mehr genützt hat, als unsere vornehmen konservative Freunde, die ich persönlich recht gerne habe und denen ich herzlich wohlgesinnt bin, die aber aus lauter Vorsicht und Furcht, sich zu kompromittieren, sich absolut passiv verhalten und nichts für uns getan haben.

Ich will mit keinen Wort sagen, dass die Mitglieder des Polsnische Nationalkomitees österreichischer fühlen wie die Altkonservativen Galiziens; ich weiss wohl, dass auch bei ihnen die treibende Kraft, für uns zu handeln, nicht der österreichische Patriotismus ist; aber das Motiv ist momentan Nebensache und die Tatsache kann nicht geleugnet werden, dass sie sich uns dienstbar erwisen haben und für uns tätig waren.

Die Stimmung im Königreich Polen war für uns nach Kriegsausbruch nicht besonders günstig. Die hochtönenden, wenn auch leeren Versprechungen Russlands haben ihre Wirkung nicht verfehlt gehabt. Ich, der ich aus meiner früheren langen Tätigkeit in Warschau etwas ganz anderes erwartet habe, war sehr enttäuscht. Ich hätte nie gedacht, dass in 7 - 8 Jahren eine solche Umwandlung in der Volkspsyche möglich sei. Ich hätte nie gedacht, dass auch in früher streng national fühlenden Kreisen eine solche Verleumgnung alter Traditionen möglich wäre.

Wenig Jahre haben genügt, aus den wütendsten Russenhassern gefügige Werkzeuge der Petersburger Regierung zu machen.

Die uns in letzter Zeit zukommenden Nachrichten aus Königreich lauten allerdings viel günstiger. Die russischen Versprechungen werden nunmehr viel kühler eingeschätzt und eine entschieden freundlichere Strömung der Monarchie gegenüber fängt an, sich Bahn zu brechen. An diesem erfreulichen Erfolg gebührt das grosse Verdienst entschieden dem Polnischen Nationalkomitee.

Sie selbst anerkennen dies in Ihrem Schreiben, wo Sie sagen, dass Polnische Nationalkomitee sich im Besitze einer Vollmacht aller politischen Parteien Warschaus - mit Ausnahme Dmowskis -befindet. Ein gläzenderes Zeugnis haben Sie dem Polnischen Nationalkomitee gar nicht austellen können.

Sie werden sagen, dass das Polnische Nationalkomitee dabei egoistische Ziele verfolgt, die später uns gefährlich werden können. Jawohl, das gebe ich zu; aber einstweilen nützt uns das Polnische Nationalkomitee und hilft uns, den Feind niederzulegen. Es wird die Aufgabe der österreichischen Staatsmänner sein, zu verhüten, dass diese uns nicht unbekannten Ziele in der Folge die Einheit der Monarchie nicht beeinträchtigen.

Ich kenne die Polen recht gut und ich habe sie wirklich gern; aber ich kann doch nicht leugnen, dass jeder Pole ob konservativ oder liberal, ob radikal oder 
sozialistisch, sein Ideal nur im unabhängigen freien Polen sucht und findet. Darüber sollen wir uns keine Illusionen machen; und ich gehe sogar weiter und erkläre, dass ich dafür bis zu einem gewissen Grade Verständnis habe.

Es ist die Aufgabe einer jeden ernsten und zielbewussten österreichischen Regierung, nicht gestatten, dass die Bäume in den Himmel wachsen und zu wachen, dass die polnischen Aspirationen nicht zum Schaden der Monarchie gereichen.

Bezüglich der Unabkängigkeit Polens denken unsere Freunde aus dem Jockey-Klub gerde so wie die Mitglieder des Polnisches Nationalkomitees, nur in der Wahl ihrer Mittel sind sie wählerischer und vorsichtiger. Sie wollen sich vor allem nicht kompromitieren und befolgen die Politik; „Wasch mir den Pelz, aber mach mir ihn nicht nass".

Diese Politik ist in kritischen Momenten, wie die jetzigen, nicht die rechtige, sie erzeugt Misstrauen und Entf remdung, was ich leider auch diesmal, und zwar auf weiter Basis konstatieren kann.

Die Konservativen, deren Tendenzen uns homogener und viel sympathischer sein müssen, haben durch ihre absolute Passivität vielfach eine dehr strenge Beurteilung ausgelöst, während das Polnische Nationalkomitee durch sein aktives, zielbewusstes Auftreten-wenn auch die Motive nicht verkannt werden- sich auf unsere Anerkennung Anspruch erworben hat.

Ich brauche es wohl kaum zu sagen, dass ich dies mit lebhaften Bedauern kontatiere.

Ebenso konstatiere ich mit Bedauern, dass das Verhalten der Polen in Lemberg zu allerlei Beschuldigungen Anlass gegeben hat. Ich will gar nicht von jenen sprechen, die gegen uns waren (Allpolen, Nationaldemokraten), aber ach von jenen, die durch übertriebene Vorsicht und aus Furcht, sich zu kompromitieren, sich in ein schiefes Licht gestellt haben. Ich weiss wohl, dass diese zum grössten Teil nicht als Verträter gebrandmarkt werden dürfen und dass man nicht von jedem verlangen kann, ein Held zu sein; nichtsdestoweniger wäre vielfach eine weniger prononcierte Gefügigkeit den Russen gegenüber in vielen Fällen wünschenswert gewesen.

Beispiele, wie das Verhalten Rutkowskis ${ }^{20}$ und anderer,waren umso erf reulicher.

Dass wir in Lemberg nicht als Rächer mit flamenden Schwerte eingezogen sind und dass man den menschlichen Schwächen Rechnung tragend vielfach Gnade vor Recht hat ergehen lassen, gereichte mir zu besonderer Freunde.

\footnotetext{
${ }^{20}$ Pomyłka autora listu, bo chodzi nic o jakiegos Rutkowskiego, ale o Tadeusza Rutowskiego.
} 
Wo Verrat wirklich konstatiert werden konnte, aber nur dort, soll man mit grosser Schärfe und Energie vorgehen, menschlichen Schwächen gegenüber aber Nachsicht obwalten lassen.

Was nun die Legionen betrifft, so haben Sie vollkommen recht, dass sie eigentlich mehr ein politisches Instrument als ein wirklicher Kriegsfaktor sind, obgleich sie auch militärisch sich recht bewährt haben sollen; aber ihre Zahl ist im Vergleich der kämpfenden Milionenarmeen so gering, dass sie eigentlich kaum in Betracht kommen.

Aber auch als politischer Faktor sind sie gar nicht zu unterschätzen; sie haben gewiss viel dazu beigetragen, dass im Königreicheine uns viel günstigere Stimmung zur Geltung gekommen ist.

Dass die Polen in den Legionen gerne das Embryo eines zukünftigen polnischen nationalen Heeres erblicken, gebe ich zu. Dass es nicht das werde, muss die Aufgabe unserer Heeresverwaltung und der österrechischen Regierung sein.

Einstweilen nützen sie uns und wir können ihnen unsere Anerkennung nicht versagen.

Auch der Wunsch, dass die Legionen im Königreich zur Verwendung kommen, erscheint mir -wie ich es auch im Erlasse betonnt habe - nicht ganz ungerechtfertigt und wir würden es gerne sehen, wenn diesem Wunsche Rechnung getragen würde.

Stellen Sie sich vor, dass die Franzosen den Elsass erobet und dort Legionen gebildet hätten. Wäre es denkbar, dass dieselben anderswo zur Verwendung gelangen?

Mit dem Kriege hört ja die Existenzberechtigung der Legionen auf und müssen dieselbe selbstredent sofort ufgelöst werden. Einstweilen mögen sie ihre militärischen und politischen Aufgaben zur allgemainen Befriedigung der Polen lösen. Wie der Krieg ausgehen wird, respondeo wie gross die Gebiete sind, welche wir den Russen entreissen können, kann heute nicht vorausgesagt werden.

Aber eins ist sicher, die Monarchie kann und darf aus dem siegreichen Kampfe nicht geschwächt hervorgehen; die polnische Frage kann demnach nur eine Lösung finden; wobei die Polen zwar ihre Bef riedigung finden, die aber nicht zur Schwächung der Monarchie nach aussen und nach innen beitragen kann.

Sie erwähnen in Ihrem Brief, dass Sie über die polnischen Verhältnisse durch Lago genau informiert sind. Ich kenne Lago und schätze ihn sehr hoch; er kannt gewiss die polnische Verhältnisse ausgezeichnet, aber ich fürchte - unter uns gesagt -dass sein Standpunkt ein etwas einseitiger ist und er seine Informationen aus dem auch mir sehr befreundeten Geselschaftskreisen holt, die aber nicht 
immer ganz objektiv sind. Ich will damit nicht gesagt haben, dass Lago nicht eine ganz ausgezeichnete Informationnsquelle sein kann.

Schliesslich will ich noch bemerken, dass ich es lieber gesehen haben würde, wenn der Erzherzog ${ }^{21}$ Herrn von Biliński ${ }^{22}$ eine Audienz gewährt hätte.

Ich habe die mir zugegekommene Antwort mit der grössten Schonung weitergegegeben und die Quelle gar nicht genannt und einfacg gesagt: „Es wurde mir aus Teschen geantwortet et cetera". können.

Nichtsdestoweniger habe ich eine gewisse Verstimmung konstatieren

Ich befürchte, dass Herr von Biliński das ihm zuteil gewordene Refus auf das Kerbkolz des Ministerium des Lussern setzen wird, da er ohnehin meint, dass man ihm gegenüber hier nicht besonders gut disponiert ist.

Vielleicht wäre es sogar gut gewesen, wenn der Erzherzog seine Ansicht über das Auftreten des Polnisches Nationalkomitees gerade heraus ihm gasagt hätte.

Es wäre das auch einfacher gewesen, als einem Geheimen Rat und vielfach gewesenen Minister, Obmann des Polenklubs et cetera, die Audienz, wenn auch in einer sehr höflichen und plausiblen Form, nicht zu gewähren.

Nun aber schliesseich meine endlosen Ausführungen und werde mich immer freuen, von Ihnen amtlich oder ausseramtlich im Gegenstande Informationen zu erhalten.

Odpis, maszynopis.

Haus.-Hof und Staatarchiv, Krieg, P.A.I., karton 900, folio 577 - 584.

\section{Dokument nr 13}

1915 lipiec 21, Wiedeń.- Pismo austro-węgierskiego Urzędu Nadzoru Wojennego (Kriegsüberwachungsamt) do austro-weggierskiego Ministerstwa Spraw Zagraniczynych lącznie z tekstem apelu polskiego Komitetu Obrony Narodowej (KON) w Ameryce skierowanego do polskiego Komitetu Generalnego Pomocy Ofiarom Wojny w Polsce powolanego w Lozannie.

Im Nachhange zur hiesige Note vom 3 März dieses Jahres wird die Úbersetzung eines offenen Briefes, der von einem Komitees amerikanischer Polen

\footnotetext{
${ }^{21}$ Chodzi o arcyksięcia Fryderyka, który był naczelnym dowódcą armii austro-węgierskiej.

${ }^{22}$ Wzmianka dotyczy ministra finansów Austro-Węgier Leona Bilińskiego.
} 
an das bekannte "Generalkomitee der Hilfeleistung für die Kriegsopfer in Polen" gerichtet ist und interessante Bemerkungen über bei die Polen herrschenden politischen Strömungen enthält, zur gefälligen Kenntnis übermittelt.

Ergeht an das k.u.k. Ministerium des Äussern, k.k. Ministerratspräsidium k.k. Ministerium des Innern, sowie an die Nachrichtenabteilungdes AOK.

Podpis tłumacza: Schweizer $\mathrm{M}[\mathrm{a}] \mathrm{j}[\mathrm{o}] \mathbf{r}$

1 Beilage.

\author{
Das Komitee der National-Wehr in Amerika ${ }^{23}$ \\ an das \\ General-Hilfskomitee in der Schweiz, Vevey. \\ Hochverehrte Bürger !
}

Als wir in polnischen Blättern, die in Amerika erscheinen, Eueren Aufruf betreffend die Vereinigung des General-Hilfskomitees in Vevey, einer Stadt in Scweiz lesen, mussten wir mit Bedauern feststellen, dass der Vorstand der polnischen Emigration in Amerika sich in Euerem Komitee einzig und allein auf eine Partei, eigentlich nur auf politische Partei beschränkt hat. Da Namen der Herren Karabasz ${ }^{24}$ und Smulski ${ }^{25}$, welche eifrig für Russland agitieren, in der Liste der Vorstandsmitglieder erscheinen, so zeigt es sich deutlich, dass nur diese Richtung durch Euch, meine verehrten Bürger, bei Nominierung des amerikanischen Vorstandes in Eurem Komitee berücksichtigt wurde, welches doch nach Eurem Versprechen keine Parteirichtung tragen und auch weder der einen noch der anderen Richtung huldigen sollte. Wir vermissten gleichfalls in der Liste Eurer Vorstansmitglieder die Repräsentanten des so hochangesehenen General-National Komitees ${ }^{26}$. Wir wollen hier nicht einmal die vielen anderen zur Stütze des Vaterlandes geschaffenen Parteien, die nach von Euch übergangen wurden.

\footnotetext{
${ }^{23}$ Chodzi o Komitet Obrony Narodowej (KON).

${ }^{24}$ Chodzi o Antoniego Karabasz, któremu jako przewodniczącemu rady nadzorującej działalność amerykańskiego Związku Narodowego Polskiego (ZNP) przysługiwało miano cenzora. Zob. M. Wrzosek, Zwigzek Sokołow Polskich w Ameryce (1887-1920). Militarne przygotowania $i$ udziat w zbrojnej walce o niepodleglość Polski, Torun 2004, s. 9.

${ }^{25}$ Wzmianka dotyczy Jana Smulskiego, czlonka zarządu Centralnego Komitetu Polskiego w Ameryce.

${ }^{26}$ Wzmianka dotyczy Narodowego Komitetu Polskiego.
} 
Da wir in einem freien Lande leben, mitten unter freien Bürgern, im Genusse der Rechte, welche zwar nicht vollkommen sind, aber weit höher stehen als die, welche die Untartanen des moskowitischen Sklavenreiches beniessen, huldigten wir und huldigen wir noch immer dem Grundsatze, dass die allgemeinen Vertretungen aus freier Wahl hervorgehen sollen. Dieser Grundsatz war immer ein wesentlicher Bestandteil des politischen polnischen Gedankens, mag er auch während das Dauer unserer Sklaverei, insbesonders im letzten Jahrzehnt unter dem zersetzzenden Einfluss der östlich Selbstherrschaft in Vergessenheit gereten sein. Deshalb trachteten wir nach wie vor, eine Verständigung aller polnischen Parteien in sollcn bahnbrechender Zeit, wie es die jetzige ist, zu erreichen, und wir, das Komitee der Nationalwehr in Amerika, sind entschieden für die weiteste Berücksichtigung aller politischen Richtungen bei der Bildung von Zentralkörpern welche unser Volk zu repräsentieren hätten.

Grundsätzlich sind wir aber dagegen, dass eine unansehnliche Gruppe von Leuten die einen nach ihrer Meinung für würdig hält, das Land Polen von der ganzen Welt zu vertreten, die anderen dagegen zur Seite schiebt. Wir wiederholen, dass wir hier auf dem politischen Boden Amerikas an die Möglichkeit einer solchen Erscheinung gernicht denken können, an eine Erscheinung, die dem Geiste so fremd ist, der die Gleichheit und Einheit der polnischen Nation anstrebt.

Wir wenden daher an Euch, meine geehrten Bürger, mit der Forderung, eine Änderung in der Wahl Eures Komitees eintreten zu lassen. Wir tun es nicht, weil wir etwa gekränkt sind, dass man uns übergangen hat, oder weil wir uns um irgendwelche Ehrenstellen bewerben. Wir hätten diese Angelegenheit garnicht berührt, wenn Euer Komitee in der Auffassung seiner Aufgaben nicht einen allgemeinen polnischen Charakter hätte haben wollen. Da aber dieser Charakter schon bei der Gründung Eures Komitees besonders prägnant gekennzeichnet war, wollen wir, dass unser Vorgehen richtig begriffen wird und zwar als eine Tat, die aus dem Begriffe der bürgerlichen Pflicht entspringt. Unsere Pflicht als Polen, die sich zu schweren aber freien grossen Aufgaben vorbereiten, zu jenen Aufgaben, welche freien Bürger in befreiten Polen erwarten, ist es unaushörlich darüber zu wachen, dass die ersten Schritte, die wir nach so vieljähriger Sklaverei auf dem internationalen Kampfboden zu machen beginnen, nicht nur der Würde unserer Nation sondern auch den Anforderungen der Demokratie und der westlicher Kultur, zu welcher unsere Nation gehörte, gehört und gehören wird, entsprachen. Wir wenden uns daher an Euch nicht mit einer Bitte, aber auch nicht mit einer Beschwerde; wir kommen zu Euch mit einer Forderung als Gleiche zu Gleichen, als Freie zu Freien, im Vertraeuen dass wir auf dieser Basis der Union entsprechend den polnischen Traditionen, eine Stütze zur gemeinsamen Arbeit 
zugleich mit allen anderen polnischen Organisationen schaffen werden und zwar nicht eine partielle sondern eine wirklich internationale polnische Repräsentation. Wir verlangen für uns und für alle anderen polnischen Vereine, die von Euch übergangen werden, eine Vretretung in Eurem Komitee und nominieren zugleich als unsern Vertreter Herrn Dr Josef Zaleski aus Chicago, welcher bei unserem letzten Kongress zum Präses der National-Wehr in Amerika ${ }^{27}$ gewählt wurde.

Unsere Forderungen motiwieren wir in folgender Weise: schon vor jenigen Jahren hat eine spärliche Anzahl von Leuten, welche enen guten Willen hatten und welche verschiedenen politischen Parteischattierungen angehörten, die Notwendigkeit einer gemeinsamen Verständigung in nationalen Angelegenheiten in Anbetracht der sich mit Riesenschritten naheden Kriegsgefahr eingesehen. Die ersten Versuche wurden auf dem polnischnationalen Kongress in Washington im Jahre 1910 gemacht. Schon im Jahre 1912 gelang es, nähere Verbindung zwischen New-York und Chicago anzuknüpfen und man begann, an die Bildung einer gemeinsamen Organisation der Emigranten aller socialen und politischen Parteien, ohne Rücksicht auf ihre Schattierung, zu denken. Die Aufgabe dieser Organisation wäre es, die Massen auf den unumgänglich notwendigen Gedanken vorzubereiten, dass wir uns wenigstens jetzt - das einzige Mal in der Geschichte unserer Nation - von den Ereignissen nicht überraschen lassen. Mit grösster Freude begrüssten wir die analogen Bestrebungen innerhalb des Vaterlandes und wir unterstützten das Auftauchen des politisch-polnischen Gedankens, mittlerweile eine provisorische Kommission zu bilden sehr warm.

Wir waren überzeugt, dass alle polnische Parteien, ohne Ausnahme, in allen drei Teilen Polens ${ }^{28}$ sich verpflichet fühlen werden, in Verbindung mit einander zu treten, dass in Zentralorgan, welches der Würde, den Interessen und Aufgaben der polnischen Nation entspräche, geschaffen wird. Wir waren dessen gewiss, dass Polen kein so mindestowertiger Organismus mit zerrütteten Nervensystem ist sondern dass es im Stande ist, seinen Willen zum Leben in einer Zentrabehörde zu verkörpern. Wir waren der Überzeugung dass schon längst die Zeit gekommen war, der Politik des dreifältigen Loyalismus ${ }^{29} \mathrm{zu}$ entsagen, welche dazu führte, dass der Geistliche Stychel ${ }^{30}$ im Berliner Parlamente und Herr Grabski ${ }^{31}$ in der Petersburger Duma zu behaupten wagten - als sprächen sie im Namen der

\footnotetext{
${ }^{27}$ Chodzi o Komitet Obrony Narodowej (KON).

${ }^{28}$ liragment podkreslony przez osobe w austro-węgierskim Ministerstwie Spraw Zagranicznych.

${ }^{29}$ J.w.

${ }^{30}$ Chodzi o księdza Antoniego Stychla.

${ }^{31}$ Wzmianka dotyczy Władysława Grabskiego.
} 
ganzen polnischen Nation - dass die polnische Sache nicht international sei und auch nicht sein solle, sondern eine innere preussische beziehungsweise russische Sache sei und immer bleiben werde. Wir glaubten, dass alle polnische Parteien die alte Wahrheit einsehen würden, dass Salus Reipublicae, was polnisch die Unabhängigkeitsidee bedeutet, allen Partei - und Klasseninteressen vorangehen soll. Es war für jeden, der einen tieferen Einblick in die eurppäischen Verhältnisse hatte, ganz klar, dass der herannahende Krieg die jetzigen Staaten noch mehr von der dynastischen zu einer rein nationalen Herrschaft treiben wird. Die Vorboten dieser Nationalisierung des staatlichen Lebens waren eben die Verfolgungen aller nicht deutschen Nationen in Preussen und alle nicht russichen in Russland. Sogar in den polnischen Verhältnissen kam diese Tendenz zum Vorschein in der karrikierten Form einer antisemitischen und antiukrainischen Kampagne, welche durch die nationale Demokratie in Szena gesetzt wurde, wo ein Sklave gegen den andern die Peitsche des Programs zu Hilfe rief. Diese Veränderung, dass ist die weitere Entwicklung der neuen gemeinsamen organisatorischen Form der jetzigen Nation, geboren in den Tagen der französischen, der Kościuszko, schon und amerikanischen Revolution, konnte man in allen Zweigen des gemeinsamen Lebens bemerken. Und doch appelierte man bei uns, wie seit jeher, an das Gefühl der Gerechtigkeit und an die Gesetze oder, was am lächerlichsten erscheint, hat man uns beweisen wollen, dass die Erhaltung des Polentums in Preussen und Russland im Interesse diese Staaten gelegen sei. Wir wussten ganz genau, dass die jetzigen Staaten aus diesem fürchterlichen Kriege nach übermenschlichen Anstrengungen, bluttriefend hervorgehen werden, aber dafür werden sie enheitlich nationale Blöcke bilden, und dass dabei die polnische Nation zu Staub zerrieben werden wird, wenn sie in sich nicht die genügende Energie finden wird, einzusehen, dass eine 25 Millionen Nationalität ihre eigene Politik zu beginnen hat, wenn auch nur nach Muster des 250 Tausend Seelen zählenden Volkes Schwarzen Berge.

Indessem ist es anders gekommen. Die unschlüssigen und unmännlichen Herzen der Polen vermochten sich weder über die Alltagssorgen zu erheben, die [Aleksander] Wielopolski so zutreffend als "Kartoffelsorgan" bezeichnete, noch über die „Ärnte”, die ja einst der grosspolnische Adel, nach Weisungen Krzysztof Opaliński, angefangen hat, da er bei Ujście sich vom Vaterlande lossagte und sich den Schweden ergab, um nur das Getreide im Felde vor Verderben und Verfaulen zu retten. Die Anderen wiederum, wie überhaupt alle lebensmüden Kriecher ohne Energie und Kampfesfähigkeit, lockte der Orient durch sein loses Verhältnis zum Begriffe der Pflichterfüllung und durch sein leichtes Leben in Verfall. Nur ein Teil der Polnischen Gesinnungsparteien, nämlich die reinen 
Volksparteien, im Russischen und österreichischen Polen haben ihre Pflicht erfühlt. Man hat angefangen, eine eigene Armee zu bilden ${ }^{32}$, zur Zeit die einzige Garantie der Rechte einer Nation. Das preussische Polen schwieg überhaupt und ging den traditionellen Weg einer organischen Arbeit ${ }^{33}$. In Amerika ist es gelungen, die matten, erschlafften, nur zu Strochfeuer fähigen Herzen der Polen für einen Augenblick zu wecken. Es schien uns, dass hier in Amerika, in der Schule des Lebens, wo der Kampf die Alltägliche Parole in den Kleinsten Lebenserscheinungen ist, endlich ein einheitlicher polnischer Wille und Drang zum Leben entstehen wird. Es wurde das Komitee der National-Wehr geschaffen, dem nur das Ziel vor Augen schwebte, dem fernen und doch so teueren Vaterlande Hilfe zu bringen. Die Entfernung von der heimatlichen Scholle sollte der Prüfstein der Vaterlandsliebe sein, die einen höheren Grad der Kraft und Patriotismus verlangt, um die räumlichen Hindernisse überwinden zu können. Es freuten sich die gerechten Herzen Polens ob der neuen Quelle der nationalen Selbstbewusstsein. Die divergierenden Kotterienfaktoren im Königreiche Polen und in Galizien blicken missbilligend auf die Erscheinungen der Konsolidierung des polnischen Gedankens in der Emigraation, in der Richtung des Kampfes um die Freiheit. Die Grafen [Aleksander] Skarbek und noch andere überschwemmten daher Amerika mit Briefen; es kann sogar Herr [Tadeusz]Cieński angefahren, in eigener Person, um die Trennung durchzuführen und zu befestigen. Unter dem Einflusse des Nationalrates in Galizien ${ }^{34}$ meldete sich zuerst vom KON, der polnische Klerus un seine Pfarreien und später nach einem glänzenden, behufs Orientierung unternommenen, Ausfluge dem National-Polnischen Verbandes, repräsentiert durch die Herren [Antoni] Karabasz und [Adolf] Rakoczy und eines Delegierten des "Sokol ${ }^{\text {"35, }}$, des Herrn Starzyński ${ }^{36}$, hat der Polnische NationalVerband ${ }^{37}$ und der "Sokol” einen Aufruf erscheinen lassen.

${ }^{3}$ Słowa podkreślone przez osobę z austro-węgierskicgo Ministerstwa Spraw Zagranicznych.

${ }^{33}$ Wzmianka dotyczy hasła "Praca organiczna".

Wzmianka dotyczy Rady Narodowej, która aspirowała do roli naczelnego polskiego organu politycznago i działała pod kierunkiem zamożnego ziemianina podolskicgo Tadeusza Cieńskiego, internowanego i prześladowanego podczas pierwszej wojny światowej przez austriackie czynniki policyjne; taka wzmianka,zakrawająca na zwyczajny donos, budzi zatem odruch potępienia. Szerzej o Tadeuszu Cieńskim por.: M. Wrzosck, Prześladowanie Tadeusza Cienskiego przez austriackq policję podczas pierwszej wojny światowej, „Niepodległość i Pamięç”, 1999, rocznik VI, nr 1 (14), s. 27- 37.

${ }^{35}$ Kolejna wzmianka dotyczy Związku Sokołów Polskich w Ameryce; zob. M. Wrzosek, Zwiq̨zek Sokolów Polskich w Ameryce (1887 - 1920), Torun 2004, passim.

${ }^{36}$ Chodzi o lekarza Teofila Antoniego Starzyńskiego, który był prezesem Związku Skołów Polskich w Ameryce.

${ }^{37}$ Wzmianka dotyczy Związku Narodowego Polskiego, powolanego w 1880 r. 
Mit dem Monate des Kriegssasbruches offenbarte sich deutlich die Partei, welche die Zersplitterung herbeigeführte. Es begann eine russophile Orgie, wie eine solche seit der Zeit der "Targowica" nicht mehr zum Vorschein gekommen war. Es kam sogar so weit, dass bei einer Feier zu Ehren der Gefallenen des Novemberaufstandes, der Präsident des National-Verbandes, Herr Kasimir Żychliński ene grosse Menge der Teilnehmer mit folgenden Worten aufforderte, an die Seite des Zarentums zu treten: „Ich gehe mit Russland, wer geht mit mir ?". Man paktierte mit anderen Slaven bei den Klangen des Lides „Boże Caria chrani” (Gott schützt den Zaren). Die Sokolvereine organisierten die polnische Jugend und sandten diese zu den Legionen des Gorczyński ${ }^{38}$ in Warschau, wo die Sokolisten [Adam] Trygar und [Leon] Sułkowski bereits Of fizierrang erreicht hatten.

Und eben diese Organisationen bilden jenes „Zentral-Komitee zur Rettung Polens, welches als parteilos in Verbindung mit Eurem Komitee WCKPR ${ }^{39}$ trat. Mit der einzigen Ausnahme der Klerikalen welche bis jetzt den neutralen Standpunkt vertraten, sind alle Organisationen Anhänger Russlands.

Vom dem was hier im Lande geschieht, kann man nicht schreiben. Wir erinnern uns alle, welche Beschimplungen, Spottnamen und Insinuierungen auf Besten und Tüchtigsten der polnischen Volksgestalten, auf die Besten unseres Landes, auf die Blüte der Intelligenz, der Kunst und Wissenschaft in Polen, gefallen sind, welche unter Führung des Piłsudski auf eigene Faust, ohne Zustimmung der österreichischen Regierung, die russische Grenze überschritten ${ }^{40}$ haben, und durch eine männliche Tat den südlichen Teil des Königreiches Polen im Namen der Unabhängigen Polens oroberten.

Wir wissen, wie man ihnen begegnete. Wir wissen doch, wie die Vertreter der polnischen Intelligenz in Lodz ${ }^{41}$ ihren Anordnungen keine Folge leisten wollten, indem sie sagten, dass nicht sie sondern die Deutschen, dort die Herren seien. Das Blut der polnischen Legion des Piłsudski floss in Strömen in den fürchterlichen, verzweiflungsvollen Anstrengungen, um das Selbstgefühl und die Volksenergie dieser Sklaven aufzurütteln.

Während Nachrichten in Warschau eintrafen, dass dort die Pferde der Kosaken von polnischen Frauen bekränzt wurden, dass die dortige Intelligenz und der polnische Adel kniefällig Adressen dem Nikolaus Nikołajewicz überreichten und dass man einem russischen General eine Karabella überreichte, die er aber

\footnotetext{
${ }^{38}$ Chodzi o Witolda Gorczyńskiego, który był organizatorem Legionów Polskich po stronie Rosji.

${ }^{39}$ Wydaje się, że do przetłumaczonego tekstu zakradla się pomyłka i chodziło w istocie o CKPR, czyli w pełnym brzmieniu polskim o Polski Centralny Komitet Ratunkowy.

${ }^{40}$ Stwierdzenie niezgodne $\mathrm{z}$ prawdą.

${ }^{41}$ Chodzi o miasto Lódź.
} 
verschmähte. Zuletzt kam noch die rcgterlichste Kunde: Teile des polnischen Volkes erbaten sich die Bewilligung der russischen Regierung zur Bildung von Legionen zur Verteidigung Russlands.

Gegenüber den polnischen Legionen des Piłsudski, dem letzten Trumpf welchen die polnische Nation in ihrem Unabhängigkeitsbestreben ausspielt, bilden polnisch Hände ein polnisches Heer, welches die Bestimmung haben soll, die Unantastbarkeit der russichen Grenzen zu schïtzen. Hier wurde die Volkssele in dem entgültigen, bahnbrechenden Momente schwer verletzt. Man hat wissentlich Uneinigkeit geschaf fene; es ist sogar so weit gekommen, dass wir beginnen uns gegenseitig zu hassen. Die polnische Nation zerfallt in Staubatome. Die Verzweiflung ergreift einen, wann wir die Zerrsetzung der polnischen Nation mit der gestählten Einigkeit der Deutschen, Franzosen, Belgier ${ }^{42}$ und Engländervergleichen. Es verschwindet der Rest der nationalen Würde. Herr [Ignacy] Paderewski fordert soeben den russischen Gesandten Iswolski ${ }^{43}$ auf, den Vorsitz bei der Versammlung des polnischen Komitees in Paris zu übernehmen, diese Iswolski, den Hencker der Unierten, der schon jetzt während des Krieges die Abhaltung der Vortrage über Polen an der Pariser Sorbonne verhinderte; und in die Verwaltung des Londoner Komitees wird der dortige russische Gesandte aufgenommen. Den Bedrücker erwählt man angesichts von ganze Europa zum Vormund und Erlöser. In London kann man sich ohne den russischen Gesandten nicgt begehen. Die Sklaverei wird zum System.

Es ist die höchte Zeit umzukehren und eine Grundlage zur Verstädigung aller polnischen Parteien zu schaffen.

Vergesset nicht, verehrte Mitbürger, dass die Verhandlungen zur Herbeiführung des Friedens ebenso in einem oder in zwei Jahren, als auch vielleicht in einem Monate ihren Anfang nehmen können. Ermannt Euch, damit die Zeit vor dem Kriegsbeginn. Bedenkt, wie wiirden wir jetzt dastehen, wenn wir uns alle vor dem Kriege geeinigt hätten und jetzt eine polnische Armee von 300000 Mann hätten: ${ }^{44}$ es wird das eine fürchterliche Sache sein, wenn auch in diesem Momente Polen nicht willens sein wird, einen Willen und nur ein Ziel hat: Die vollständige nationale Unabhängikeit ! Sonst müssen wir wirklich verbluten und als Beute fremden Leuten geopfert werden.

${ }^{12}$ Tu pojawia się kolejne przekłamanie, ponieważ społeczeństwo belgijskie teì nie było monolitem mając swoich „aktywistów" i „pasywistów”; te właśnie określenia miały być przeszczepione niebawem na grunt polski.

"Chodzi o rosyjskiego ambasadora we Francji Aleksandra lzwolskicgo.

4 Slowa podkreślone w tekscie przez osobę $z$ austro-węgicrskiego Ministerstwa Spraw Zagranicznych. 
Schauet hin, wie unsere Feinde die Stimmung jenseits der Grenzen bearbeiten. Jeder von ihnen spielt sich genädigst auf den Vormund Polens auf, zweitklasige petersburger Schauspielerinnen wie Lydia Jaworski - Bariatynska schreiben wöchentlich einige Male in englischen Zeitungen, von der Eintracht, die zwischen den Polen und Russen entstand. Russland gab die Losung aus, dass die polnische Angelegenheit berets geordnet sei, dass die Polen mit der Autonomie einverstanden seien. Die jüdische Presse, zweifellos im Einverständnisse mit Rusland, verbreitet Nachrichten vom Barbarentum der Polen, von der Unabfähigkeit ein selbstständiges Leben zu führen, und behauptet, dass die nur russische Regierung imstande die wilden Polen zu kurieren. Und die Polen selbst geben es zu. Wer sich heute von der Unabhängigkeit lossagt, wer nicht selbe fordert in einem Momente, wo allen Nationen trotz Milionen Verlusten an Gut und Blut ihre nationale Unabhängigkeit verteidigen, der wirklich nur ein Zerrbild eines Polen, der negiert den jetzigen mennschlichen Typus und anstatt die vesprochene Vereinigung aller Polen nach Sprache und Glauben, wird er nichteinmal eine berenzte Selbstherrschaft erreichen. Man kann ein Leben damit beginnen, dass man sich der Sklaverei anpasst, denn dieser Weg führt, wie uns das Thierreich beweist, zum Parasitentum. Im geselschaftlichen Leben können wir uns das beste Beispiel an den Juden nehmen.

Die Paktierung und die polnische Unmännlichkeit machten die Polen wissentlich zu Parasiten, die sich vom riesigen Körper Russlands nähren.

Es ist die höchste Zeit, sich der integrierenden Arbeit zu widmen, um dem weiteren Zerfalle Einhalt zu tun.

Am leichtesten können wir das bewerkstelligen, wir, die wir in der Fremde wohnen, in neutralen Ländern, weit entfernt von den Kriegsgesetzen, welche einem den Mund mit einer deutlich berredten Kugel verschliessen.

An Euch, meine verehrten Mitbürger, wenden wir uns mit der Forderung, Euer Komitee in diesem Sinne $\mathrm{zu}$ reorganisieren und $\mathrm{zu}$ erweitern. Jede Verzögerung ist ein Verbreche, bagangen an unserem Volke.

Die Hilfe, die wir Opfern des Krieges bringen, soll als Basis für den Beginn der Arbeit dienen. Die Würde des Volkes erheischt es jedoch, dass diese Hilfe nicht das Zeichen einer philantropischen Bettelei, vor fremden Türen tragen soll. Man muss den Nothleidenden Hilfe bringen, mit diesem Grundsatze sind wir doch alle einverstanden. Es gibt keinen unter uns, der dem Schrecklichen Elend, oder eigentlich der drohenden Vernichtung der polnischen Bevölkerung auf den Schlachtfeldern nicht steuern wollte. Aber wir dürfen diese Hilfe nicht als ein Mildhätiges Werk, sondern als eine unentbehrliche Funktion eines einheitlichen Volksorganismus betrechten. 
Wenigstens in dieser Hinsicht wollen wir zeigen, dass wir ein Ganzes sind, und nicht Partikel verschiedener Staaten, nicht polnische Infiltrationen in den Körpern anderer Völker. Es mögen sich wenigstens auf diesem Felde die anarchistischen und zersplitterten polnischen Geister zur gemeinsamen Handlung vereinigen. Darum sollten sich auch in Eueren Komitee die Vertreter aller polnischen Lager und aller polnischen Parteien zusammenfinden. Jeder dieser Lager tritt mit dem Leben der polnischen Nation in Berührung und kann in ausgiebiger Weise zur Hilfe beitragen. Es Wird Euch nie gelingen, ein parteiloses Komitee zu Bilden. Ihr habt doch ein Beispiel an dem CKPR in Amerika ${ }^{45}$, welcher auch nicht parteilos ist und seine Vertreter bei Euch hat. Es gibt in der Welt keine parteilosen und keine, keiner Richtung angehörenden Personen, namentlich in Kriegszeiten, mit Ausnahme der nicht denkenden Sklaven oder nicht anders, als eine Vereinigung eine Anzahl von Leuten, zur Erreichung eines bestimmten Zieles. Der Mangel eines Lebenszielen kennzeichnet die Dekadenz.

Habet keine Angst, dass ein Euerer Mitte Reibungen entstehen werden. Das Leben ist ein Kampf, der Tod ist der Zerfall in kleine, wenn auch gut organisierte Kreise. Auch die sich am meisten bekämpfenden Kräfte können immer eine gemeinsame Grundlage zu gemeinsamen Handeln finden und eine solche Grundlage hat die polnische Nation bisher immer besessen. Es ist hundert mal besser, sich im Kreise solcher Leute zu bekämpfen, als durch Vermeidung dieser Reibungen - zum Bruderkampfe getrieben zu werden. Zu einem Bruderkampfe, wie ihn Herr [Roman] Dmowski nach seinen Recepte vom 1905 mit der Organisierung der Warschauer Legionen, unter den Fittigen des Zarentum, zu beginnen versucht.

Möge auch er in Euer Mitte weilen. Die Erkenntnis und der Parlamentarismus sind die besten Mittel gegen das Condotjerentum. Es möge daher Euer Komitee eine Art Ausschuss zur Durchführung aller ökonomischen Angelegenheiten von ganz Polen werden. Fordert alle polnischen Parteien, alle vaterländischen Hilfskokomitees, die in Euer Organisation nicht vertreten sind, zur Entsendung ihrer Vertreter auf.

Indem wir es als unsere Pflicht erachten, in nationalen Angelegenheiten mitzuarbeiten, melden wir uns hiermit zum Beitritt in Euer Komitee, als Komitee der National-Wehr in Amerika, gegründet am 12 Dezember 1912, welches heute schon durch 130 Lokalkomitees in allen Standen der Nordamerikanischen Union repräsentiert wird, und fordern, unsere Vertretung dahin entsenden zu dürfen.

\footnotetext{
${ }^{45}$ Chodzi o Polski Centralny Komitet Ratunkowy w Ameryce.
} 
Wir sind überzeugt, dass durch gemeinsame Beratungen über die Verhinderung des ökonomischen Unterganges Polens, über die Hilfeleistung für die Kriegsopf er, die polnischen Lager sich miteinander verständigen werden, so dass uns der Friedenskongress geeinigt zum entschidenen gemeinsamen Handeln wird. Wenn Ihr aber unser Forderung nicht einverstanden seid, so verlangen wir wenigstens eine klare, deutlich motivierte Antwort.

Wir sind ein Repräsentationskörper, hervorgegangen aus den allgemeinen Wahlen der öffentlichen Versammlungen, die für alle Polen in Amerika zugänglich sind; und auf dieser Basis begründen wir unser Recht, von Euch eine Antwort verlangen zu dürfen.

Wir proponierten dasselbe dem fast conträren Lager in Amerika, in einem unserer Aufrufs vom 17 August, gleich nach Asbruch des Krieges (Dienstbezügliche Nummer des „Wici” sammt Auf ruf legen wir bei). Leider haben wir auf unseren Aufruf gar keine Antwort erhalten. Das conträre Lager hat es vorgezogen, kleinmütig zu schweigen, da es wohl wusste, dass es uns keine abschlängige Antwort auf einen su ruhigen und gemässigten Vorschlag geben könne. Und zur Eintracht hat die russophile Partei ihre Einwilligung nicht geben wollen.

Wir hoffen, meine verehrten Mitbürger, dass wir von Euch eine erschöpfende Antwort erhalten werde. Eine Kopie unseres Briefes übersenden wir dem Museum in Rappersvil zur Bestätigung unser Bestrebungen zum Zwecke der Vereinigung aller polnischen Seelen.

Wir senden Euch, meine verehrten Bürger, unserem Gruss und beenden unseren Brief mit dem Ausrufe, welcher unsere Grossväter und Väter in den hundertjährigen Freiheitskämpfen einiges mit dem, heute bereits längst $z u$ Gunsten der Compromissformeln verhalten Aufrufe: „Es lebe das unabhängige Polen!".

Chicago am 3 April 1915.

Das Exekutivkomitee der National-Wekr in Amerika.

Podpisali: Dr J[ózef] Zaleski -Präsident

J.A.Gintowt, Jan M. Sienkiewicz, Dr K[azimierz] Żurawski Vicepräsidenten

T[omasz] Siemiradzki - Kassier, S[tanisław T. Rayzacher, Dr M. Bochenek - Vice-sekräter

J[an]Borkowski, B[ronisław] Kułakowski, J[ózef Maślanka, L[udwik] Majcher, Z. Piotrowski, W.M. Szpunar, Tabeński - Komitees-Mitglieder. 
Oryginał pisma przewodniego i odpis załączonego tekstu, maszynopisy. 1 laus.-1 lof und Staatsarchiv, Krieg P.A.I., karton 900, folio 672-684.

\section{Dokument nr 14}

1915 lipiec 24, Kraków.- Raport przedstawiciela austro-węgierskiego Ministerstwa Spraw Zagranicznych przy Naczelnej Komendzie Etapów dla ministra barona Stefana Buriana o sytuacji w Warszawie.

Die fortschreitenden Erfolge der verbündeten Waffen in Polen geben einigen Mitteilungen, welche mir nach meiner Rückehr von Lemberg von befreundeten Pesönlich-keiten der hiesigen polnischen Geselschaft über die Lage in Warschau gemacht werden sind, grössere Aktualität.

Ich war in meiner letzten Warschauer Zeit und nach Verlassen diesen Postens wiederholt bemüssigt über die russophile Haltung eines Teiles der Aristokratie der polnischen Hauptstadt Meldung zu erstatten. Diese Meldungen wurden dann unmittelbar in der öffentlichsten Weise bestätigt durch den famosen von so viel bekannten Warschauer Persönlichkeiten unterschriebenen Aufruf, welcher den unverbrüchlichen Anschluss des gesamten Polentums an Russland proklamiert und in Connexe sicht mit dem Manifeste des Grossfürsten Nikolaj Nikolajewitsch an die polnische Nation. Es ist bekannt, welchen nachteiligen Einfluss dieses, die „russische Orientierung der oberen Schichten Warschaus verkündigende Dokument, sowohl im Königreich Polen wie auch auf die national-demokratische Partei Galiziens und einen Teil des ostgalizischen Adels ausgeübt hat. Nun wo sich die Kriegsglück entschieden gewende zu haben scheint, sind, wie ich hier aus vertraulicher Quelle erfahre, die Herren Initiatoren des Manifestes in alle Winde zerstoben, weil die Repressalien unsererseits im Falle der Einnahme Warschaus befürchten. Unter den Entflechenen scheinen sich auch die Herren zu befinden, welche wie Graf Józef Potocki und Herr [Ignacy] Szebeko in Lemberg während der Russenherrschaft für den Anschluss des galizischen Adels an Russland agitiert haben. Nur Prinz Zdzisław Lubomirski, ein ehrenwerter, wenn auch sprunghafter und leidenschaftlicher Amateurpolitiker soll zurückgeblieben sein. Auch dieser ist in Lemberg gewesen, hat sich aber daselbst wie ich autentisch feststellte unter dem Eindrucke der herrschenden russischen Wirtschaft entschlossen mit der zu Anfang des Krieges beobachteten Haltung zu brechen und hat dann aber im wohltätigen Sinne auf die Schwankenden polnischen Elemente in Lemberg eingewirkt. Sein Einfluss in Warschau wird gewiss kein schädlicher sein. 
Die Abwesenheit der Herren, die sich in Erwartung das russischen Siegen auf die russisch-polnische Verbrüderung festgelegt hatten, von Warschau wird für uns im Falle einer Einnahme der Stadt keineswegs von Schaden sein, vielmehr die Situation vereinfachen. Nach dem Friedesschlusse werden diese Parteigänger recenten Datums alle zurückkehren und sofort nur den einen Gedanken haben, sich uns zu ralliren ${ }^{46}$ - vorausgesetzt nämlich, dass wir ihnen nicht nachlaufen werden sondern ihnen zeigen, dass wir auch ohne sie unseren Weg $\mathrm{zu}$ finden wissen. Wie ich seinerzeit zu melden die Ehre hatte, waren es ganz andere politisch für uns verlässlichere und weniger opportunistische Elemente, welche bis zum letzten Augenblick mir treu zur Seite standen und denen es unter anderen zu verdanken ist, dass trotz den drohenden und nachher von der russischen Regierung wirklich verhängten Strassen unsere Mobilisierung mit Hilfe eines Teiles der Presse weiten Kreisen der Bevölkerung und insbesondere unsere Reservisten bekannt gemacht werden konnte. Die Elemente, auf welche ich in der letzten Zeit meiner Warschauer Tätigkeit die Propaganda für uns mit guten Erfolg stützte, waren einerseits die sich um die katholische Zeitung „Przegląd Katolicki". Mit deren Redakteuren ich enge Bezihungen pflegte, gruppierende in den breiten Kreisen der Bevölkerung sehr einflussrecche christlich-soziale Fraktion, anderseits die Dissignierten der Nationaldemokratie, deren Organ „Goniec”, wie ich seinerzeit zur Kenntnis Seine Exzellenz dem Grafen Berchtold zu bringen mir erlaubte, bis unmittelbar vor Kriegsausbruch mit mir in Beziehungen stand und in vollkommen desinteressirter Weise durch geschickt redigirte austrophile Artikel uns wesentliche Dienste geleistet hat. Auf diese beiden Gruppen müsste meines unmassgeblichen Erachtens jetzt in Falle der Besetzung Warschaus neuerdings zurückgegriffen werden, da es gelten wird, zwei Klippen zu vermeiden, die nämlich, die Sympathien für uns hauptsächlich auf Gruppen zu gründen, welche essentiell subversiver Natur und infolge dessen an und für sich gefährlich, dann aber auch speziell prädisponierter sind, schnell mit den militärischen Kommanden, insbesonders wenn es sich um deutsche handelt in Konflikt zu geraten, anderseits die, dass wir uns an solche Kreise wenden zu müssen uns bemüssigt sein, welche nicht für Österreich-Ungarn, sondern nur für die polnische Unabhängigkeitsidee zu gewinnen sind und welche wir nicht unmittelbar, sondern nur durch Vermittlung polnischen Politiker, etwa des Nationalkomitees und seiner Delegierten, zu capacitieren vermögen.

${ }^{4}$ Stowa podkreslone $w$ tekscie prawdopodonie przez ministra Buriana, a na marginesie nastçpująca uwaga: „ganz nichts!". 
Als ich zum letzten Male Eurer Exzellenz meine Aufwartung zu machen die Ehre hatte, war über den Besetzungs-und Verwaltungsmodus Warschaus während des Krieges zwischen uns und der kaiserlich deutschen Regierung noch keine Vereinbarung zustande gekommen. Ob eine solche seither erfolgt ist, ist mir unbekannt. So weit meine mehrjärigen Warschauer Erfahrungen reichen, wird gerade im Verhältnisse etweiger deutscher militärischer und Verwaltungsbehörden zu der einheimischen von Deutschenhass durchgetränkten Bevölkerung das schwierigste politische Problem für uns während einer militärischen Okkupation liegen und die Vermittlung zwischen zwei so disparaten Elementen wird nur durch die grösste Aufmerksamkeit unter Vermeidung zu starker Anlehnung an die extremen Parteien von rechts und von links, vor allem aber durch möglichste Ausschaltung der zu sehr nach einer oder nach der anderen Seite engagierten galizischen Politiker zu erreichen sein.

Der k.u.k. Legationsrat: L. Andrian

Oryginal, maszynopis.

Haus.-Hof und Staatsarchiv, Krieg, P.A. 1., karton 900, folio 692- 693.

\section{Dokument nr 15}

1915 sierpień 5, Wiedeń. - Pismo posła Stanisława Downarowicza do warszawskiego przedstawiciela Austro-Węgier hrabiego Stefana Ugrona o wcześniejszej i aktualnej sytuacji w Warszawie.

In der Beilage erlaube mir Eurer Exzellenz:

1) Die neusten Nachrichten aus Warschau und überhaupt von jenseits der Frontlinie vorzulegen;

2) Auch erlaube mir einen Auszug aus meinem nach Rückehr von meiner dorthin vorgenommenen Reise dem Obersten Polnischen Nationalkomitee vorgelegten Berichte ergebenst beizuschliessen - wobei ich vor Allem meine allgemeinen Schlussfolgerungen betreffs Russland, welche auf Grund persönlicher Beobachtung entstanden sind, der geneigten Aufmerksamkeit Euerer Exzellenz empfehle - da diese Schlussfolgerungen auch von den Militärbehörden in Piotrków als interessant anerkannt wurden;

3) Kurzen Auszug aus dem dem k.u.k. Ministerium des Äusseren seinerzeit unterbreiteten Berichtes über Warschau. 
Bezugnehmend auf die Unterredung, welche ich am 24 VII leitendes Jahres mit Eurer Exzellenz zu führen die hohe Ehre hatte, und auf die damals gefallene Bemerkung Eurer Exzellenz, die Anwerbung für die Legionen gehe in Königreich schlecht, woraus sich schliessen liesse, dass das Oberste Polnische Nationalkomitee dort keiner Sympatien sich erf reut und keine Unterstützung seitens der dortigen Bevölkerung geniesst - erlaube mit Eurer Exzellenz den Bericht

4) Über einen drastischen Fall, nämlich über die Verhaftung des Legionen Offiziers Gorzechowski in der Gegend von Lublin zur gefälligsten Einsichtnahme ergebenst zu unterbreiten.

Ich kenne Herrn Gorzechowski persönlich sehr gut als einen ruhigen, besonnenen und im höchsten Grade taktvollen Mann und kann daher über sein vollkommen correctes und tadelloses Benehmen keinen Zweifel hegen.

Der Fall ist leider nicht vereinzelt, im Gegenteil, er ist einer von vielen und daher für das Verhältniss der K.u.k. Militärbehörden hinter der Front zu den Polnischen Legionen, zur Anwerbungs - Aktion und zum Obersten Polnischen Nationalkomitee charakteristisch.

Auf Grund meiner genauen Kenntnis der Verhältnisse in Königreich Polen muss ich feststellen, dass dieselben im Gouvernement Lublin, was die Volkstimmung anbelangt, von unserem Standpunkte die günstigsten sind obwohl die K.u.k. Armee beim ersten Vormarsch leider sehr viel zur Schwächung dieser für sie freundlichsten Gefühle der Bevölkerung beitragen hat. So wurde dort damals zum Beispiel einer der hervorragendsten nationalen Führer, welcher antirussisch und für die Monarchie freundlich gesinnt ist, gleich im Anfang verhaftet und fortgeführt.

In Betreff eines anderen Momentes der erwähnten mir gef.[älligst] gewährten Unterredung, wo Eure Exzellenz gegen die Zulassung der Angesandten des Obersten Polnischen Nationalkomitees nach Warschau noch vor dem Einmarsche der Truppen, oder wenigstens zusammen mit denselben, sich ausgeschprochen haben - erlaube mir Euere Exzellenz ergebenst zur gef.[fälligst] Kenntnis zu bringen, und zwar auf Grund der uns zugekommenen sicheren Informationen, dass seitens der preussischen Behörden Vorbereitungen getroffen wurden, damit in Warschau gleich am Anfang eine Presscampagne ähnlich der in Lodź geführten, über die Euere Exzellenz genau informiert sein dürften, eigentlich werde. Dieser Aktion und ihren für die Österrreichisch-Ungarischen Monarchie nachteiligen Folgen kann nun meiner Meinung nach, die Erfüllung aller in meinem Warschauer Berichte aufgestellten Postulate, vor allem aber die sofortige Zulassung der Abgesandten des Obersten Polnischen Nationalkomitees nach Warschau, vorbeugen. 
Genehmigen Exzellenz den Ausdruck meiner vorzüglichsten Hochachtung Ergebenst St. von Downarowicz

Załącznik nr 1

Bericht aus Warschau erhalten am 21 Juli 1915

Die Stimmung der polnischen Bevökerung in Warschau, inwieweit sie sich in legalen Formen abspiegelt, ist vorallem stark pessimistisch bezüglichaller russischer Seite gemachten Versprechungen. Die letzten Kriegsereignisse, die ungeheuer schweren Niderlagen der Zarsarmee, die dem Fall Warschaus als unmittelbar bevorstehend gewärtigen lassen, ermutigten die Unabhängikeitselemente, das ganze russenfeindliche Lager und steigerten seine Kräfte. Die Bedeutung der antirussischen Parteien ist so sehr in Warschau begriffen, dass der Einfluss derselben auf die allgemeine Meinung immer deutlicher zu Tage tritt. Zugleich kommt in den russophilen Kreisen eine unverkennbare Mutlosigkeit und eine sehr herabgestimmte Tonart zum Vorschein.

Den Umwachung der Stimmung in Warschau kennzeichnen am besten die Artikel der Blätter die die durchschnittliche repräsentieren. Sie treten in den letzten Tagen mit Energie und Entschiedenheit allen Versuchen entgegen, eine Panik hervorzurufen, und auf diese Weise die Bevölkerung zur Abreise ins innere Russland zu nötigen. Der Inhalt derArtikel, die Argumente, die hier ins Treffen geführt werden, um das Publikum zu überzeugen - alles atmet den kaum vrhellten Jubel, dass bereits eine bessere Zukunft für Warschau in Sicht ist und dass die sinnlose Angst, die die unkritischen Köpfe benebelt, vielleicht ein Vorspiel zum Ausbruch der Freiheit bildet.

Die letzte Hoffnung der russophilen Partei, eine Unterstützung in dem seit langen angekündigten "Demokratischen Klub" zu finden, wurde enttäusht. Der Klub bildete sich endlich im Juni, hat aber niemandem herangezogen ausser der kleinen Zahl von ehemaligen Gegnern der National-Demokratie, die jedoch während des Krieges den Verheissungen des Grossfürten Lein gingen und darauf rechnen, dass der Sieg des Vier-Verbandes eine günstige Lösung der polnischen Frage, die Vereinigung der polnischen Provinzen und die Verleibung einer weitreichenden Autonomie an das wiedererweckte Polen herbeiführen könne. Es sind das in Gegensatze zur Nationaldemokratie in politischen Dingen naive Leute, die kleinen Einfluss auf die breiteren Bevölkerungsschichten haben und deren Anhängerschaft nur gewisse Gruppen der Intelligenz bilden, die in blinder 
Verehrung zu Aleksander Świętochowski emporschauen. Der "Demokratische Klub" beschäftigt sich nur mit theoretischen politischen Diskussionen, die in einem streng gewählten Kreise von Ideologen und Doktrinären geführt werden. Der „Demokratische Klub” besitzt gar keine Popularität und sucht die nicht einmal zu erlangen, man interessiert sich auch mi ihm gar nicht.

Das Warschauer "Nationalkomitee" (Nationaldemokraten und eine kleine Anzahl von Realisten) hält jede Woche seine geheime Versammlung ab. Vom Zeit zu Zeit veranstaltet es grössere Versammlungen, wobei als Gäste auch Anhänger anderer Parteien erscheinen. In einer dieser Versammlungen referierte Dmowski über die aus 12 Personen ( 6 Polen und 6 Russen) bestehende Kommission, die in Peterburg über die polnische Frage baraten sollte. Die Nachricht von der Ernennung diser Kommission wurde in Warschau allgemein als Symptom der russischen Niederlagen aufgenommen. Die Lage muss schlimm sein, dachte man, wenn die Versuche, die Polen durch Versprechungen zu gewinnen, wieder erneuert werden. Sogar seitens der Anhänger des Programms der Vereinigung (aller Provinzen Polens unter dem Zarenscepter) wird vielfach eingestanden, dass den russischen Verheissungen nicht zu trauen ist; sie hegen jedoch den Glauben, dass die Koalition Russland beim Worte halten werde. Dmowski betonte mit grossem Nachdruck die hohe Bedeutung der für die polnische Frage eingesetzten Kommission, die er als Verheissung weitreichender, noch gar nicht absendbarer Reformen histellte und bezeichnete es als wertvolle Tatsache, dass für die Regulierung der polnischen Frage Polen zur Teilnahme herangezogen wurden, dass man also über uns nicht ohne uns entscheiden werde. Hingegen misst er der Frage der städtischen Selbstverwaltung keine Bedeutung mehr bei; auch sonst begeistert sich in Warschau niemand für diese Sache. Es finden zwar Versammlungen von Realitätenbesitzern, Kaufleuten und so weiter statt, in denen die Frage der Selbstverwaltung und der Wahlen behandelt wird, allein die Stimmung dieser Versammlungen ist schläfrig und apatisch. Die Leute empfanden das Unreale einer Reform, die keine politische Bedeutung hat und deren praktische Durchführung angesichts der unsicheren Kriegslage zweifelhaft ist.

Die den polnischen Privatschulen zugestandene Erleichterung (nämlich das Recht, die Reifeprüfungen im Beisein des Delegierten des Unterrichtbezirks vorzunehmen und auf Grund derselben Reifezeugnisse auszustellen, die den staatlichen gleichfertig sind) wurde vom der Jugend sehr widerwillig aufgenommen. Ihre Halbheit und Zweischneidigkeit beruht darauf, dass sie dem Unterrichtsbezirk einen Weg zu einer noch schärferen Beaufsichtigung des Privatunterrichts, als sie bis nun geübt wurde, öffnet; ausserdem verschaffen sie, 
es keine polnische im Lande gibt, nur den Zutritt zu den russischen Universitäten und Polytechniken, welche die Jugend so lange hartnäckig zu boykottieren entschlossen ist, bis Warschau höhere polnische Lehranstalten erhält. Die Jugendorganisationen beschlossen, keine Gebrauch von dem neuen Rechte zu machen, bezüglich dessen übrigens im Vorhinein die Bestimmung galt, dass es nur auf Wunsch des Maturitätskandidaten in Anwendung kommen soll. Diesen Beschluss haben nicht alle befolgt: den Schülern, welche im Beisen des Delegierten geprüft zu werden verlangten, wurde es von ihren Kollegen sehr verübelt. Die Erwartung, dass das ganze Schulwesen polnisch wird, sobald nur die polnische Frage im Einklage mit dem Wünschen der Nation entschieden wird, lässt die winzigen Errungenschaften geringschätzen.

Die Räumung Warschaus betrifft in erster Reihe die Familien der Staatsbeamten, denen angesagt wurde, dass sie durch ihr Verbleiben am Platz im Falle der Einnahme der Stadt, des Rechtes auf ihre Gehälter und Ruhegelder verlustig gehen. Die Beamten selbst sollen im letzten Momente wegtransportiert werden und dürfen dann bis zur Beendigung des Krieges nicht zurückkommen: sie wären also von ihren Familien getrennt, wenn diese vorher nicht ebenfalls fortreisen würden. Sie werden nach dem Inneren Russlands, meistens nach Moskau, gebracht, doch ist es ihnen nicht gestattet, sich den westlichen Gouvernements Litauens, Podoliens und Wllyniens niederzulassen. Ausser der Beamten unterliegen der Evakuation auch die Arbeiter bei den Staatsbahnen, weswegen unter ihnen eine aufrührerische Stimmung herrscht; die Arbeiter sind nämlich überzeugt, dass sie in Russland in Not und Elend geraten wurden. Weiter wird die nach dem 14 Juli 1914 angekommene Bevölkerung entfernt, welche vor der fremden Armee flüchtend, in Warschau zusammengeströmt war, das heist die Obdachlosen. Ausserdem werden die Juden weggebracht, wobei die Beobachtung gemacht wurde, dass alle Logik zuwider, hauptsächlich polnische Juden der Evakuation unterliegen, während die sogenannten "Litwaken" (die russische Juden) zurückbleiben. Diese Erscheinung ist vielleicht damit zu erklären, dass hier Bestechungen und Verbindungen mit im Spiele sind. Endlich wird die männliche Bevölkerung vom 18 bis 50 Lebensjahre aus der Stadt entfernt, was damit begründet wird, dass die deutsche und österreichische Armee dieser Männer, sie es dem Heer einverleiben, dass also die russische Regierung sie von dieser Gewalt bewahren will. Gegen diese Evakuation macht sich natürlich die stärkste Opposition geltend. Die Unabhängigkeits-parteien, besonders unter den Arbeitern und der Bauernschaft bereiteten (in den ersten Julitagen) Aufrufe vor mit der Aufforderung, Widerstand zu leisten und sich der zwangsweisen Entführung zu entziehen. (Es wurden auch Aufrufe gegen die Aushebung zum 
Waffendienste im Monat Mai verbreitet). Da in Russland die strikte Ausführung von Verordnung eine Seltenheit und eine Sache des Zufalls ist, so ist es möglich, dass es einer bedeutender Anzahl von Leuten dieser Kathegorie gelinegn wird, sich der Evakuation zu entziehen. Es verreisen die Familien der russischen Offiziere und der russischen Bureaukraten. Die Staatsbank ist verreist.

Hingegen ist unter der polnischen Bevölkerung die Tendenz allgemein an Ort und Stelle zu verbleiben. Das Zentrala Bürgerkomitee beschloss unter keinen Umständen Warschau zu verlassen. Die politische Häftlinge aus Mokotów (die zur Katorga verurteilt sind) sind bereits forttransportiert worden. Hingegen sind in der Zitadelle und am „Pawiak” noch genug Häftlinge vorhanden, die bis nun noch nicht abgeurteilt sind und noch im April während der in den Redaktionen von Volksblättern vorgenommenen Revisionen oder im Zusammenhange mit diesen arrestiert worden waren; diese sind noch bis zum 2 Juli am Platz gewesen.

Über die russischen Niederlagen ist Warschau nicht klar genug informiert, es errät sie aber. Schon die Dimission des Grossfürsten an und für sich bezeugt sie. Einen sehr humoristischen Eindruck machte die Bekanntgabe in den Warschauer Blättern, dass der Erzbischof Eulogius bei seiner Wegreise aus Galizien alle Heiligtümer mitgenommen hat. Die Allgemeinheit weiss ganz gut von den Mangel an Offizieren in der Armee. Es fällt auf, dass Polen den Kosakenregimentern zugeteilt werden.

In der Gegend von Warschau, am linken Weichselufer (bei Żyrardów und Grodzisko) vernichtet Militär auf Bef ehl der Behörden die Ernte auf den Feldern, zerstampft die kartoffelf elder, mäht das Getreide nieder und zertritt es und lässt die Baulichkeiten in Flammen aufgehen. Ebenso geschiecht im Gouvernement Lublin. Überhaupt ist die taktik vom Jahre 1812 wiederaufgestanden, die Taktik vollständigen Verwüstung des Landes vor der Ankunft der fremden Armee. Die Bevölkerung ist wegen dieser Vorgehens sehr niedergeschlagen und erbittert. Im Podolien und in Ukraina ist die Vernichtung des Ernteertrages und die Zerstörung von Hab und Gut noch nicht zur Tatsache geworden, aber es wurde bereits der Bevölkerung angesagt und für den Fall der Annäherung der fremden Armee anbefohlen. Die Bauern, die von der Erwägung ausgehen, dass sie noch immer Zeit haben werden die eigene Habe zu zerstören und zu berauben (in der Gegend von Żmerinka), was die Gutsbesitzer, besonders die Polen in fürchterliche Unruhe versetzt. Manche von ihnen versehen sich insgeheim mit Waffe, um ihr Hab. und Gut verteidigen zu können. Ausserdem droht der polnischen Bevölkerung noch eine andere Gefahr, nämlich seitens der russische Soldaten.

Von der polnischen Gutsbesitzerschaft und Intelligenz Wolhyniens, Podoliens und Ukraina wurde Verband Polnischen Patrioten in Ruthenenlande gegründet. 
Dieser Verband steht in Einvernehmen mit den Unabhängigkeitsorganisationen in Warschau und Königreich Polen, leiht ihnen materielle Unterstützung und hat seine Kreise in Odessa und Charków, von Kiew nicht zu reden, wo die polnische militärische Organisation sehr kräftig, lebensfähig und opferwillig ist.

In Kiew ist zwischen der polnischen Jugend, die der Unabhängigkeitsidee huldigt, einerseits und der ruthenischen Jugend derselben Richtung ein Einvernehmen zustande gekommen, das in einem in zwei Sprachen erschiedenen Aufruf zum Ausdrucke kam.

Seitens der russischen Reaktion, werden Versuche unternommen, gegen die Polen aufzuhetzen, Tumulte und Pogromme hervorzurufen. Im Hauptsitze des ortodoxen Phanatismus, in Poczajew, ist ein Aufruf des Archimandrit Witalis gedruckt worden, der sich "an die Polen des Połocker, Kiewer und Wolhynischen Gouvernements" richtet. Der Auf ruf beginnt mit einer historischen Ausführung folgenden Inhalts:

Die Zyrrill und Methodius bekehrten Polen waren vorerst ortodox, aber nach einigen Jahrhunderten haben ihnen Zbigniew Oleśnicki, später die Jezuiten und König Sigmund den Katholizismus mit Gewalt aufgedrungen. Gegenwärtig ist es blos dem Einfluss ihren Gemahlinnen, ihrer Jungfrauen, überhaupt der Frauen zuzuschreiben, dass sie noch Polen und Katholiken sind. Sie sollten sich besinnen und zum ortodoxen Glauben zurückkehren, denn sobald das russische Volk erfahren wird, dass sie Abtrünnige und Verträter sind, so wurde es in Sorge geraten, für dessen Folgen der Archimandrit nicht bürgen könne.

Natürlich denkt der Autor des Auf rufs gar nicht daran, dass dieser irgendeine Wirkung auf die Polen haben werde, aber er setzt voraus, dass der Aufruf nicht ohne Erfolg von den "russischen Volke" gelesen werden wird.

Es sind auch überall eif rige Bestrebungen am Werke, um gegen die Juden gerichtete Unruhehe hervorzurufen - in Warschau sind sie gänzlich erfolglos. Die Kunde von der Moskauer Kravallen verbreitet die Polizei selbst. Die Polizisten erzählen in den Fabriken ganz umständlich, wie sich die Tumulte abgespielt haben und lassen zum Schluss nebenbei die Warnung fallen, dass man es nicht ebenso machen soll. Die polnische öffentliche Meinung findet die Erklärung der Moskauer Vorfälle darin, dass die Regierung, die den Unwillen des Volkes gegen den Krieg und die Einberufungen zum Waffendienste sicht, in der Angst vor einem elementar anbrechenden Auf ruhr, den gährenden Unwillen lieber selbst gegen die Deutschen, die Kaufleute fremder Staatsangehörigkeit, die Polen ablenkt, um zu verhüten, dass sie sich in regierungsfeindlichen Demonstrationen Lust machen. Die russische revolutionären Parteien sind zwar in emsiger Tätigkeit begriffen, beratschlagten und verhandeln miteinander, laden sogar manchmal auch Polen 
zu ihren Beratungen ein, scheinen aber vorläufig machtlos zu sein. Aufruhr und anarchische Zustände sind warscheinlicher als eine Revolution. In der Armee hat sie das Verhältnis zu den Polen seit der Zeit der Niedelage verschlimmert.

Die Freiwilligenscharen, die seinerzeit vom Nationalkomitee organisiert wurden, werden von den Polen „Weichselkosaken"genannt. Die Werbung für diese Abteilungen hat gänzlich aufgehört. Als ihnen die polnische Kommandosprache genommen wurde, wollten viele aus dem Verbande dieser Freiwilligenabteilungen austreten. General [Edmund] Swidziński zog sich zurück. Er hatte elle seine Unterredungen mit dem General [Mikołaj] Iwanow, alle Versprechungen desselben notiert und als sie nicht erfüllt worden sind, stellte er, mit diesem Material ausgerüstet, fest, dass die Gegenseite den Vertrag aufgelöst hat und reichte seine Dimission ein.

Im Gegensatze zu jenen "Weichselkosken" stehen die polnischen Legionen sogar bei dem russischen Militär wegen ihrer Tapferkeit in hoher Achtung. Es gibt heute keine Partei im Lande (sogar die National-Demokratie und ihren Führer mit eingerechnet) die sich auf dem ritterlichen Ruhm der Legionen nicht was zugute täte und sich feststellte, dass die Legionen ein neues, glanzvolles Geschichtblatt geschaffen haben.

Gegenwärtig wird in Warschau und im Königreich Polen eif rig das Gerücht verbreitet, dass die tapfere Lagionsjugend hintergangen worden sei. Dass Osterreich die Legionäre schlecht behandle, an die aussichtslosesten Punkte dirigiere und schlisslich, dass die Legionäre Chikanen angesetzt sind. Auf Grund solcher Gerüchte entsteht von Zeit zu Zeit die Meinung, die Legionen existieren nicht mehr, sie seien aufgerieben oder aufgelöst. Natürlich finden diese Gerüchte keinen Glauben bei Unabhängigkeitsparteien, die von diesseits der Kamplinie, zwar verspätete, doch stängige und wahrheitsgetraue Informationen erhalten; doch finden sie Anklang beim breiten, keiner Partei angehörigen Publikum, das sich jetzt sehr lebhaft für die Legionen interessiert und mehr von ihnen weisst, als in der legalen Presse zu lesen ist. Unter diesem Publikum hat das Buch „Polnische Kämpfe" (Boje Polskie) grosse Verbreitung, eine Sammlung von Schilderungen der Kämpfe der Legionen, die den in Piotrków erscheinenden „Wiadomości Polskie" entnommen ist.

Załącznik nr 2

Auszug aus dem Berichte eines Mitgliedes des Polnischen Obersten Nationalkomitee über Russland aus Anlass seines Aufenthaltes dortselbst während der Zeit vom 15 bis 20 Mai 1915 
Allgemeine Schlüsse auf Grund der gesammelten Hindrucke

Russland wird unbedingt den Krieg verlieren.

Russland hat sehr gute Soldaten, kann, was Menschenzahl anbelangt, jede Konkurenz aufnehmen, besitzt genug Getreide und Fleisch, leidet jedoch an Mangel von Offizieren, Waffen und Munition. Würden auch die Mängel auf diese oder andere Weise behoben werden, wäre der Soldat noch besser, müsste das heutige Russland, angesichts der vorzüglichen Organisation seines Gegners und der Anpassungsfähigkeit der Deutschen an die Bedürfnisse des Krieges, doch die Campagne verlieren. Je länger die Campagne dauern wird, desto ärger für Russland. Da noch am Anfang recht und schlecht funktionierende Mechanismus hat sich gelockert und wird sich immer mehr lockern. Das heutige Russland ist übehaupt zur Bildung und Erhaltung einer gesunden und brauchbaren Organisation unfähig, insbesondere ist es zur Abstellung der Mängel während des Krieges unfähig. Es unterliegt daher fümich keinem Zweifel, dass Russland den Krieg verlieren werde.

Die eine organisierte planmässige und zielbewusste Revolution in Russland während des Krieges glaube ich nicht.

Der psychologische Moment diesen "nationalen Krieges" spricht gegen die Möglichkeit einer solchen Revolution. Jeder, der gegen die Regierung und gegen die Armee auftritt, wird für einen preussischen Agenten gehalten. Die energischesten Elemente des revolutionären Lagers wurden in die Armee eingereiht. Die Eigentümlichkeiten des heutigen Russlands bringen es mit sich. Dass weder die Regierung, noch die Revolution sich zu einer wirksamen Organisation nicht aufraffen können.

Wie die Regierung, auch wenn sie wollte, die Diebstähle und Korruption in der Bureaukratie nicht entfernen wird, ebenso wird die heutige rissische revolutionäre Organisation sich vor dem Verrate, Provokation und dem Eindringen der Ochrana nicht schützen können.

Es kommen vor und werden erstärkern können unorganisierte, für Russland charakteristische, Hunger und Teuerungsrevolte. Starke Gährungen und Unruhen können nach Niederlagen eintreten.

Nach dem Kriege ist eine besser organisierte, planmässige sich auf die Armee stützende revolutionäre Bewegung möglich. Persönlich glaube ich an den prinzipiellen Erfolg auch dieser Bewegung nicht.

Solange Polen sich unter russischer Vormundschaft befindet, ist für uns gleichgültig, wer in Russland regieren wird. Es werden sich die Metoden des Vorgehens ändern können, der Zweck wird immer derselbe bleiben. 
Einen empfindlichen Stoss können dem heutigen Russland die Zentralmächte durch mutige Aufrollung der polnischen Frage und die Wiederherstellung des polnischen Staates bei gleichzeitiger Verdrängung Russland nach Osten und Nordosten versetzen. Erst nach einer solchen militärischen und politischen Niederlage Russlands wird die Wiedergeburt, die Erneuerung und die Gesundung Russlands eintreten können.

Russland besitzt nur eine einzige, vorzügliche, harmonische und wirksame Organisation - die Organisation der Staatspolitik, besonders der äusseren Politik.

Im Gebiete der Verwaltung und der Organisationstechnik kann noch so ein Chaos, Rechtlosigkeit und Willkür herrschen, jeder Beamte kann ein besonders System, besondere Metode haben und stehlen - handelt es sich daher um Richtlinien der, das innere leben Russlands überschreitender Staatspolitik, so existiert eine ausserordentliche Orgaanisation der russischen Gehirne, die darauf beruht, dass vom Ministerpräsidenten bis zum Bezirksvorsteher, ja sogar bis zum einfachen Schutzmann und Gendarmen jedermann bewusst oder instinktmässig versteht, um was es sich handelt, und was notwendig ist. Man kann 100 oder 1000 Leute bestehen, trotzdem wird sich das allgemeine Bild und Wirkung nicht ändern. Die Organisation der Gehirne umfasst übrigens nicht nur die offiziellen Kreise, sondern auch das ganze Russland.

Ich habe das Gefühl, dass zum Beispiel die polnische Frage heute nur Russland versteht, darin liegt seine Überlegenheit über den Zentralmächten. Jeder Russe versteht dies wenigstens, dass die polnische Frage eine innere Frage Russlands sein soll, und dass nicht zugelassen werden darf, dass die Initiative darüber in nichtrussische Hände käme. Besonders wäre es für Russland peinlich, wenn die polnische Frage zum europäischen Problem werden würde. Wenn man überhaupt die krigsführenden Parteien gegenüberstellt, trägt man den Eindruck davon, dass dieselbe Präzision, welche jede deutsche Technik und Organisation des äusseren Lebens kennzeichnet, in den russischen Politik zu finden ist, während umgekehrt diese Seite bei den Zentalmächten an die Kopf und Hilflosigkeit der russischen Verwaltung erinnert.

Man kann daher voraussehen, dass Russland, nachdem es den Krieg militärisch verlieren wird, politisch den Sieg davontragen werde, wenn die Zentralmächte sich neben den grossen Kriegstaten nicht $\mathrm{zu}$ einer breiten, historischen Geste auf dem Gebiete der Politik nicht aufschwingen werden, von allem durch mutige und klare Aufstellung der polnischen Frage, und wenn sie, nachdem sie sich dazu entschlossen haben, die Metode der halben Mittel, Provisorien und des Oportunismus nicht fallen lassen werden. 
Załącznik nr 3

Auszug aus dem von einem Mitglied des Obersten Polnischen Nationalkomitees verfassten und durch den Präsidenten des OPNK am 26 VI 1915 dem k.u.k. Ministerium des Äussern in Wien unterbreiteten Berichts.

Ich war vom 2 Februar bis 30 Mai 1915 hinter der russischen Frontlinie.

Diese Zeit habe ich hauptsächlich in Warschau zugebracht. Die mittelbar rusophile sogenannte "Koalitions - Orientierung", welche auf die mit Russland verbündeten Mächte Frankreich und England rechnet, hat zu Gunsten der russenfeindlichen fast zu existieren aufgehört.

Das direkte Verständigung und Aussöhnung mit Russland erstrebende Lager hat das sogenannte Nationalkomitee zum Mittelpunkt. Es war jedoch schon beim Ausbruch des Krieges sehr schwach und im Laufe der Ereignisse wurde es durch Sezessionen noch vielfach geschwächt. Heute ist es diskreditiert, abgesondert, jeden Einflusses und jeder Bedeutung vollkommen bar.

Der Einfluss und die Bedeutung der Unabhängigkeitslager ist im steten Wachsen.

Das Oberste Polnische Nationalkomitee und die Polnische Legionen erf reuen sich grosser Popularität. Warschau erwartet dieselben mit höchster Sehnsucht.

Die Stimmung Warschaus und des ganzen Königreich Polen hinter der Frontlinie kann nur als Heishunger, einen eigenen Staat zu besitzen, bezeichnet werden.

Die Stimmung den Zentramächten gegenüber - abwartend. Diese reseve wurzelt hauptsächlich in Befürchten, dass sich die Zentralmächte, nach dem siegreichen Kriege, mit Russland - auf Trümmern der polnischen Sache - wieder aussöhnen könnten.

Die Meinung aller Warschauer politischen Kreise, mit welchen ich als Mitglied und Abgesandter des Obersten Polnischen Natinalkomitees verhandelt habe - stimmt dahin überein, dass die Zentralmächte sowohl Warschau als auch das ganze Königreich Polen für sich leicht gewinnen und eine Elementar-Bewonung gegen Russland hrvorzurufen könnten, wenn Nachfolgendes veranlasst wird:

I. Die polnische Frage müsste durch Verkündigung eines Kaiserlichen Manifestes in Warschau aufgestellt werden, in welchem die Unteilbarkeit des Königreiches Polen und die Errichtung einen polnischen Staates aus den Russland entrissenen Ländern in Verbindung mit Galizien proklamiert wäre. 
II. Der Verkündigung dieses Manifestes in Warschau sollte vorangehen:

1) Die Änderung der bisherigen Taktik gegenüber dem OPNK und seine Tätigkeit, sowie die Anerkennung des OPNK als vorläufig einzigerpolitischer Repräsentanz Polens ${ }^{47}$.

2) Bewilligung zur Veröffentlichung eines Aufrufes des OPNK an die Bevölkerung des Königreiches Polen

3) Die Vereinigung sämmtlicher Truppenteile der Polnischen Legionen in ein einheitliches Ganze auf Terrain des Königreiches Polen, die Ermöglichung der freien Entwicklung ihrer Kräfte durch Freigabe der Anwerbung, die konsquente Festsetzung ihres Charakters als Ausganspunktes der polnischen Wehrmacht und zwar durch Überlassung sämmtlicher Funktionen hinter der Front in Händen des OPNK, sowie des Kommandos an der Front in Händen von Legionsautoritäten.

4) Eine entsprechende Form der Besetzung Warschaus und zwar:

a) es sollte einigen Abgesandten des OPNK eventuell in Begleitung einer Legions-patrouille, die Ankunft in Warschau einige Stunden vor dem eigentlichen Truppeneinmarsch ermöglicht werden, um die öffentliche Meinung, beziehungsweise ihre Führer und Repräsentanten vorzubereiten;

b) den Polnischen Legionen sollte die Bewilligung erteilt werden, an der Spitze beider ${ }^{48}$ verbündeten Armeen in Warschau einzurücken;

c) die Kommendanten der einrückenden Truppen und andere Organe der Zentralmächte sollten sich in allen Angelegenheiten soweit an sich nicht um Verkehrungen rein militärischen Charakters handelt - an jene Personen wenden, welche ihnen von den Abgesandten des OPNK bezeichnet werden; insbesonders müsste man sich in Sachen der Einquartierung von Truppen, Kommanden, und Behörden an das Einquartierungs-bureau wenden, welches von dem Abgesandten des OPNK im Einvernehmen mit angesehenen Bürgern und in Verbindung mit der dortigen geheimen polnischen Militärorganisation in Warschau errichtet wurde, und welches ein Verzeichnis der vorhandenen Kasernen und öf fentlichen Lokale mit der Angabe ihrer betreffenden Dimensionen, ihren Zugestandes und so weiter zur Verfügung halten wird.

${ }^{17}$ Słowo zaznaczone rozstrzelonym pismem i dużymi literami w tekscie dokumentu.

${ }^{18}$ Slowo zaznaczone $w$ tekscie rozstrzelonym drukiem. 
Die Herausgabe des Manifestes ist von grundsätzlicher Bedeutung für die polnische Frage.

Die Vollziehung dessen, was unter II die Absätz I.2, und 3 enthaltet, wurde schon heute die öffentliche Meinung beruhigen und die antirussische Partei, sowie ihre Aktivität stärken. Der Absatz 4, bezweckt die unmittelbare, energische Einwirkung auf die Strasse - auf die Volksmassen, die sofortige Unterbindung der russophilen Einflüsse auf die Massen, die Hebung der Autorität von Repräsentanten der antirussischen Politik, die Stärkung des Vertrauens und der Synpathie, für die einrückenden Truppen. Von hoher Bedeutung ist Punkt 4.c) weil man bei Beschreitung den dort bezeichneten Weges, tags darauf über ganz Warschu verfügen wird, insbesonders aber über die hervorragendsten Vertreter des Hochadels und so genannten Realpolitik, welche heute aus überwiegend opportunistischen Gründen im russophilen Lager sich befindet; wird man aber den entgegengesetzten Weg betreten, nämlich die Beziehungen der verbündeten Armen zu Warschau mit den Russophilen anknüpfen, so wird man wohl bei ihnen Gehorsam für die erlassenen Befehle finden, aber auch nichts nehr; wogegen das ganze antirussische Lager abgestossen und diskreditiert werden wird.

Wenn schon die Rede von den Bedingungen ist, welche die russophilen Strömungen von der Oberfläche des polnischen Lebens verscheuchert sollen, so wäre es nicht ohne Bedeutung, wenn man endlich aufhören würde, auf Warschau und andere polnische Städte aus Flugzeugen, Bomben herabzuwerfen. Während der ganzen Zeit des viermonatlichen Aufenthaltens in Warschau seitens des Schreibers dieser Zeilen, haben die deutschen Bomben den russischen Behörden keinen Schaden ${ }^{49}$ zugefügt, dagegen fielen stets Privatpersonen als Opfer dieser Bombenwürfe, was zur Folge hatte, dass die Bevölkerung über die deutschen Flieger und Truppen fluchte. Möchtem diese Flieger statt Bomben etwa Nachrichten vom Kriegsschauplatz, nach denen das Volk dürstet, möchten sie insbesondere Nachrichten über die Polnischen Legionen und die Publikationen des OPNK herabwerfen, so würden sie von der Bevölkerung sehnsuchts erwartet werden, sie würden ihre Stimmung glänzend beeinflussen und ihre wärmsten Sympathien gewinnen.

"9 Slowa zaznaczone $w$ tekscie rozstrzelonym drukiem. 
Załącznik nr 4.

Die Verhaftung des Oberleutnants der Legionen Gorzechowski.

Der Erkundungsoffizier der I Brigade Jan Gorzechowski erhielt den Befehl sich in Aufklärungsangelegenheiten von Urzędów nach den entfernten gelegenen Bezirken des Gouvernements Lublin zu begeben. Er empfing eine Ermächtigung vom Kommando der I Brigade „zur unbehinderten Durchf ahrt und Aufenthalt in allen vom k.u.k. Heere besetzten Gebieten des Gouvernements Lublin" (8 VII), die durch das k.u.k. Kommando des VIII Corps („kann im Bereiche des VIII Corps unbehindert passieren" - Hundemann Oberst 9 VII).

Mit diesem Befehle ritt er am 18 VII in das Lublinergebiet, die nötigen Informationen sammelnd, über die er an geeigneter Stelle einen Raport erstattete. Er war vom Cavallerie - Wachmaister Kozłowski begleitet. Wohin immer er ritt, überall meldeten sich beim Anblicke seiner Uniferm die Bauern und die Jugend und fragten ihm über die Polnischen Legionen aus und wie sie zu ihnen gelangen könnten. Unter der Jugend war die Erwartung der Legionen allgemein, den in jenen Gegenden entwickeltten sich geheime militäridche Organisationen, die Piłsudski noch vor dem Kriege grüdete un die in den letzten Monaten sehr intensiv exeszirten sich also zum Kampfe mit Russland in den Reihen der Polnischen Legionen vorbereitend. Solchen Organisationen gibt es in Lubliner Gouvernement 37. Gorzechowski stiess auf solche Verbindungen in Zwierzyniec, Szczebrzeszyn und Zamość. Die Organisation in Zwierzyniec entsendete sofort nach dem Abgange der Russen einen Delegierten nach Krakau, damit er erfahre, wo und auf welche Weise man in die Legionen eintreten könnte. Unverzüglich nach seinem Eintreffen wurde Gorzechowski vom Kommissär der Polnischen Konfederation empfangen und die wenigen Personen, die sich alsbald versammelten, erlegten sof ort 150 Rubel für die Zwecke der Legionen. Die Organisation in Zwierzyniec besitzt ebenso wie auch alle anderen für ihre Mitglieder Waffen, Munition und entsprechende Sanitäre Einrichtungen.

Oberleutnant Gorzechowski, der ohne Bewilligung der k.u.k. Behörden die Mitglieder der militärischen Organisation den Legionen nicht zuführen wollte, begab sich nach Erlangung einer entsprechenden Bewilligung nach Zamość, wobei er auf dem Wege nach Szczebrzeszyn Anmeldungen von einer grösseren Anzahl Mitgliedern der militärischen Organisation erhielt - dasselbe auch in Zamość.

In Zamość, wo sich der Sitz des Hauptkommandos [General August] Mackensens befindet, meldete sich Oberleutnant Gorzechowski auf den Rat 
des österreichischen Zivil-kommissärs bei dem Deutschen Etappenkommando (24 VII) und stellte dem Oberstleutnant die ganze Angelegenheit dar. Dieser von der antirussischen Stimmung der Jugend entzückt, sprach die Hoffnung aus, man werde auf dem ganzen von der Armee Mackensen besetzten Gebiete Freiwillige einbringen können, obgleich die Deutschen Militärbehörden den Legionen nicht geneigt sind. Indessen wendete er sich wegen einer formellen Bewilligung an das Kommando Mackensem. Beim der Unterredung war der „Nachrichtenoffizier"des österreichischen Generalstabes Hauptmann Braune anwesend, der der Information Oberleutnants Gorzechowski gegenüber, die Bevölkerung sei den Legionen so geneigt, dass die Bauern auf die Erzählung von ihnen und auf dem Anblick polnischer Soldaten hin weinten, seine Zweif el über die Stimmung der Bevölkerung ausdrückte und diese damit motivirte, dass er keine Leute zu Erkundungen bekommen könne. Hauptmann Braune spricht russisch versteht aber nicht polnisch, wie überhaupt die dortigen Offiziere (die polnische Sprache nicht verstehen und der Gendarmeriedienst ausschlisslich in Händen von Deutschen und Ungarn ruht), ungläubig empfing er die Mitteilung von der Anmeldung Freiwilliger in die Legionen und erklärte, er werde sich in dieser Sache an das AOK wenden. Hauptmann Braune begab sich mit dem adiutanten des Etappenkommandanten in das Kommando Mackensens und beauftragte Oberleutnant Gorzechowski sich am folgenden Tage wegen Antwort zu melden. Oberleutnant Gorzechowski liess in Zamość den Wachmaister Kozłowski zur Empfangnahme der Antwort zurück und ritt selbst nach Zwierzyniec.

Am 25 VII meldete sich Wachmaeister Kozłowski bei Hauptmann Braune, der ihm mitteilte: "Ich erhielt eine ausführliche Antwort vom AOK; es ist aber die Anwesenheit Oberleutnant Gorzechowski notwendig um die Grenzen zu besprechen, in denen er die Anwerbung durchführen kann; darauf beauftragte er dem Polizeikommissär Batorski mittelst Automobil nach Zwierzyniec um Oberleutnant Gorzechowski zu fahren". Unterwegs nach Szczebrzeszyn begegnete Kommissär Batorski dem Oberleutnant Gorzechowski und erklärte ihm: „Die Antwort des AOK ist günstig, es müssen nur Details besprochen werden". Beide kehrten um, worauf unterwegs in Gegenwart des Kommissärs Batorski sich Burschen an den Oberleutnant Gorzechowski mit der Frage wendeten, wie er sie zu den Legionen kommen könnten. Als Oberleutnant Gorzechowski am Abende in Zamość eintraf, sagte ihm Hauptmann Braune: „Ich bin jetzt sehr bescheftigt, ich bitte Morgen um $8.30 \mathrm{zu}$ kommen um die Marschrute genau zu besprechen, denn die Bewilligung des AOK ist ausführlich.

Am 26 VII um 8.30 früh meldet sich Oberleutnant Gorzechowski bei Hauptmann Braune zugleich mit dem Wachmeister und wird mit dem Befehle 
begrüsst: Die Herren werden ihre Säbel und Revolver übergeben - auf Befehl des AOK ist Oberleutnant Gorzechowski verhaftet und wird dem K.u.k. Kommando der Legionen in Piotrków übergeben werden. Die Bitten des Oberleutnants Gorzechowski man möge ihn gestatten von Zwierzyniec die Pferde, die Ordonanz, sein Geld und seine Bagage zu holen, wurde nicht berücksichtigt. Auch dem Wachmeister Kozłowski, dem der Verhaftsbefehl nicht betraf, wurde es nicht gestattet zur Brigade zurückzukehren. Beide wurden mittelst Automobil nach Bipsk bei Bełżec in Galizien an das dortige österreichische EtappengruppenKommando bei der deutschen XI Armee abgeführt, von dort aber brachte sie der Train Oberstleutnant Saborsky mit dem Gendarmerie Wachmeister über Jarosław, Krakau, Szczakowa nach Piotrków unter der stärkteste Aufsicht, wobei dem Oberleutnant Gorzechowski nicht gestattet wurde mit irgend Jemandem zu sprechen. (Auf der Eisenbahnstation in Rzeszów wollte Oberleutnant Gorzechowski durch den daselbst getroffenen Leutnant Sulistrowski dem Kommando der I Brigade von dem Vorfalle Kenntniss geben, was Oberleutnant Saborsky nicht gestattete), Die ostentative Überführung der verhafteten Legionäre hat in ganzen Lubliner Gouvernement den schlechsten Eindruck gemacht, es erregte auch Sensation auf dem ganzen Wege nach Piotrków. In Piotrków wurden die Verhafteten den k.u.k. Behörden übergeben, diese aber überführten sie an das Platzkommando der Legionen, wo die Verhafteten die weiteren Verfügungen seitens des ku.k. Gruppenkommando für die Polnische Legionen erwarten. (Oberst Grzesicki amtirt heute - 28 VII - krankenheitshalben nicht).

Es muss bemerkt werden, das Oberleutnant Gorzechowski den Kommanden in Zamość wie am deutlichsten erklärte, dass er sich mit der Anwerbung nicht befasse, da er hiezu keine Bewilligung habe, er wolle nur das fertige Material der Mitglieder der militärischen Organisation, die schon lange das Kommando Piłsudskis anerkennen, zu den Legionen dirigieren.

Wenn den Mitgliedern der militärischen Organisation unmöglich gemacht wird in die reihen der Legionen einzutreten, so könnte das eine politische Katastrophe in Lubliner Gouvernement hervorrufen. Die dortige Bevölkerung ist trotz der fürchterlichen Opfer, zu denen es von den Deutschen Truppen gezwungen wird, der Armee der Verbündeten sehr geneigt. Die grosse politische Aufklärung im Lubliner Gouvernement befielt es indessen der Bevölkerung den Feind einzig in den Russen zu sehen, in der Überzuegung, dass sie in den verbündeten Armeen eunen Verbündeten hat. Deshalb kann sie es auch und wird es niemals verstehen, warum es Freiwilligen nicht gestattet ist in den Reihen der Legionen gegen Russland zu kämpfen. Diese Entäuschung kann die schlimmsste Verfassung hervorrufen, die Bevölkerung gegen die Verbündeten Armeen 
feindlich stimmen und die Mitglieder der militärischen Organisationen sogar zur Akten der Verzweiflung drängen Es muss damit gerechnet werden, dass diese Organisationen Waffen besitzen, mit denen sie es vortreulich verstanden vor russischen Behörden als Verschwörer aufzutreten. Die Verstimmung im Lubliner Gouvernemet könnte sich auch der ganzen Bevölkerung des Königreiches Polen jenseits der kampflinie mitteilen und von schweren Folgen begleitet sein.

Piotrków, am 29 VII 1915.

Oryginal memoriału i odpisy czterech załączników, maszynopisy.

Haus.-1 lof und Staatsarchiv, Krieg P.A.I., karton 900, folio 147-165.

\section{Dokument nr 16}

1915 sier pień 14, [Cieszyn].- Pismo arcyksięcia Fryderyka do austro-węgierskiego ministra spraw zagranicznych Stefana Buriana z supozycja dot yczqcą ewentualnego rozwiazania Legionów Polskich.

An Seine Exzellenz Freiherrn von Burian k.u.k. Minister des Äusseren in Wien

In dem in den Tagesblättern von 11 dieses Monats veröffentlichten Aufrufe $\mathrm{e}^{50}$ hat das Oberste Polnische Nationalkomitee ein Programm entwickelt, durch welches ohne jedwede Rücksichtsnahme auf die Interessen und den Willen der Monarchie, sowie auf den Standpunkt der verantwortlichen Faktoren, über die von den verbündeten Heeren eroberten Gebiete frei forfügt wird und bezüglich der künftigen Gestaltung der polnischen Länder seitens einer Gruppe unverantwortlicher Politiker ganz bestimmte Richtlinien vor der Öfentlichkeit festgelegt werden, ohne dass diesen Ideen die Genehmigung der massgebenden Stellen zuteil geworden wäre.

Bisher ist das Armeeoberkommando - aus militärischen und noch mehr aus politischen Gründen - der vom OPNK ins Leben gerufene Legionsidee wolwollend gegenübergestanden und hat diesen Formationen, sowie der Militärsektion, cji.

${ }^{\text {so }}$ Wzmianka dotyczy tekstu zawartego w załączniku $\mathrm{nr} 3$ do dokumentu $\mathrm{nr} 14$ niniejszej publika- 
seine Unterstiitzung - und oft auch seine Nachsicht - in weitgehender Weise zugewendet.

In Anbetracht der inopprtunen, befremdenden und mit den vom AOK bei der Legionsbildung vervolgten nicht in Einklang zu bringenden Enuntiation des OPNK, tritt an das AOK die Frage heran, ob es auf dem bisher eingeschlagenen Wege verbleiben soll, oder, ob dem Legionswesen - zumal angesichts der erfolgten Vertreibung der Russen aus Polen - in absehbarer Zeit ein Ende zu bereiten ist, wobei die Auflösung der Militärsektion, als der hauptsächlichen politischen Agitationsstelle, in erster Linie in Betracht käme.

Im Hinblick auf den eminent politischen Charakter dieser Angelegenheit glaubt jedoch das AOK diesbezüglich keine Entscheidung treffen sollen, ohne vorher das Einvernehmen mit Euer Exzellenz gepflogen und von Euer Exzellenz Standpunkt Kenntnis erlangt zu haben.

Das AOK beehrt sich daher, Euer Exzellenz um eine gefällige Rückäusserung im Gegenstande zu ersuchen.

[podpisał arcyksiążę] Fryderyk

Oryginal, maszynopis.

Haus.-Hof und Staatsarchiv, Krieg P.A.I., karton 900, folio 82.

\section{Dokument nr 17}

1915 sierpień 19, Miejsce wystawienia dokumentu nieznane.- Raport przedstawiciela austro-węgierskiego Ministerstwa Spraw Zagranicznych przy Naczelnej Komendzie Etapów o wydaleniu brygadiera Józefa Piłsudskiego z Warszawy.

Der, wie es scheint, nicht ungefährlich erkrankte Brigadier Piłsudski traf vorgestern, begleitet von einigen Legionsoffizieren in Warschau ein. Bald nach seiner Ankunft, welche schnell in der Stadt bekannt worden war, erschien ein ziemlich zahlreicher Zug von Jungen Leuten vor den Fenstern seines Hotels, ihm eine Ovation darzubringen. Während die Sympathienkundgebung im vollen Gange war, schritt eine deutsche Militärabteilung ein, welche mit Brachialgewalt die Demonstranten auseinander sprengte, und eine halbe Stunde später erhielt der General den schriftlichen Befehl, die Stadt Warschau, wenn ich nicht irre innerhalb zwei Stunden, zu verlassen. Wenn auch die unangemeldete Herkunft des Generals Piłsudski inopporun gewesen sein mag und die Scheu der Deutschen vor 
Strassenauläufen begreiflich ist, so lässt sich wohl nicht leugnen, dass die schroffe Massregelung eines Generals unserer Armee überflüssig war und ausserdem, da es sich um einen in weiten Kreisen so volkstümlichen Mann wie Pilsudski handelt, unserem Prestige keinsewegs zuträglich. Dass der Vorfall in kürzer Zeit stadtbekannt wude, braucht wohl kaum erst gesagt zu werden und dass an das Factum, dass den polnischen Volksführer seine Eigenschaft als k.u.k. General nicht vor einer so drastischen Massregelung schützen konnte, Commentare über die Übegriffe der Deutschen uns gegenüber geknüpft wurden, ist für einen Kenner der hiesigen Verhältnisse ohne weiteres klar.

Ich erhielt die erste Mitteilung vom Vorfalle durch den k.u.k. Verbindungsoffizier bei der 9 Armee, Major von Remiz, welcher das Vorgehen General Piłsudski gegenüber entscheiden ungehörig gefunden, und noch bevor er $\mathrm{zu}$ mir kam, an zuständiger deutscher militärischer Stelle die Sache zur Sprache gebracht hat. Zu diesem Zeitpunkte hatte der General schon dem Befehl Folge geleistet und Warschau verlassen. Ich meinerseits glaubte mit Hinblick auf meine zunächs twesentlich informative Aufgabe in der polnischen Hauptstadt und in Berücksichtigung der bereits erfolgten Demarsche des Majors von Remiz von irgendwelchen Schritten in der Agelegenheit absehen zu sollen.

Auch in Übrigen ist das Verhalten der deutschen Behörden gegenüber den Legionen kein sonderlich wohlwollendes. Speziell die ganz unter offziöser Inspiration segelnde deutsche "Warschauer Zeitung" verabsäumt es nicht alle feindlichen Stimmen der russophilen Presse gegen Teilnahme an den Legionen ihren Lesern fast tagtäglich vorzusetzen. Auch dem k.u.k. Verbindungsosffizier gegenüber ist $\mathrm{zu}$ wiederholtenmalen der Wunsch laut geworden, dass die Warschau befindlichen Legionäre möglichst bald die Stadt verlassen möchten. Für die Anwerbung von neuen Legionären wurde deutscherseits nur eine Frist von drei Wochen concediert, angefassen von 21 leitendes Monats; nach Ablauf dieses Termines hat jede Werbung hier aufzuhören und sämtliche Legionäre müssen die Stadt verlassen. Schon diese dreiwöchentliche Werbefristist deutscherseits ungern zugestanden worden.

Nunmehr hat aber die Anwerbungsfrage, wie mir der Chef des Kriegsdepartements der Legionen, Oberstleutnant von Sikorski, heute mitteilte, noch eine besonders ungünstige Wendung genommen. Teils infolge der Missstimmung der Warschauer Bevölkerung gegen das deutsche Regime (vergleich meinen ergebensten Bericht von heutigen Tage lit. D), teils infolge des Eindruckes der Massregelung Piłsudskis verspricht die Werbung hier recht geringe Resultate zu zeitigen, was natürlich die Legionensache sehr kompromittieren würde. Abgesehen nämlich von den moskalophilen und opportunistischen Parteien, 
welche selbsteverständlich a limine gegen die Legionansbildung gewesen sind, haben nunmehr auch die verschiedenen Unabhängigkeitsf ractionen erklärt, nur dann für Anwerbung sich aussprachen zu wollen, wenn eine programmatische Erklärung der Zentralmächte über die Unteilbarkeit und Sälbstständigkeit des Königreiches, dessen Angliederung an die Monarchie sie zustimmen würden, vorher erfolgt wäre. Alle antirussische Gruppen scheinen auf diesem Standpunkte zu stehen und es ist das Losungwort ausgegeben worden: „Bevor man die Legionenbildung gutheisse, müsse man wissen, wofür sich eigentlich die Legionäre schlagen werden. Das Land habe zu grosse Opfer an Gut und Blut bringen müssen, um noch mehr junge Leute aufs Ungewisse hin in den Tod zu schicken".

Oberstleutnant von Sikorski, der ein kluger Mann zu sein scheint, sieht wohl ein, dass eine derartige Ennuntiation der Zentralmächte kaum zu erlangen sein wird, und er befindet sich deshalb in keiner kleinen Verlegenheit. Er trägt sich jetzt mit dem Gedanken, die ganze Werbung auf später hinauszuschieben, damit jetzt kein offenkundiges Fiasko entstehe. Inzwischen hofft er, werden Mitglieder des Nationalkomitees herkommen und durch ihre Einwirkung auf die antirussischen Parteien deren Widerstand gegen die bedingungslose Legionswerbung beseitigen, worauf dann die Anwerbetätigkeit mit Ansicht auf Erfolg eröffnet werden könnte. $\mathrm{Ob}$ allerdings die deutschen Militärbehörden in Warschau in eine Verschiebung der Erwerbungsperiode einwilligen werden, scheint mir noch gar nicht ausgemacht zu sein.

Der k.u.k.Legationsrat: L.Andrian

Oryginal, maszynopis.

Haus.-Hor und Staatsarchiv, Krieg P.A.I., karton 900, folio 102 a -102 b. 


\section{Dokument nr 18}

1915 sier pień 22, Cieszyn.-Pismo przedstawiciela austro-węgierskiego Ministerstwa Spraw Zagranicznych przy AOK Wiesnera do ministra Stefana Buriana z uwagami dot yczącymi raportów Stefana Ugrona i pisma Stanistawa Michałowskiego.

\section{Hochgeehrter Herr Minister}

Im Beantwortung Ihrer gütigen Mitteilungen vom 15 dieses Monats beehre ich mich Ihnen vorerst mitzuteilen, dass ich einen Auszug aus der Aufzeichnung über Ihr Gespräch mit Herrn Ostrowski dem Armeeoberkommando übergeben habe. Betreffend Piłsudski bin ich in der Lage zu berichten, dass er, wie ein Oberstbrigadier des Heeres, vor nicht langer Zeit durch Verleihung des Eisernen Kronenordens mit der Kriegsdekoration ausgezeichnet wurde. Dass dies in polnischen Kreisen nicht bekannt sein solte, würde mich wundern.

Die Eingabe des Herrn von Downarowicz sammt 4 Beilagen erlaube ich mir in der Anlage zurücksenden und zu der gelinde gesagt, einseitigen Darstellung der Verhaftung des Legions Oberleutnants Gorzechowski und zu den daran azuknüpfenden Rekriminationen auf Grund gepflogener Nachfrage und Einsichtnahme in die betreffenden Akten Nachstehendes auszuführen.

Wie der Militärsektion des Obersten Polnischen National Komitees dem Legionskommando und den Legionsoffizieren bekannt sein muss, und all den sonstigen Vielen, die in Legionsachen mitreden, wenigstens bekannt sein sollte, ist es vorerst allen Polen, auch in Russisch - Polen, gestattet, in die Legion einzutreten. Es ist also ganz falsch, wenn in der betreffenden Schilderung behauptet wird, es sei den Mitgliedern der in Russisch-Polen bestehenden Organisationen nunmöglich gemacht in die Reihen der Legionen einzutreten". Bekannt ist diesen Kreisen weiters, dass es zwei Zonen der besetzten Gebietes gibt, eine in der die Werbung freigegeben und eine, in der sie, wiel noch unkontrollierbar, berboten ist, nach den gesammelten Erfahrungen eine sehr weise Massregel des Armeeoberkommandos. Dass das Gebiet östlich der Weichsel noch zur Verbotszone gehört ist ebenso bekannt als selbstverständlich.

Oberstleutnant Gorzechowski, der mit einerbestimmten Kundschafteraufgabe entsendet worden war, hat diese Mission - wie aus der Darstellung übrigens ersichtlich ist zur Entfaltung einer ihm keineswegs obliegenden Werbetätigkeit im Verbotsgebiete ganz bewusst missbraucht und wurde deshalb über Weisung des Armeeoberkommandos nicht blos verhaftet, sondern in der Folge auch aus der Legionen entlassen. 
Inwieweit sich dieses Dinstesvergehen mit der von Herrn von Dovnarowicz garantierten Korrektheit und dem Takte dieses Legionsoffiziers vertragen, will ich nichtuntersuchen, muss es aber als unzulässig und zu energischen Widerspruche herausfordernd bezeichnen, dass dieser Fall zur Exemplifizierung missgünstigen Verhaltens des Armeeoberkommandos gegenüber der Legionswerbung herangezogen wird. Wenn die Militärsektion auch im verbotenen Gebiete werben will, soll sie die (so notwendige) Verbotszonenanordnung bekämpfen, aber nicht unter Verschweigung der wahren Sachlage Übertretungen dieser Vorschrift als ganz erlaubte Handlungen hinstellen und den wegen Verletzung dieser Anordnungen Bestraften als Märtyrer präsentieren.

Wen Sie, HOCHGEEHRTER HERR MINISTER, meine zwei Berichte über die seitens der Militärsektion des Obersten Polnischen National Komitees beobachtete Haltung in der Werbefrage Berücksichtigen, werden Sie zugeben, dass die strenge Behandlung Gorzechowskis vollauf gerechtfertigt war. Falls Herr Gesandter die Absicht haben, Herrn von Downarowicz über diesen Fall aufzuklären - was ich unvorgreiflicherweise für höchst opporun halten würde - wäre es vielleicht gut, ihm die Sünden der Militärsektion auf dem Werbegebiete vorzuhalten und beizufügen - was ich bei voller Kenntnis der Aktenlage mit voller Beruhigung sage, und wofür ich die Verantwortung gerne übernehme, dass das Armeeoberkommando im Rahmen der hinausgegebenen Vorschriften die Werbung für die Legion nicht beeintächtigt. Den unleugbar geringen Zulauf zur Legion aus russisch-polnischen Kreisen, auf den ich schon einmal hingewiesen habe, einer hemmenden Einflussnahme des Armeeoberkommandos in die Schuhe zu schieben, ist ebenso bequem als ungerecht. Meines Erachtens haben wir kein Interesse daran die Legende von der durch die Schuld des Armeoberkommandos verdorrenden Legion fortwuchern $\mathrm{zu}$ lassen, sondern allen Grund, dieses, als Agitationsmittel gegen uns verwertete Märchen energisch zu zerstören.

Wenn es Herrn Piłsudski genehm wäre seine polnische militärische Organisation zu den Fahnen der Legion zu rufen, dann bedürfte es hiezu nur eines Winkes seinerseits und keiner Werber. Wie ich mir zu melden erlaubt habe, hat er es aber expressis verbis abgelehnt, diese Organisation zu mobilisieren, bevor nicht "seine Bedingungen" erfüllt sind. Jetzt aber den „Gracchus de seditione querens $z u$ spielen und $z u$ tun, als ob das Armeeoberkommando es hindern würde, dass die Organisation zu den Waffen greift, halte ich, soweit mein Urteil reicht, für eine Zumutung, welche vollen Einblick in die selbssüchtigen, intriganten Methoden der Piłsudskis und Genossen gewährt - von denen wir in letzter Zeit manche unerfreuliche Probe erhalten haben. 
Ihrem Briefe vom 7 Juli 1915 habe ich entnommen, dass Sie meinen gewiss scharfen Urteile in diesen Fragen nicht bestimmen. Ich bekenne offen, dass ich ein ungläubiger Tomas geblieben bin und in der Militärsektion - wenigstens in ihrer jetzigen Gestalt - auch weiterhin eine grosse Gefahr erblicke. Ich kann es daher auch nicht unterlassen, auf die unerhörte Unverschämtheit hinzuweisen, welche darin liegt, wenn uns in dem vorliegenden Mémoire angedeutet wird, dass die Piłsudskischen Organisationen Waffen besitzen und durch unser Verhalten „sogar zu Akten der Verzweiflung" gedrängt werden könnten.

Ohne dass Jemand diesen Verschvörern etwas getan hätte, wagt man es uns mit ihrer Revolution gegen uns zu drohen ? Wenn diese Leute aufstünden, täten sie es ja nur weil Pilsudski sie riefe.

Denken Sie nicht, Herr Minister, dass ich Gespenster sehe. Ich glaube verläufig nicht an diese Revolution, obwohl sie mir unter gewissen Bedingungen nicht ausgeschlossen schiene. Aber in der ganzen erpresserischen Kühnheit dieser Drohungen erblicke ich eine solche Gefahr, dass es mir ratsam erscheint die Piłsudskis und tutti quanti samt der gepriesenen Legion - mit Geld und Ehren reich bedeckt - baldigst kalt zu stellen. Jaworskische Pronunciamentos die vielleicht demnächst unter den Druck Piłsudskischer Revolutionsandrohungen gestellt werden, können wir nicht brauchen. Was wir brauchen, ist jetzt ein offenes Wort an die Polen und eine energisch zugreifende Hand, welche diese radikalen Führer beiseite schiebt.

Ich werde Gelegenheit haben, über diese Dinge in den nächsten Tagen mit Ihnen zu sprechen und schliesse daher diese Ausführungen, die allerdings, wie ich fürchte, nicht Ihre Zustimmung finden werden.

Mit dem Ausdrücke der ausgezeichnetsten Verehrung und Hochachtung bin ich, Hochgeehrter Herr Minister Ihr ergebenster Wiesner

Oryginal, maszynopis.

Haus.-H lof und Staatsarchiv, Krieg P.A.I., karton 900, folio 133-136. 


\section{Dokument nr 19}

1915 sierpień 24, Warszawa.- Raport przedstawiciela austro-węgierskiego Ministerstwa Spraw Zagranicznych Leopolda Andriana dla ministra Stefana Buriana o negatywnym stanowisku polskich niepodleglosciowych ugrupowan politycznych przeciw rozbudowie Legionów Polskich i przeciw austro-polskiemu rozwiqzaniu politycznemu sprawy polskiej.

An Seine Exzellenz den Herrn Minister des k.u.k. Hauses und Äussern Stephan Baron Burian von Rajecz.

Der Vorstand des Kriegsdepartements der Legionen Oberstleutnannt von Sikorski hat mir gestern neuerdings über seine äusserst missliche Situation geklagt. Wie seinerzeit erwähnt, gestanden ihm die deutschen Militärbehörden, welche die Legionen keineswegs mit einem liebevollen Auge betrachten, nur eine dreiwöchige Werbef rist für Warschau zu. Nun aber ist er in der peinlichen Lage nicht mit der Werbung beginnen zu können, weil die Anhänger der Unabhängigkeitsparteien, welche noch vor kurzem die eigentlichen, wenn nicht die eizigen Allierten unseres Obersten Polnischen Nationalkomitees in Congress Pollen waren, drohen, durch energischeste Propagandtätekigkeit, ja durch Strassentumulte die Werbetätigkeit für die "österreichischen" Legionen zu jähem Abschluss zu bringen. Aus meiner bisherigen Warschauer Berichterstattung und zuletzt aus meinem heutigen ergebensten Berichte lit.A ist es Euer Exzellenz bekannt, dass nicht zum geringsten Teile die zweideutige Politik des dermaligen hiesigen deutschen Spiritus rector Geheimrat [Georg] Cleinow an diesen Abrücken der früheren "antirussischen" Parteien von uns Schuld trägt. Aber auch ein persönliches Moment ist dazugekommen, die von mir seinerzeit erwähnte Ausweisung des Brigadiers Pilssudski aus Warschau durch die hiesigen deutschen Militärbehörden. Die ganzen linksstehenden Parteien sind auf Pilsudski eingeschworen, der jetzt krank und verbittert auf dem Land in der Nähe von Warschau bettlägerig ist. Seine hiesigen Anhänger geben das Schlagwort aus, dass der General durch die ihm zuteil gewordene Behandlung desillusioniert, selbst nicht mehr an den Nutzen von Legionen im Verbande der österreisch-ungarischen Armee, für die Zwecke der polnischen Nation glaubt. Oberstleutnant Sikorski hat ihn aufgesucht und in einer vielstündigen Unterredung den Versuch gemacht, von Piłsudski einen Widerruf der ihm imputierten Äusserung zu erlangen. Der General aber, welcher tatsächlich über die eben erlittene Unbill und wegen anderer Vorfälle der letzten 
Monate äusserst verstimmt $\mathrm{zu}$ scheint, soll sich hinter die Formel verschanzt haben, dass er nichts erklärt habe und nichts zu widerrufen brauche.

Vom Standpunkte der politischen Interessen der Österrechisch-Ungarischen Monarchie kann ich diesen ganzen Zwischenfall nur lebhaft bedauern, denn dass rein militärisch gesprochen, die Vermehrung oder der Wegfall der Legionen nicht von grosser Bedeutung sein mag, will ich gerne glauben. Die Legionen repräsentieren aber das polnische Element, welches vom Anfang des Krieges an und auch zu einer Zeit, als es um unsere Sache weniger günstig stand, für Osterreich-Ungarn geblutet und die polniesche Sache mit der österreichischungarischen identifiziert hat. Ob es zweckmässig war, Legionen zu bilden, möchte ich dahingestellt sein lassen. Unumstösslich erscheint mir die Notwendigkeit, dass wir die polnische Frage nur durch tätige Mitwirkung wenigstens eines Teiles des Polentums in unseren Sinne lösen werden, sowie dass es schon wegen des moralischen Effektes auf die ganze polnische Öfentlichkeit unbedingt notwendigt ist die jetzt als „zu österreichisch” verfolgte Fraction, welche zu einer Zeit mit uns ging, als fast das ganze Königreich Polen für Russland war und unsere Antilegionsparteien die berühmte abwartende Haltung beobachten, contre vent et marée zu unterstützen. Ich habe deshalb auch seit meiner Anwesenheit hier in unausfälliger Weise alle meine Verbindungen dahin ausgenützt, um dem Oberstleutnant Sikorski seine schwierige Stellung auch den deutschen Behörden gegenüber möglichst zu erleichtern. Was die Frage des Generals Piłsudski betrifft, bin ich allerdings machtlos. Vielleicht wäre es der hohen Einwirkung Eurer Exzellenz möglich, durch Besprechung mit den kompetenten obersten militärischen Faktoren irgendseine Auszeichnung für den so überaus volkstümlichen Legionführer zu erwirken, dessen Verlust für die austropolnische Sache sich gewiss für uns politisch unangenehm fühlbar machen würde.

Über die von den Deutschen geduldete direkt antiösterreichische Sprache der früheren russophilen Warschauer Presse habe ich Eurer Exzellenz früher Bericht zu erstatten mir erlaubt. Eine Probe der seit der Abschwenkung der linksstehenden Parteien und der Affaire Piłsudski gleichgef alls gegen uns orientierrten Sprache der uns vormals ganz ergbenen grossen Zeitung "Goniec" erlaube ich mir im Anbuge beizulegen. Euer Exzellenz wollen gütigst entschuldigen, dass ich den gegen die Reise des Doktor Leo nach Warschau gerichteten, gegen die Person dieses Politikers höchst gahässigen Artikel aus mangel an Beamten im Original und nicht in Übersetzung beilege. 
Załącznik.

Chicanen der k.u.k. Organe in Kongress Polen, welche die rationelle Werbung in die Legionen verhindern.

Die Tatsache, dass die Bevölkerung des Königreiche Polens sich den Legionen gegenüber reserviert verhält, ist nicht geringen Masse dem Verhalten der k.u.k. Behörden dem Legionen und der Bevölkerung gegenüber zuzuschreiben. Das Vorgehen der Behörden macht dem Ansehen einer zielbewussten und systematischen Aktion gegen die nationalen Rechte und Aspirationen der polnischen Nation. Der anfängliche Entusiasmus für Österreisch hat sich stark abgekühlt nachdem Tatsachen bekannt wurden, welche von Voreingenommenheit und Geringschätzung der Legionen durch die Behörden zeigen. Durch Missgriffe einzelner Organe werden gewiss die besten Intentionen der k.u.k. Regierung antstellt und das Wachsen der Bevölkerung gefördert. Nachstehend wollen wir konkrete Tatsache anführen.

Die Gründungsurkunde der Legionen betrachtete dieselben als ein aus der Geselschaft, deren politischer Represntant das Oberste National Komitee ist, herrvorgegangenes Freiwilligenkokorps; das Militärdepartement des Obersten National Komitees war die einzige Institution, welche zur Durchführung der Werbung für die Legionen besorgt war. Anfänglich wurden dieser, fasst auschliesslich auf galizischen Boden betriebener Werbung keine Schwierigkeiten bereitet. Dank dem riesigen Entusiasmus der polnischen Geselschaft in Galizien wurden in kurzer Zeit zwei Infanterieregimenter, entsprechende Cavallerie und Artillerieabteilungen gebildet und das bereit kämpfende erste Regiment ergänzt. Ausserdem wurde ein ganzer Komplex von Einrichtungen und Institutionen hinter der Front geschaffen. Aus erklärlichen Gründen wurde die Werbung unter österreichischen Staatsbürgern verboten. Nach dem Vormarsch der verbündeten Armeen wurde das Militärdepatement des Obersten Nationalkomitees nach Russisch-Polen verlegt und die Werbetätigkeit lediglich auf den Okkupationgebiete bewilligte.

Nun wurden dieser Werbetätigkeit von seiten einzelner Militärkommandanten und Verwaltungsorgane, sowie von seiten der Zentralbehörden (AOK) Schwierigkeiten in den Weg gelegt. Ist dass Nichtzulassen der Werbetätigkeit in der Nähe der Frontlinie eklärt, so sind die Schweirigkeiten, die derselben gemacht wurden in den von der Frontlinie weiter entfernten Raume durch nicht begründet und rufen den Verdacht hervor, dass man dem Ausbau der Legionen entgegenarbeiten will. So wurde zum Beispiel mit dem Befehl des AOK vom 
11 April 1915, Nr 8251 / die Werbetätigkeit im Bezirk Olkusz verboten. Dieser Bezirk hat regen Anteil an der Gründung der Legionen genommen. Hier kommen die erstem Schützenabteilungen Piłsudskis.

Im August 1914 lieferte der Bezirk sehr viele Freiwillige Rekruten. Die dortige Bevölkerung hat viel Opfer für die Legionen und deren Familien gebracht. Das Werbeverbot musste nachteilig die Stimmung der patriotischen Bevölkerung beeinflussen.

Nach dem Vorrücken der Frontlinie gegen Radom hat das Kommando der 6 Armeegruppe ein telegraphisches Verbot des Überschreitens der Pilicalinie durch die Legionen erlassen und die vorgehende Meldung über den Zweck und Antrag einer jeden, sich dorthin begebenten Legionäre abverlangt.

Mit Befehl des AOK vom 28 Mai 1915 Nr 9773/3 wurde dem Obersten Nationalkomitee und dem Militärdepatement befohlen, sich von jeder Politischen-und Werbetätigkeit im Kreise Kielce zu enthalten. Und hier muss hervorgehoben werden, dass die Stadt Kielce allein circa 1000 Freiwillige für die Legionen geliefert hat und das zwischen der Bevölkerung und den Legionen einige Beziehungen bestanden. Während der Russenzeit bestanden dort sogar geheime Organisationen, welche die Hilfe für die Familien der Legionäre, den Nachrichtendienst und die Werbung neuer Freiwilliger in Falle eines neuerlichen Einmarsches der verbündeten Armeen zum Zwecke hatten. Diese Beziehungen sollten jetzt erneuert und fortgesponnen werden, insbesondere sollte man den darbenden Familien der Legionäre zu Hilfe eilen. Nachdem aber die Ausgabe von Reisedokumten für die dorthin beordeten Legionäre verweigert wurde und die dortigen Behörden jeden in Kielce sich befindenden Legionär zu verhaften drohten, wurde jede Tätigkeit unterbunden, was bei der Bevölkerung in Kielce Missstimmung hervorgerufen hat.

Neben den territorialen Eischränkungen wurden auch Einschränkungen in der Werbe-tätigkeit selbst eingeführt. Es ist einleuchtend, dass eine aufklärende Agitation notwendig ist, um die von den Russophilen jahrelang bearbeiteten Polen in Königreich Polen für die Idee der Legionen zu gewinnen. Nun verbieten verschiedene Verordnungen jede wie immer geartete politische Agitation zum grossen Schaden für die Sache. So hat zum Beispiel das Kreiskommando in Dąbrowa mit dem Schreiben vom 8 Juni 1915 erklärt, dass es nur eine stille Werbeaktion ohne Versammlungen und ohne irgendwelche politische Aktion zulassen kann.

Ebenso erklärte das Kreiskommando in Piotrków, dass in den Versammlungen nur die Darstellung des Verhältnisses zu Russland, sonst aber kein anderes politisches Thema berührt werden darf. (Zuschrift des k.u.k. Kommando der Gruppe der Polnischen Legionen Nr 1187 vom 2 Luli 1915). 
Derartige Verfügungen.erschweren ungemein die Werbetätigkeit und reduzieren ihren Erfolg aufs minimum.

Es wurde sogar verboten äussere Abzeichen $\mathrm{zu}$ tragen, was für die empfänglichen Gemüter der Polen aneinfernd wirken würde. So wurde mit Befehl des AOK Nr 8704 vom 28 Mai den Funktionen des Obersten Nationalkomitee das Tragen von Uniformen unc Distinktionen unbedingt verboten, und nur das schwarz-gelbe Armband zugelassen, was keinen agitatorischen Werth besitzt. Am 28 Juni 1915 erhielt das Militärdepartement vom k.u.k. Gruppenkommando den von köherem Stellen erlassenen Befehl die von den Bureaus und Abteilungen ausgestellten nationalen Fahnen zu entfernen. Diese Verfügung hat bei der Bevölkerung in Piotrków peinliches Aufsehen hervorgerufen, besonders als man efuhr, dass die Entfernung der Fahnen auf Anordnung des k.u.k. Behörden erfolgt ist.

Die Änderung der bisheriger Werbetätigkeit wurde mit Befehlen des AOK $\mathrm{Nr} 9380$ und $\mathrm{Nr}$ 10342, die Militärdepartement durch das k.k. Kommando der Legionen am 10 Juli 1915 übermittelt wurden angeordnet.

Bevor jedoch die Befehle zu Kenntnis des Militärdepartement gelangt sind und bevor dasselbe seine Emissäre abberufen konnte, haben verschiedene Behörden bereits der Werbetätigkeit der Emissäre in verschiedenen Ortschaften rücksichtsloserweise in Ende bereitet. Besonders feinselig verhält sich den Legionen gegenüber das k.k. Kreiskommando in Piotrków. Dasselbe sendete Gendarmen nach Wadlew, Grabica, Bełchatów, Szydłów, Kleszczów, Sulejów, welche die sich dort befindenden Emissäre verhafteten und sie an das k.k. Kreiskommando in Piotrków einlieferten.

Ebenso wurde in Olkusz der Oberleutnant Dr Buchowiecki ${ }^{51}$, in Dąbrowa alle Emissäre mit ausnahme des Leutnant Klemensiewicz ${ }^{52}$ und Feldfebel Semis ausgewiesen.

Zur ersprisslichen Werbetätigkeit ist die Agaitation der Presse notwendig. $\mathrm{Zu}$ dem Zwecke werden vom Militärdepartement entsprechende Zeitungen und Broschüren in Piotrków herausgegeben. Nun ist die Zensur in Piotków so streng, dass die Pressetätigkeit ganz unterbunden ist. Wurde doch zum Beispiel "Dziennik Narodowy” wegen eines Artikels konfisziert (Anfang Mai) der Loyalitätskundgebungen und Anhänglichkeit an die Habsburgerdynastie der in Piotrków Anfang Mai versammelten Delegierten aus allen Teilen Russisch-

${ }^{51}$ Imienia doktora Buchowieckiego nie udało się ustalić; chodziło być może o Stanisława Bukowieckiego?

${ }^{32}$ Chodzi zapewne o Zenona Klemensiewicza, późniejszego wybitnego językoznawcy i uczonego. 
-Polen Darlegte ! Das Legionenblatt „Wiadomości Polskie” darf nicht ins Ausland expediert werden, obwohl es in jeder Nummer erstklassiges Agitationsmaterial gegen die Russophilen bringt und dessen Verbreitung gerade unter den im Auslande lebenden, den russophilen, franko - und anglophilen Strömungen ausgesetzten Polen von grössten Nutzen wäre. Die sehr gute Agitationsbroschüre "Auferstehung Polens durch Russland" wurde vom Kommando der Gruppe der Polnischen Legionen und vom Kreiskommando in Piotrków zensuriert freigelasen und dann von AOK wegen einziger Stellen, deren Streichung gefordert wurde, wieder konfisziert. Manche höheren Offiziere stehen auf dem Standpunkte, dass man nur von der Angliederung Rusisch -Polen an Österreich sprechen darf, ohne jedoch nur mit einem Worte die polnische Frage zu erwähnen!

Die Werbetäatigkeit wird auch durch verschiedenen Einschränkungen betreffend der Verkehr einzelner Werbestellen fast ganz unterbunden. Vor allem wurde die Institution der Couriere des Militädepartement aufgegeben. Die Aufgabe der Couriere war das Antragen und Zustellen von Befehlen und von Material für die Werbearbeit, was durch die Feldpost nicht immer oder mit grosser Verspätung geschehen konnte. Der Befehl des AOK Nr 9964 vom 23 Juni verbietet sogar Schritte betreffend die Reise der Mitglieder des Militärdapatement zu unternehmen.

Mit dem Befehl GAEK ${ }^{53} \mathrm{Nr} 5144$ vom 28 Juni wurde die Zensur aller Telegramme nicht nur den k.k. Gruppenkommando, sondern auch dem Telegraphenreferenten im SAEK ${ }^{54}$ angefohlen. Bei der Anstellung von Marschrouten für die Funktionäre des Militär-departements werden vom k.k. Gruppenkommando fortwährend Schwierigkeiten gemacht, wodurch die Dienstreisen äusserst erschwert sind.

Mit Befehl des AOK vom 13 Mai Nr 8058 wurde die Einziehung der Nachrichtenexpossituren angeordnet. Das Militärdepartement ist zwar dankbar hat die Befreiung von der schwierigen und unangenehmen Arbeit, welche jedenfalls den Verbün-deten Truppen wertvolle Dienste geleistet hat. Die Nachrichtenexposituren waren jedoch auf den deutschen Okkupationsgebiete, wo die Aktion der Legionen noch grösseren Chicanen als auf dem österreichischen Gebiete ausgesetzt war, das einzige sichtbare Zeichender Existenz der Legionen für alle diejenigen, die sich für die Legionen entusiasmiert haben.

\footnotetext{
${ }^{53}$ GAEK - General Armee Etappenkommando.

s4 SAEK - Stelle Armee Etappenkomando.
} 
Noch grössere Bedeutung hat die Einziehung der sogenannten Militärkommissariate in Galizien, wahrscheinlich deswegen, weil deren Tätigkeit (Unterstützungen, Agitation et cetera) ausschlisslich zur Kompetenz des Militärdepartements gehören. Die Kommissariate waren unmittelbar vom Militärdepartement abhängig und funktionierten in seinem Auftrage, indem sie den Familien der Legionäre Unterstützung Schutz gewährten. Auch diese Massregel wird in Galizien als ein, den Polen unfreundlicher Akt betrachtet und ungünstige Schlüsse über das Verhalten der Behörden gezogen.

Die Frage der Unterstützungen für die Familien der Legionäre aus Kongress Polen ist bis jetzt noch nicht erledigt. Von den vielen Familien der Legionäre, welche jetzt Not leiden, haben nur zwei in Miechów Unterstützungen erhalten. Die Erledigung dieser Angelegenheit wird immer verschoben, was auch zur Besserung der Stimmung nicht beiträgt ${ }^{55}$.

Oryginał raportu i odpis, albo kopia załącznika; maszynopisy.

Haus,-Hof und Staatsarchiv, Krieg, P.A.I., karton 900, folio 125 - 144.

${ }^{55}$ Nie udało się ustalić kim był autor załącznika. Jego autorem mógł być podpułkownik Władysław Sikorski. Nie ma też daty, ale należy przypuszczać, że tekst ten zostal przygotowany na przełomie lipca i sierpnia 1915 r. 


\section{Confidential documents of Austrian-Hungarian Ministry of Foreign Affairs regarding the Polish cause of 1915}

\section{Summary}

The publication includes 19 documents which contain valuable information about the Polish cause during the First World War and the history of Polish Legions.

A document that stands out in this collection is a matter-of-fact article prepared by Stanisław Downarowicz, who was a Polish envoy in Austrian Parliament. This important document was passed on to Austrian-Hungarian Minister of Foreign Affairs Stefan Burian, and contains a matter-of-fact critique of Austria-Hungary attitude to the Polish cause and the conductof Austrian-Hungarian occupational authorities in the part of the Kingdom of Poland territory the Russian troops retreated from. Moreover, the publication includes several documents reflecting political situation in the territory of the Kingdom of Poland occupied by the armies of central countries (Germany and Austria-Hungary). These documents do not only contain characteristics of general political situation, but they were also thought as an attempt to justify the conduct of Austrian-Hungarian factors of the Kingdom of Poland occupation. Besides, the publication includes crucial information about details of Józef Piłsudski’s banishment from Warsaw in August 1915. On the other hand, an important letter of Austrian-Hungarian General MilitaryHeadquarters (Armee Oberkommando- AOK) mentions the idea of Polish Legions' liquidation in 1915 if Poles, particularly Józef Piłsudski, put across clear political postulates of sovereign nature.

\section{Poufne dokumenty Austro-Węgierskiego Ministerstwa Spraw Zagranicznych dotyczące sprawy polskiej w 1915 r.}

\section{Streszczenie}

Publikacja obejmuje 19 dokumentów, które zawierają cenne informacje dotyczące sprawy polskiej podczas pierwszej wojny światowej i dziejów Legionów Polskich.

$\mathrm{Na}$ czoło publikowanych dokumentów wysuwa się rzeczowy elaborat przygotowany przez Stanisława Downarowicza, który był polskim posłem do austriackiego 
parlamentu. Ten ważny dokument został przekazany austro-węgierskiemu ministrowi spraw zagrancznych Stefanowi Burianowi, a zawiera rzeczową krytykę stosunku Austro-Węgier do sprawy polskiej i do postępowania austro-węgierskich okupacyjnych władz wojskowych na tych obszarach Królestwa Polskiego, $\mathbf{z}$ których ustąpiły wojska rosyjskie. Publikacja obejmuje ponadto kilka dokumentów odzwierciedlających sytuację polityczną na obszarach Królestwa Polskiego zajmowanych przez wojska państw centralnych (Niemiec i Austro-Węgier). Te dokumenty zawierają nie tylko charakterystykę ogólnej sytuacji politycznej, ale były pomyślane po części także jako próba usprawiedliwienia zachowań czynników austro-węgierskiej okupacji ziem Królestwa Polskiego. Są też w tej publikacji istotne informacje o tym, jak w sierpniu 1915 r. doszło do wydalenia Józefa Piłsudskiego z Warszawy. Ważne pismo austro-węgierskiej Naczelnej Komendy Armii (Armee Oberkommando- AOK) zawiera natomiast wzmiankę o zamysłach dotyczących likwidacji Legionów Polskich w 1915 r., skoro Polacy, zwłaszcza Józef Piłsudski, wysuwają konkretne postulaty natury politycznej i niepodległościowej. 